Portland State University

PDXScholar

6-16-1973

\title{
The Doctrine of Experience in the Philosophy of Jonathan Edwards, Puritan Divine
}

Joseph S. Trachtenberg

Portland State University

Follow this and additional works at: https://pdxscholar.library.pdx.edu/open_access_etds

Part of the Ethics and Political Philosophy Commons, Metaphysics Commons, and the Religious Thought, Theology and Philosophy of Religion Commons

Let us know how access to this document benefits you.

\section{Recommended Citation}

Trachtenberg, Joseph S., "The Doctrine of Experience in the Philosophy of Jonathan Edwards, Puritan Divine" (1973). Dissertations and Theses. Paper 1681.

https://doi.org/10.15760/etd.1680

This Thesis is brought to you for free and open access. It has been accepted for inclusion in Dissertations and Theses by an authorized administrator of PDXScholar. Please contact us if we can make this document more accessible: pdxscholar@pdx.edu. 
AN ABSTRACT OF THE THESIS OF Joseph $S$. Trachtenberg for the Master of Arts in Political Science presented Tune 16, 1973.

Title: The Doctrine of Experience in the Philosophy of Jonathan Edwards, Puritan Divine.

APPROVED BY MEMBERS OF THE THESIS COMMITTEE :

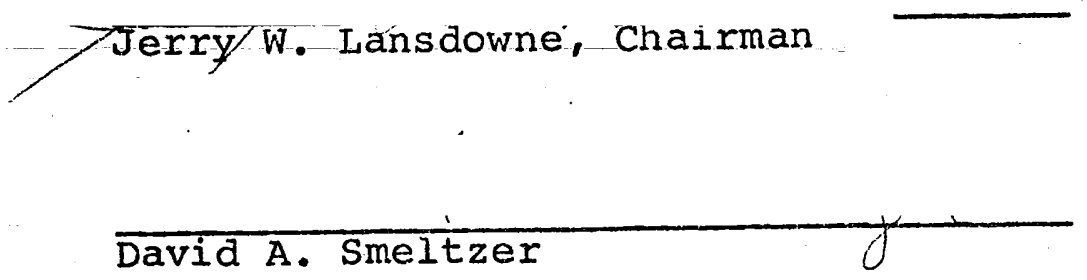

Thomas D. Morris 


\section{ABSTRACT}

A number of basic themes suggest themselves as focal points for a study of the thought of Jonathan Edwards. The dissertation is an attempt to argue that experience is one of them, and that an attentive eye to the doctrine of experience will reveal it as the unifying theme of his philosophy. Specifically, at the center of Edwards' aesthetic and religious vision there lies a rich and profound sense of experience, and of the relation of all things to some form of perception.

The evidence is to be found in Edwards' extensive published and unpublished writings. Among the several editions of his collected works, the 1808 worcester edition and the 1829 Dwight edition are the most complete and most reliable. Another especially valuable source is the "Miscellaneous Observations," a notebook of random thoughts Edwards kept throughout his life. Parts of this journal are published, but a great deal remains unpublished in the Yale University Library, and contains a wealth of insights into the mind of Edwards.

It is important to note the doctrinal influences of covenant theology. There had always been a disposition among the Puritans to emphasize real assent in religious matters. Their gradual acceptance of experience as a guide to doctrine can be attributed to the influence of medieval NeoPlatonism as well as to their own historical situation. 
Three elements form the center of Edwards' doctrine of experience. They are the idea of beauty, the sense of the heart, and the theological concept of grace. An explanation of each of these components in themselves and in their interrelations reveals the full meaning of experience.

A sense of beauty suffused his own personal experiences and allowed him to see the world in relation to the universal consciousness of God. Man perceives the presence of divine consciousness throughout reality with a sense of the heart. The seat of man's cognitive life is his heart, which includes the understanding as well as the will. By defining grace as a "new simple idea," Edwards proposes that it is a new principle of nature within man, and that it is a taste for moral excellency which is specifically designated as love.

As a metaphysical principle, the consent to being is an attempt to rethink the category of substance in terms of relation. The truly significant fact of the doctrine resides in an implicit theory of value-response--that value is objectively rooted in God, and that everything gives consent to it through man.

Edwards' theology is an effort to place Newtonian physics into a wider frame of reference. He adapts the concepts of atoms, space, and gravity to an organic metaphysics of consent. Divine creation is a diffusive process 
of communication, and natural objects and events are called "images or shadows" because they bear an intrinsic relation to God's communicative nature. The specific agency of creation is to be found in the Incarnation, which is the capstone of his whole system of thought.

Experience has held a position of preeminence among the major themes of American philosophy. The conclusion of this paper is that Edwards' philosophy can be viewed as the systematic explication of his doctrine of experience, and that it is possible to consider him an early exponent of the American tradition which gives experience a position of primacy in relation to thought. 


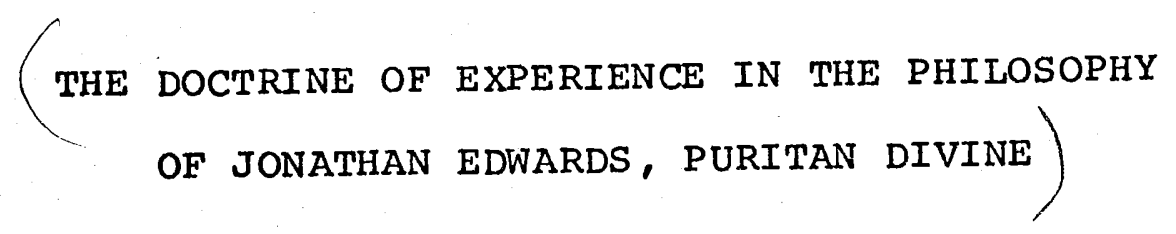

\author{
by \\ Joseph S. Trachtenberg
} A thesis submitted in partial fulfillment of the
requirements for the degree of

\author{
MASTER OF ARTS \\ in \\ POLITICAL SCIENCE
}

Portland State University

1973 
TO THE OFFICE OF GRADUATE STUDIES AND RESEARCH:

The members of the Committee approve the thesis of Joseph S. Trachtenberg presented June 16, 1973.

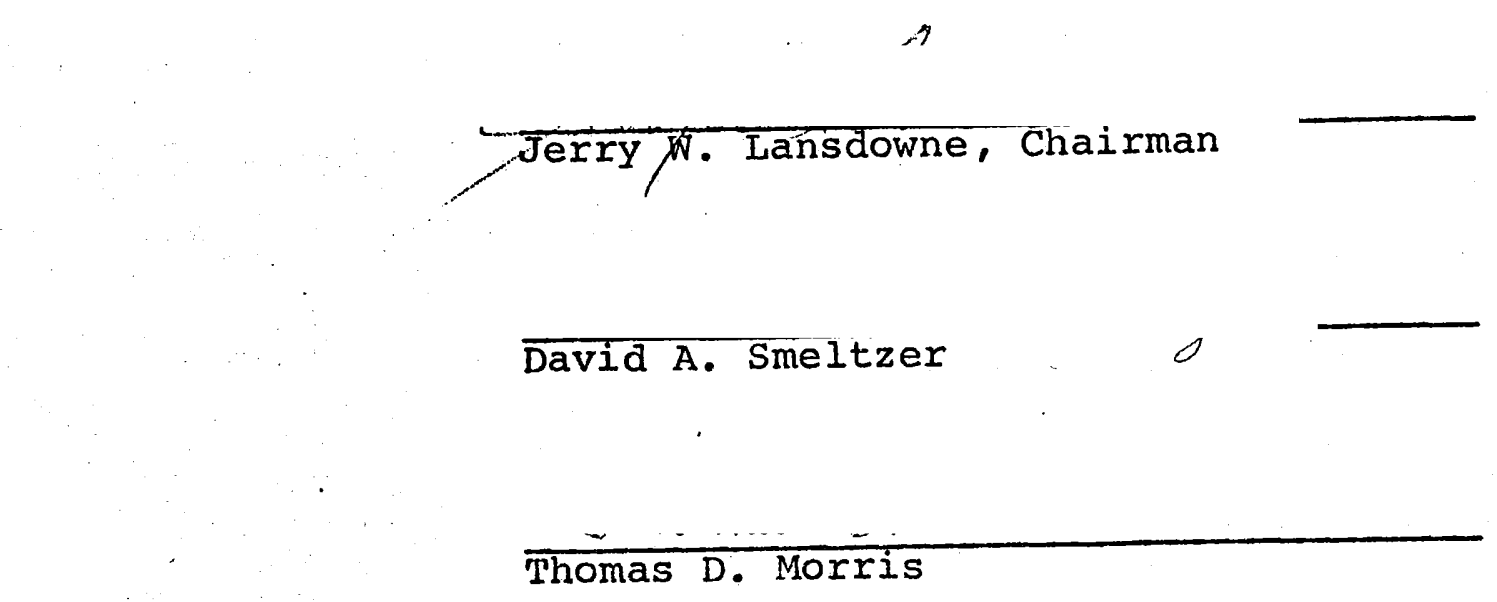

$y_{1}$

in

APPROVED :

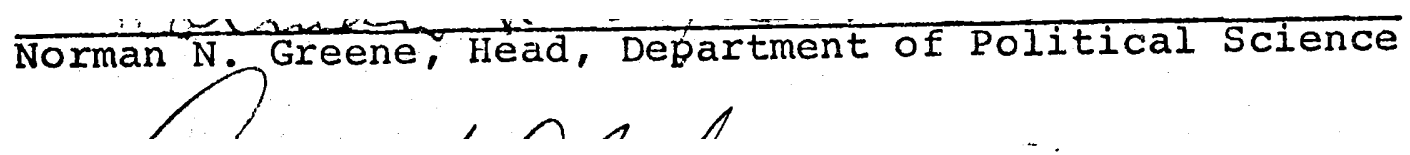

David T. Clark, Dean of Graduate Siudies and Research 


\section{ACKNOWLEDGMENTS}

I wish to acknowledge the contribution and influence of Professor George Smith McCowen, Jr. Professor of History at Willamette University, who originally introduced me to Jonathan Edwards; and also, the assistance of my advisor, Professor Jerry Lansdowne, Portland State University. 
TABLE OF CONTENTS

PAGE

ACKNOWLEDGEMENTS . . . . . . . . . . . . . . . iii

CHAPTER

I EDWARDS AS ARTIST. A POSSIBLE INTERPRETATION. • 1

II PURITAN MYSTICISM .............. 14

III EXPERIENCE AND THE DECLINE OF PURITAN DOCTRINE:

A HISTORICAI PERSPECTIVE. . . . . . . . . . 31

IV OF BEAUTY AND SENSIBILITY IN EDWARDS! DOCTRINE OF EXPERIENCE. . . . . . . . ...... 49

v THE SENSE OF THE HEART. . . . . . . . . . 72

VI GRACE AND EXPERIENCE. ............. 89

VII CONSENT TO BEING: A METAPHYSICS OF VAIUE . . . 110

VIII EDWARDS ' METAPHYSICAI THEOLOGY: THE PRESENCE OF

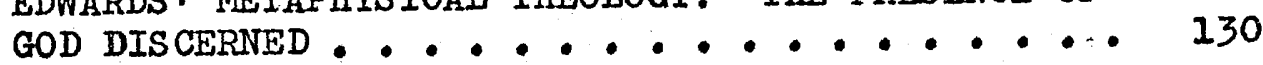

IX CONCLUSION. . . . . . . . . . . . . 172

BIBLIOGRAPHY . . . . . . . . . . . . . 176 


\section{CHAPTER I}

\section{EDWARDS AS ARTIST. A POSSIBLE INTERPRETATION.}

Current interest in the philosophical career of Jonathan Edwards is part of a larger co-operative attempt of political theorists, philosophers, theologians, and historians to bring the full. weight of their scholarly understanding to bear on the colonial origins of American civilization. We have perhaps reached that stage of national consciousness where such an enterprise will yield important results in a comprehensive evaluation of America. Hopefully, we in the Twentieth Century are sufficiently removed from our Seventeenth and Eighteenth Century forbears to gain a meaningful perspective of their lives. Moreover, it can be argued that we are better prepared than previous generations to see Puritan life as an integral stage in the development of contemporary America.

Two points should be made: that Edwards was an original thinker of major importance, and that in the range and depth of his thought he has particular relevance in the mainstream of American thought. The originality and 
universality of Edwards is to be found, I believe, in his synoptic view of the science, philosophy, and theology of his time. His thought has contributed greatly to American theory: the Calvinist approach to life as exemplified by Edwards represents a major influence of early colonial theology on later American thought. Thus, these early writings should be evaluated to discover such a tradition which was originally couched in theology and philosophy, and yet forms a significant aspect of the fountainhead in the mainstream of American theory. 1

When we look closely at his life and thought, we are immediately struck by his immense preoccupation with experience. From the time of his childhood at East Windsor, to his reading of Locke and Newton as a Yale student, to his long pastorate at Northampton, and finally to his exile at stockbridge where he produced his best writing, the controlling theme of his life was experience. In his preaching and in his writing, he never permitted abstractness to dominate at the expense of experience. One can discern through this Calvinistic perspective that was Edwards' the empirical flavor in his written works and in his sermons; and if his writing is a gigantic cipher, as Perry Miller

${ }^{1}$ Perry Miller, Jonathan Edwards (Cleveland: Meridian, 1959), p. ii... See also A. C. McGiffert, Jonathan Edwards (New York: Harper \& Brothers, 1932), p. 16. 
suggests, then the key is to be discovered somewhere in his rich sense of experience, of the presence of all things in perception. Coupled with experience is another theme: an intuitive awareness, almost poetic in nature, that the world of perception is engulfed by a larger reality which eludes direct perception, but is nevertheless present in it. What I am suggesting is a symbolic awareness that the objects and events of nature have their existence in relation to a wider order which while not susceptible of direct perception is indirectly perceived in some intuitive way as an integral dimension of these things. To understand Edwards' empiricism is to understand the nature of this intuition: it is to recognize the marriage and synthesis of Platonism and empiricism.

Taken together, the two themes of experience and symbolic awareness constitute a manifestation of an even more fundamental trait of his personality: an intense awareness of beauty. The over-all purpose of this paper is to demonstrate experience as the dominating theme and vehicle of his life and thought, but this can be achieved only through an appreciation of the importance of his aesthetic nature. Any claim to greatness that can be made for Edwards must rest squarely on his extraordinary ability to perceive and to construct 
a philosophical-theological system on that perception. 2

The point of this preliminary discussion, to which space will be devoted at the outset, then, is to set Edwards into some historical perspective. As a thinker who broke new ground, he belongs to the Enlightenment. However, he occupies a rather unique position in relation to the Europeans who did not pass their lives in the New England wilderness. This fact is decisive, and I would hope to underscore it in my presentation of his aesthetic nature.

The most important event of his intellectual life occurred, by his own words, at Yale when he discovered Locke's Essay Concerning Human Understanding, and the possibilities offered by the new philosophy of empiricism. It was also as a student that he had access to Newton's Opticks and Principia, which were given to the infant Connecticut college by the author. The reading of these two giants of the Enlightenment were not isolated events. Edwards suspected almost immediately that Newton's physics and Locke's psychology were revolutions in the outer life of the cosmos and the inner life of man which, taken together, constituted the greatest single achievement of the human intellect in the classical modern period. He

2 see: for a full discussion of this matter Roland A. Delattre, Beauty and Sensibility in the Thought of Jonathan Edwards (New Haven, Connecticut, 1968). 
set about to draw out the far-reaching implications this revolution held for religious thought. A great deal of his intellectual toil began here in the reading of Newton and Locke. His adolescent genius produced the then brilliant insight that physical science and the new empirical philosophy might be beautifully harmonized, indeed synthesized, with his version of traditional calvinism. The result of his reading was marked by two precocious essays which he wrote, "Notes on the Mind" and "Notes on Natural Science." Using the formulae of Lockean psychology and Newtonian science, he sketched out in these works all the major themes that were to occupy his entire life; the consent to being, the nature of virtue, idealism and empiricism; the philosophical and theological interpretation of atoms, space, and gravity; and his fundamental thoughts on God and the nature of beauty and freedom.

But the most important event of his career at Yale was not an intellectual experience at all, it was his religious conversion. From this experience he committed himself to religion as the main business of his life. The importance of the conversion went far beyond his personal spiritual life. "It became the cornerstone of his whole structure of thought, determining the basis not only of his revival preaching, but also of his religious philosophy."

3ola Winslow, Jonathan Edwards, 1703-1758, A Biography (New York: Macmillan, 1941), p. 75. 
He called upon his intellectual resources to translate this new religious sense into a coherent and meaningful doctrine. This became his life's work. "The Mind" and "Natural science" must be seen in the light of his religious conversion and not apart from it. After this, nothing in his life can be fully appreciated except in its religious significance. There can be no question as to the religious thrust of his whole life. It was decisive. The unity of his thought, the rationale of his entire system, and the structure of his doctrine rest on a common denominator which is thoroughly religious.

Two facts merit mentioning here about Edwards' position in our intellectual and cultural history. First, American scholarship is making either an appraisal or a reappraisal of practically every facet of his mind to uncover his contribution to American philosophy, psychology and theology. Second, one of the most prominent facts uncovered in his biography is the role that aesthetic feeling plays in the formation of his personality. Yet little effort has been made to see the connection between his place in American culture and his aesthetic nature which enabled him to comment on the major aspects of the American experience. Only a minority of scholars entertain the notion that he secured a permanent place in our history as an artist, "one of America's five or six major artists, who happened to work with ideas instead of with 
novels." 4

Perry Miller claims that Edwards succeeded better than any other artist "in generalizing his experience into the meaning of America." 5 Professor Miller sees the case for Edwards' modernity in his ability to speak out about science and psychology with such universality that we in the twentieth century are just catching up to him. He was much more than a theologian, he was an artist who used theology as his medium.

It is to Miller's credit to have inaugurated the renascence of Edwardsean scholarship by approaching him as an artist. Miller's genius is manifested by his sustained analysis of Edwards' thought to demonstrate that it ranges far beyond the doctrinal limitations of Puritanism. But criticism of his effort has not been lacking. ${ }^{6}$ Vincent Buranelli, for example, praises Miller's

4 Perry Miller, Jonathan Edwards, p. ii.

5 Miller, Jonathan Edwards, p. iii.

${ }^{6}$ The best example is Vincent Tomas, "The Modernity of Jonathan Edwards," New England Quarterly, XXV (March, 1952), 60-84. For other discussions of Miller's treatment of Edwards, see the following reviews of his book: Joseph Haroutunian, Theology Today, VII (January, 1951), 554-556; Reinhold Niebuhr, Nation TCLXIX (December 31, 19.49), 648; Thomas H. Johnson, Saturday Review (January 7, 1950), 17; R.W.B. Lewis, "The Drama of Jonathan Edwards," Hudson Review, III (1950), 135-40; Mary Ellen Chase, Review of Jonathan Edwards, New York Times Book Review (December 11, 1949), 4; Orville Prescott, Review of Jonathan Edwards, New York Times (December 7,1949$), 29$; J.H. Nichols, Review of Jonathan Edwards, Church History, Xx (December, 1951), 75-82. 
scholarship but feels some uneasiness about his "highly personalized" interpretation. ${ }^{7}$ He fears, as other critics do, that the line between Edwards' and Miller's own thought is blurred beyond discernment. This approach makes it difficult to distinguish his understanding of Edwards from his own original and quite subtle philosophy. Nevertheless, Buranelli is quite correct in saying that anyone who takes issue with aspects of Miller's version of Edwards is obliged to show why. While he has opened up the category of experience more than anyone else, and has pioneered the interpretation of Edwards as an artist making larger pronouncements on American life, he has not argued their full significance. In Miller's genius we also find a deficiency. He fails to appreciate fully that if Edwards can be seen as an artist, the philosophical consequences of such a conclusion must be researched in terms of Edwards' aesthetic intuition. Most essentially, he has not understood how thorough-going an artist Edwards was; and how style, method, and content are fused into a single metaphysical doctrine. This would seem an essential question to be investigated in order to unearth the guiding assumptions of Jonathan Edwards' philosophy.

Henry Bamford Parkes proposes a thesis similar to

7Vincent Buranelli, "Colonial Philosophy," William and Mary Quarterly, third series, XVI (July, 1959), 358. 
Miller's, but less comprehensive in scope. He sees the meaning of Edwards' thought ranging far beyond the boundaries of eighteenth century Puritanism. The whole American experience is mirrored with remarkable clarity in his theology, which was "a symbolic expression of the deep psychic forces" rooted in American culture. As a poet, he ranks with the great writers of the nineteenth century in foreshadowing the major themes of our national literature.

On the one hand his doctrine of a spiritual and divine light immediately imparted to the soul pointed toward Emerson and Whitman. On the other hand his intoxication with the idea of omnipotence, the cruelty that it implied, and the overweening pride of logic with which he set out to explain the entire universe, represented tendencies that pervaded the writings of Poe and Melville. 8

However interesting it may be, Parkes' thesis is weakened by the assumption that Edwards' doctrine is characterized by a fundamental split. It takes for granted that the overweening pride of logic and the cruel Calvinist omnipotence are locked in mortal combat with the spiritual and divine light. Undoubtedly, there is stress within the soul of Edwards, but it is translated too easily into a major ambivalence of the American psyche. Parkes' analysis is too facile for an enormously complex mind, and not necessarily a true characterization of the Puritan

${ }^{8}$ Henry Bamford Parkes, The American Experience (New York: Alfred Knopf, 1947), p. 83. 
intellect. It does not penetrate to the unique and undivided source of Edwards' intellectual and moral energy. Parkes in no way demonstrates that he has grasped the center of his vision. He fails to appreciate the aesthetic intuition, below the surface of awareness, which sparked the symbolic imagination of Edwards into a single, unified vision of a beautiful world.

The experience of beauty dominated Edwards to a greater extent than is commonly suspected. It is a basic concept to which we must return again and again if we would hope to appreciate the center of his vision. We can almost say his life was spent in constant analysis and clarification of this idea of beauty, or excellence, as he was accustomed to call it. Time and again, Edwards' critics have marveled at such an anomalous task for a Puritan theologian. "Esthetic categories are the last which one might expect to find in a rigid Calvinist philosophy, written in New England, by a Puritan of Puritans." 9 The explanation lies largely in Edwards' own personality, nourished by the frontier. A wilderness experience dominated and nurtured his aesthetic sensibility, giving shape to his theory of beauty and his pattern of philosophy. The complete expression of his philosophy, then, was unquestionably a product of a life passed in rich experience

9 Herbert Schneider, The Puritan Mind (New York: Henry Holt, 1930) p. 142. 
and purified by a process of distillation of an intense aesthetic awareness.

We find Edwards' qualification as an artist in his ability to articulate the deepest forces of his age and his culture in the setting of colonial, Calvinist America. No one can be more in time and place than the artist, for it is his unique vocation to bring to acute personal consciousness the total complexity of his historical situation. While the philosopher or the statesman may represent an abstracted awareness of one or another aspect of that milieu, the artist is the total living personification of it. His expression may be abstract, but he seeks to find the embodiment of ideas in empirically verifiable forms. He comes closest to a living, symbolic articulation of the culture in all its complexity, in all its ambivalence, and in all its passion. No writer "ever emerged more directly out of the passions, the feuds, and the anxieties of his society." 10 I would add that no individual in eighteenth century New England understood this better, or was as conscious of his relation to society than Edwards. His imposing philosophical-theological edifice testifies to an artistic intuition in keeping with the demands of his age.

The reassessment of Edwards has produced an assortment of diverse philosophical categories for which he seems ${ }^{10}$ Miller, Jonathan Edwards, p. 1. 
to qualify. They range from Miller's judgment that he was preeminently a naturalist to the less extreme and more traditional view that he was an idealist. Others have called him a pantheist, a mystic, a monist, an empiricist, and even a medieval scholastic, or platonist. Whatever the classification, one cannot ignore the dominance of his religious consciousness and the aesthetic sensibility which characterized that consciousness. These two facts of his intellectual biography loom over all other facts. He was a mystic who thought that he experienced the presence of divine beauty in the world. If religious conversion gave him a mystical sense of God, then he brought to it a new doctrine of experience. Here is the uniqueness of Edwards. For it allowed him to comprehend the world by means of experience which uses the empiricism of Locke as its point of departure. The following pages are designed to establish a vital link between his mysticism, and faith, and the empirical element in his epistemology, thus isolating the structure of Edwards' rational perspective and its guiding assumptions.

This work will trace the empirical turn his religious mysticism took when it confronted the requirements of Lockean analysis and the resulting doctrine is completed in the affective epistemology which he calls "a sense of the heart," and in his interpretation of grace as a "new simple idea." We shall then study the extensions of 
experience into metaphysics (showing that the consent to being entails a direct perception of God in His Imminence and Transcendencel. Such an approach and the conclusions to be drawn will show Jonathan Edwards the artist and empiricist not only representing the Calvinist-Puritan period to historians, but more importantly, how he both can be characterized as an artist and as a major contributor to the early origins of what was to become the mainstream of American thought. 


\section{CHAPTER II}

\section{PURITAN MYSTICISM}

The cosmological view of Edwards is similar in many ways to the Aristotelian and especially the Neo-Platonism which shaped the theology and cosmology of the Middle Ages. This similarity is far from sheer historical accident, for the connections between medieval and puritan thought are strong. To a greater extent than is commonly suspected, the theological heritage of the Puritans was medieval in origin. Their overt distaste for some of the surviving practices of scholasticism was in keeping with the spirit of the Reformation and with their adaptation of Ramist logic. But this could not hide the marked influence of medieval Neo-Platonism on their thought. In spite of their constant denunciation, Perry Miller writes, "the settlers of New England retained with few alterations the cosmology of the Middle Ages." 1 In fact, the influence has been far greater on seventeenth century Puritanism than on sixteenth century Protestantism in general. Ralph Barton Perry

\footnotetext{
${ }^{1}$ Perry Miller The New England Mind. The Seventeenth

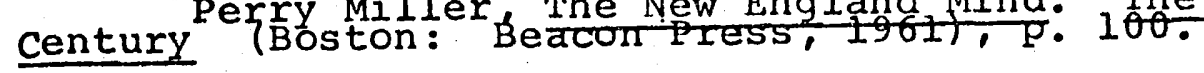


argues that "the main body of puritan doctrine .. . is medieval Christianity. In America, it was the chief link of continuity with the medieval past." 2 And Miller further claims that "at every turn we encounter ideas and themes which descend . . e from medieval philosophy." 3

The medieval mind sought to harmonize all knowledge with Christian revelation and to fuse it into a single view of reality. The age was marked by the attempt to use all the disciplines to portray the cosmos as a divine presence. All knowledge is one, and it bespeaks a theophanic world. In the seventeenth century, too, the theophanic theme prevailed, and men sought to probe the mystery of God's infinity through science and mathematics. The theme is at the heart of the systems of Descartes, Spinoza, Cudworth, H. More, Leibniz, and the natural philosophy of Newton. The Puritans were no exception to their age: they also sought to unify the various disciplines into a single religious vision not unlike the theophanic cosmologies of the twelfth and thirteenth centuries.

The term cosmology is used here in the general sense of a unified way of viewing the world. It has a wider scope than metaphysics, for it includes theology and

2 Ralph Barton Perry, Puritanism and Democracy (New York: Vanguard, 1944), p. 83 .
3 p. 104 .
The New England Mind. The Seventeenth Century, 
mythology as well as philosophy, and is generally considered to be an entirely experiential orientation to the world rather than a conceptual one. The concern of the present chapter, then, is to show that central to Edwards' cosmology is a Neo-Platonism which evolved through the Middle Ages. But first it is necessary to estaiolish the connection between Puritanism and medieval Neo-Platonism in a more specific way. A great deal of attention has been paid in recent years to Puritan mysticism in the seventeenth century. That there was a mystic strain in the Puritan movement of that time is evidenced by the emergence of such groups as the Quakers with their strong belief in the mystic brotherhood of man and the indwelling of the Holy spirit in each individual. "There have been few periods in any country," one author tells us, "that have been so intensely and profoundly mystical as was (the) first half of the seventeenth century." 4 Unlike earlier versions of mysticism, this one seemed to reach into the hearts of ordinary men and to establish itself as the basis for popular political democracy. It originated and grew out of the Puritan religion itself, but its roots sank deep into the medieval past.

The mystical element of Puritanism was one readaptation of puritan piety, theology, and polity

4 Rufus M. Jones, Mysticism and Democracy in the English Commonwealth (Cambridge: Harvard University Press, 1932), p. 12 . 
which grew out of a scriptural literalism and was also an antidote for extreme literalism and legalism .... Springing primarily from Dionysius, the medieval German mystics, the German spiritualist, Jacob Boehme, and the Family of Love. 5

William Haller's testimony concurs with this belief that while it was an indigenous phenomenon, Puritan mysticism was also the reappearance of an older tradition.

One source for it was undoubtedly to be found in feelings among the people that reached far back into medieval popular Christian faith. However that may be, the fact is at any rate significant that, in addition to the sermons and polemics of preachers ... there began to appear in England after 1600 vernacular versions of the writings of continental ${ }_{6}$ enthusiasts and mystics of an older time. ${ }^{6}$

There is much evidence to support the claim that mysticism was not alien to Puritanism, but that it sprouted from the main stock of early Puritan orthodoxy. At its incipient stage in the sixteenth century, the Puritan religion was already producing an element which stressed the supremacy of experience over reason, and immediacy over remoteness in theological matters. 7

5 Jerald C. Brauer, "Puritan Mysticism and the Development of Liberalism," Church History, XIX (Sept., p. 152)

${ }^{6}$ William Haller, The Rise of Puritanism (New York: Columbia University Press, 1938), p. 206.

7 Winthrop C. Hudson, "Mystical Religion in the Puritan Commonwealth," Journal of Religion, XXVIII (January, 1948): 51-56. "The early impetus to mystical religion in Puritanism was rooted in an intense interest in practical piety, a religion of the heart as opposed to an intellectual faith. By the end of the sixteenth century, one element in the Puritan movement was moving in the direction of a pietistic emphasis on immediacy in religion, stressing direct communion with God, and characterized by an insistence upon personal experience." 
In his effort to purge religion of all intermediaries between the individual and God, ${ }^{8}$ whether it be priest, saint, or an ecclesiastical hierarchy, the Puritan came to value direct, personal experience of God more and more. With the growth of Puritanism in the seventeenth century, experience came to the fore even more as a primary authority. Their theological interest was not dogmatic, but experiential, according to Geoffrey Nuttail. "There is theology, but, in a way which has hardly been known since st. Augustine . . • This stress on experience is, indeed, a characteristic of the seventeenth century in England." 9

It might be said of Puritanism that one of its significant and distinguishing features was its insistence that man could establish a direct, experiential relation to God, a relation in which the emotions played as important a role as reason, if not more so. The awakening of a new sense of religion with its stress on the personal rather than the institutional element brought new meaning to the gospel story, and a fresh approach to the way in which the Christian message was to be witnessed. The walls of separation between God and man which for centuries had been maintained by ecclesiastical

$$
{ }^{8} \text { R. B. Perry, p. } 364 \text {. }
$$

${ }^{9}$ Geoffrey F. Nuttall, The Holy spirit in Puritan Faith and Experience (Oxford: Basil Blackwell, 1946), 
authority were now removed, and man discovered in a new way that the gospel was a powerful and saving force. "It was insufficient to contemplate and adore God as the Creator, eternal but distant in the heavens. God must be found in direct personal experience, present now by His Holy Spirit in the heart, making men able to say with Job, 'I have heard of thee by the hearing of an ear; but now mine eye seeth thee. " 10

Nuttall's thesis is substantiated in the writings of the leading Puritan thinkers of the seventeenth century, men such as Richard Sibbes, John Preston, and Thomas Goodwin, who forged the theology of the Covenant which became the foundation of all Puritan belief. ${ }^{11}$ Their appeal to experience over reason in matters of faith is quite strong, as for example, sibbes' distinction between notional and discursive knowledge. The latter he calls "knowledge with a taste." God gives to man knowledge per modum gustus which cannot be replaced with any weaker form.

There is no other principle to prove the word, but experience from the working of it . • . Experience is the life of a Christian. What 12 is all knowledge of Christ without experience?

10 Nuttall, p. 135

${ }^{11}$ see Perry Miller, "The Marrow of Puritan Divinity," Errand into Wilderness" (Cambridge, Mass.: The Belknap Press, 1956), pp. 48-98.

12 sibbes, quoted in Nuttall, p. 39. 
Goodwin follows. closely by referring also to knowledge as a

form of taste:

God hath put into every creature a taste, and a discerning of what shall nourish it $\cdot \dot{b}^{\circ}$ And as the senses in a man are suited to objects in the world, a man's eyes to colours, his ears to sounds, his stomach to meats, so hath God made the things of the gospel to suit the regenerate part, and the regenerate part to suit them ... in Philippians $i .9$. The knowledge of the saints it is called sense.. . it is a judgment which ariseth from, or at least is joined with sense, a taste, a suitableness that the soul hath to things revealed. 13

The great architect of covenant theology, John Preston, whose work, The New Covenant, is prerequisite to any understanding of the thought of seventeenth century New England, 14

similarly emphasizes the knowledge of God by experience. "The workes of Nature are not in vain," he tells us, for "when a man lookes on the great volume of the world, there those things which God will have known, are written in capital letters." While some truths are wholly revealed by God through scripture, there are other truths "that have some vestigis, some characters stamped upon the creature, whereby we may discerne them, and such is this which we now have in hand, that, there is a God." 15

${ }^{13}$ Goodwin, quoted in Nuttall, p. 39.

14 Miller, "The Marrow of Puritan Divinity," Errand into the Wilderness, p. 59.

15 Preston, quoted by Miller, Ibid., p. 77 . 
The best account of the development of covenant theology in the seventeenth century has been given by Perry Miller. The theme of his remarkable essay, "The Marrow of Puritan Divinity," focuses on the covenant as a device to bring an inscrutable Calvinistic God into a reasonable relationship with man. The arbitrary God of sixteenth century Calvinism has to be made more reasonable and more accessible to man through the ordinary channels of human experience. Thus the idea of God and man entering into a compact emerged slowly but surely in the minds of Puritans, and the mysteriously transcendent and arbitrary deity became less umpredictable and more amenable to the demands that human experience made of him. Our stereotyped image of the Puritan conception of God as severe, inflexible, and quite unapproachable is inconsistent with the notion of a God who has arranged a reasonable agreement with man about the terms of salvation, and who acts for the most part within the boundaries of that agreement. Miller points out that it is wrong to suppose that Puritan doctrine in the seventeenth century was a rigid authoritarianism which prescribed dogmatic truths about a harsh and tyrannical supreme Being. "We ought to be very much disconcerted by their continual appeals to experience and reason" if we persist in using this stereotype. ${ }^{16}$ To such a devout Puritan as Edwards, ${ }^{16}$ Miller, quoting Preston, p. 70 . 
the God of the covenant made himself increasingly available to man through his ordinary faculties, and so experience became a reliable measure of God's character and of his chosen way of carrying on commerce with man. 17

This notable emphasis on experience is attributable in great measure to the influence of Neo-Platonism. If there was a definite mystical strain in Puritanism, 18 as all evidence seems to show, then it was due in great part to a familiarity with and dependent on Neo-Platonic thought. Indeed, Perry Miller has shown that the greatest single influence on puritan thought, excluding the Bible, was not Calvin so much as it was Augustine. ${ }^{19}$ But their knowledge of Augustine and of Plato had been heavily colored by the Cambridge platonists, 20 and by such Renaissance thinkers as Ficino, Mirandola, and Cusa. 21 And so while the works

17Miller, quoting Preston, pp. 63, 65.

$18 \mathrm{~A}$ pioneering study of the origins of Puritan mysticism has been done by Jerald C. Brauer, "Francis Rous, Puritan Mystic, 1579-1659: An Introduction to the Mystical Element in Puritanism." Unpublished doctoral thesis, University of Chicago, 1948.

19 Miller, The New England Mind. The Seventeenth Century, p. 4 .

${ }^{20}$ See Clarence Gohdes, "Aspects of Idealism in Early New England," The Philosophical Review, XXXIX (November, 1930), 537-555.

\section{${ }^{21}$ See Jones, pp. 107-108.}


of Plato, Plotinus, and the Pseudo-Dionysius were in the Harvard and Yale libraries, ${ }^{22}$ they included commentaries by Ficino and by the Cambridge school of Cudworth, More, Glanvill, and Theophilus Gale. The writings of Edwards, for example, testify to his dependence on Cudworth and Gale. The Puritan's interpretation of Plato and Augustine was thoroughly mystical. It can be shown to what extent they had read and absorbed the great Neo-Platonic mystics of the Middle Ages. They had the opportunity to read the Pseudo-Dionysius when John Everard translated his Mystical Theology into English, and they had access to Nicholas of Cusa's Vision of God which Everard translated along with Giles Randall. 24 Francis Rous, who is called the first Puritan mystic, quoted Dionysius frequently, and cited Augustine more often than he cited calvin. ${ }^{25}$ He moved into mysticism "not through the influence of near contemporary continental thinkers and movements but through puritanism itself bolstered by reading such men as plato,

\section{Gohdes, p. 542.}

23 An excellent study of the effect on Edwards of the Cambridge Platonists has been done by Emily Watts, "Jonathan Edwards and the Cambridge Platonists." Unpublished doctoral thesis, University of Illinois, Urbana, 1963.

${ }^{24}$ Jones, p. 64, and Haller, p. 206.

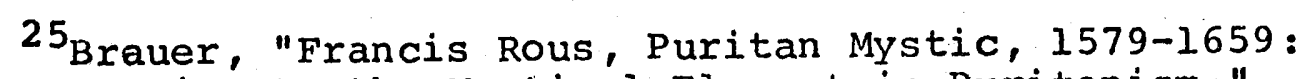
An Introduction to the Mystical Element in Puritanism," p. 52 . 
Augustine, Gregory and Bernard--all of whom had been available to Puritans at all times." 26 cotton Mather is known to have purchased the works of Dionysius for his library in 1682.27

There is clearly an abundance of evidence that the Puritans had first hand contact with medieval mysticism, and that in their sense of God's immediacy they had close affinities with this older tradition. It would be strange indeed if we were to find no mysticism in a religion which was as emotional and as experiential (in its incipient stages, at least) as Puritanism.

In turning our attention to Edwards, we discover an individual who by temperament was disposed to religious mysticism. His insistence on real assent to the truths of God is extended so as to become the central theme not only of his personal religious life, but also of his epistemological, metaphysical and moral speculations. Whether he discusses knowledge as a species of affection, or the consent to being as an ontological category, or the sense of the heart as essential to our knowledge of God, Edwards seems to be promoting the logic of experience over purely ontological reasoning. He seems to be inspired by a fundamental difference between the two ways of knowing,

$$
\begin{aligned}
& 26_{\text {Brauer, p. } 33 .} \\
& { }^{27} \text { Gohdes, p. } 538 .
\end{aligned}
$$


and by the primacy of one way over the other in most matters of importance. The stronger form of knowledge is based on observation and is to be preferred to knowledge which is based exclusively on some form of ontological insight. Thus, he writes:

There is a difference between having an opinion, that God is holy and gracious, and having a sense of the loveliness and beauty of that holiness and grace. There is a difference between having a rational judgment that honey is sweet, and having a sense of its sweetness. A man may have the former, that knows not how honey tastes; but a man cannot have the latter unless he has an idea of the taste of honey in his mind. 28

Edwards shares a Dionysian view of a world which is the diffusion of God's being. The universe acts, he tells us, as if it were "animated and directed by one common soul," and the reality of God interpenetrates all creation so as to constitute a single order. And yet God is at the same time utterly transcendent and utterly inaccessible as He is in Himself. Like Dionysius and the entire mystical tradition, Edwards refuses to compromise any one aspect of the universe to any other aspect. He tries to do justice to them all and to maintain, in however paradoxical a form, a world which is at once the living presence of its source but not totally identified with it. For example, the groundwork of Edwards' system is laid out in the doctrine of an Absolute God, an eternal, 28 Works (Dwight ed.) VI, p. 177 
infinite, omnipotent and omniscient being. He insisted on and emphasized divine sovereignty, not only because the tenets of Calvinism dictated it, but also because the universe demanded it. The world of Edwards' experience was precarious and exhibited an unbridled ruthlessness and arbitrariness. This was especially true of a life spent in the New England wilderness. There had to be a theological accounting for this aspect of the cosmos, and he went to the orthodox Calvinist doctrines of divine wrath, divine election, and original sin. He would not gloss over such realities as suffering, injustice, and inequality, but would give them their full sway.

Nevertheless, it may be said that he constantly strove to readapt the principles of Calvinism along the lines of Neo-Platonism. Thus, God, as the transcendent, superabundant Good is the first cause of all that exists. But his sovereignty, Edwards insists, must be maintained above all other considerations. There can be no "indigence, insufficiency and mutability in God, or any dependence of the creator on the creature." 29 God could not have created out of any deficiency in His nature, but only out of the super-abundance of His Goodness. His motive in creating does not go beyond Himself, and His desire to communicate is a manifestation of a "supreme and ultimate

${ }^{29}$ The Works of President Edwards ( 8 volumes; Wor-

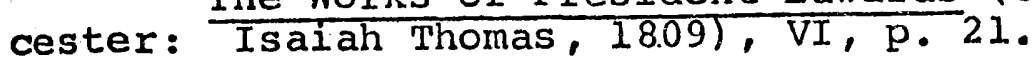


regard to himself." 30

But God's nature is all communicability, and the universe is the "glorious and abundant emanation of his infinite fulness of good." 31 It is God expressing Himself through the multiplicity of finite forms. He speaks out of the fullness of His nature and not out of any deficiency or lack. Therefore, the universe is a continuous statement about the plenitude of God, a divine declaration of His inner nature which man stands in the presence of. It speaks to man of the immeasurable and inexhaustible creative energy of Divine Love or Goodness. The Neo-Platonic tradition is marked by the identification of Goodness as the first source of all things. A. O. Lovejoy remarks in connection with Dionysius that "God's 'love' . . . consists primarily rather in the creative or generative than in the Redemptive or providential office of deity." 32 In the universe of Edwards, the attribute of Goodness or Love means more than passive compassion or a sort of reflex action God might have to man's condition. It means the creative energy and vital force which sustains all things in existence. Edwards is true to the Neo-platonic tradition to the point of using the metaphor of light as his prime example of what is meant by

${ }^{30}$ Thomas, p. 34 .

$31_{\text {Thomas, p. } 33}$ 32 A. O. Lovejoy, The Great Chain of Being. A Study of
the History of an Idea Tambridge, Mass.: Harvard University Press, 1936), p. 67. 
divine emanation. To illustrate the manner of the emanation of God's Goodness, he points to the way in which the sun radiates heat and light. 33

The communication of Goodness results in an hierarchical order which stretches from the lowest forms of inanimate matter to man who is "the highest of creatures." It is based on the relative nearness or remoteness of every creature to God. But the important fact of Edwards' idea of hierarchy is that the entire scale is mediated by communication to produce an inter-related world reaching from God, through man, and down into the lower levels. Thus :

In the creation there is an immediate communication between one degree of being and the next degree of being. Every wheel immediately communions with the next wheel, man being at the top. Without doubt there is an immediate communication between the Creator and this highest of creatures according. to the order of being. 34

Every other creature participates in this immediate communication between God and man according to the degree of its own capacity. The capacity is determined by the

${ }^{33}$ See Dissertation Concerning the End for Which God Created the World, Works, Worcester ed.' VI passim. Also, Images or shadows of Divine Things, Perry Milier, ed., (New Haven: Yale University Press, 1948), p. 64 .

${ }^{34}$ The Philosophy of Jonathan Edwards from His Private Notebooks, Harvey Townsend, editor (Eugene, Oregon: University of Oregon Press, 1955), p. 127. 
position the creature occupies in the hierarchy. There is in Edwards, then, a principle of continuity which sees a cosmic unity brought about through divine communication.

God's work from the beginning of the universe to the end, and in all parts of the universe appears to be but one. It is all one design carried on, one affair managed, in all God's dispensations towards all intelligent beings, viz. the glorifying and communication of himself in and through his Son Jesus Christ as God Man, and by the work of redemption of fallen man. 35

But this unity is achieved in the immediate communication between God and man. The principle of continuity throughout the universe is made possible through man in his immediate relation to God. And when Edwards speaks of immediate communication, he refers to some form of experience. This brief glimpse into some of the basic ways in which the cosmos appeared to Edwards prompts the following general observations. First, he is essentially committed to giving full consideration to all aspects of the relationship between God and His world. This means accepting His sovereignty and transcendence as a primary state, but at the same time seeing that the full meaning of transcendence resides in its relation to the opposite pole of finite existence. In other words, God's sovereignty and transcendence are intelligble only insofar as they can be seen in relation to His immediacy and imminence. ${ }^{36}$ second, with

35 Works, (Dwight ed.) VIII, p. 521.

36 Charles Hartshorne and William L. Reese, Philosophers Speak of God (Chicago: University of Chicago Press, 1953), pे. $2-4$. 
such a view it is but a short step to depicting the world as a dynamic affair of mutual interdependencies in which the concept of knowledge becomes infused with affection. 

EXPERIENCE AND THE DECLINE OF PURITAN
DOCTRINE--A HISTORICAL PERSPECTIVE

Before proceeding to an examination of Edwards' doctrine of experience and the role it played in his metaphysical theology, it is important to comment on the more general features of Puritanism in the seventeenth and eighteenth centuries. By the time Edwards appeared on the scene, the rudiments of Puritan belief had undergone drastic changes at the hands of time and experience. Upon graduation from Yale, Edwards steppes into a world in which.Puritanism had been eroded by a century of the struggle for survival in New England. His own doctrine of experience was as much a direct conscious response to this struggle as it was a result of it. Therefore, it is necessary to understand the status of theology at this time if we hope to gain a full appreciation of his position.

There is a tendency to view history in terms of a separate series of events, the segments having very few or no important connections between them. But when one sees the Puritan migration of 1630 , along with the other 
collateral events of the seventeenth century, the story constitutes a major chapter in the history of ideas. The history of the Bay colony must be viewed as an important aspect of the Christian drama of that period. Reformed Christendom, according to the Puritans, had not achieved a sufficient purity enabling it to recover the spirit of the primitive Church. Anglicanism was a case in point. Retaining much of the character of the Roman Church, it tended to minimize the Bible as the essential source of God's message to man. The Puritans moved to the opposite extreme and believed that scripture contained the complete word of God, replete with a moral and social prescription for human life.

The difference between the Anglican and the Puritan . . was that the Puritan thought the Bible, the revealed word of God, was the word of God from one end to the other, a complete body of laws, an absolute code in everything it touched upon; the Anglican thought this a rigid, doctrinaire, and utterly unjustifiable extension of the authority of scripture. The Puritan held the Bible was sufficiently plain and explicit so that men . . could establish its meaning and intention on every subject, not only in theology, military tactics, inheritances, profits, marriages and judicial procedure. 1

Perry Miller reminds us that they were incurably authoritarian in their attitude toward the Bible. "There was nothing essential to be learned outside revelation."

${ }^{1}$ Perry Miller and Thomas Johnson, The Puritans (2 vols.; rev. ed.; New York: Harper Torchbook, 1963), I, P. 43. 
And yet Scripture did not contain the complete word of God, for the Puritans maintained a belief that God's nature is always partly hidden from man.

One important result of this belief was their "discovery" that the Bible contained the outline for the organization of the visible church. At the heart of the discovery was the idea of a covenant between God and man. The covenant brought men together, into a gathered church, to form a Bible commonwealth. This was one of the prime motives of the 1630 migration to America, and it formed the basis of the Puritan theology of community-building. ${ }^{2}$ Massachusetts would become a "City upon a Hill," a "Model of Christian Charity" for all the world to behold. ${ }^{3}$ They went about their task with an intense religious zeal that makes it impossible for us to ignore. "It is notorious," says Santayana, "how metaphysical was the passion that drove the puritans to those shores." They went to fulfill a spiritual mission to achieve an authentic Christian life.

2 Daniel Booratin, The Americans. The Colonial Experience. (New York: Random House, 1958), pp. 15-16.

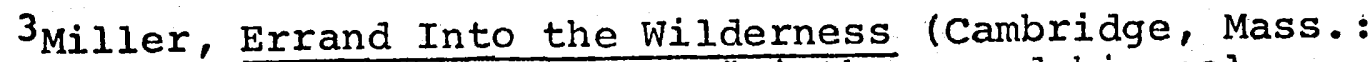
The Belknap Press, 1956), p. 11. "Winthrop and his colleagues.. believed their errand was not a mere scouting expedition: it was an essential maneuver in their drama of Christendom. The Bay company was not a battered remnant of suffering separatists thrown upon a rocky shore; it was an organized task force of Christians, executing a flank attack on the corruptions of Christendom. These Puritans did not flee to America; they went in order to work that complete reformation which was not yet accomplished in England and Europe." 
But their mission was not finished when they succeeded in establishing their churches, for "an endless migration of the mind was still before them." 4

Indeed the great enterprise was not over after the first generation entrenched itself in New England, but by 1660, it had altered radically. The endless migration of the mind was, in fact, the far greater challenge of coming to terms with an entirely new experience. The Puritans soon realized that the hazards of life in the wilderness surpassed those of living with the Anglican Church in England. At this point experience gained the upper hand over religious doctrine, and the process began of modifying theology to meet the demands of their new life.

The day-to-day struggle to survive in the wilderness worked a curious revolution on the Puritans. For them, the overwhelming fact of experience was a cruel, hostile and very demanding frontier environment.

They felt the impact of primeval nature -suffered its dangers and hardships, responded to its challenge, and exploited its resources.

4 George Santayana, Character and Opinion in the United states (New York: Doubleday, 1958), p. 3. James Truslow Adams has argued in The Founding of New England (Boston: The Atlantic Monthiy Press, 1921), that religious motives played a minor role in the settling of the Bay colony, that the Puritans sought economic and imperial gains from their migration. This interpretation is challenged by Miller, in his Orthodoxy in Massachusetts (Cambridge, Mass.: Harvard University Press, 1933). 
They were vividly aware of the 'wilderness' in which their lot was cast; and in terms of this encounter they dramatized both theif hardships and their providential opportunity.

This last point made the difference between surviving and perishing during those first years. For the sake of sheer physical survival they were forced to dramatize their hardships through religious experience, to see that every turn of events held a symbolic meaning. "It was almost impossible for the Puritans to take America on its own hostile terms." 6 The terms had to be dictated, and they had to be Christian. More specifically, they had to be the terms of the covenant. So as the second and third generation Puritans lost sight of the original mission of building a model community for Europe, their lives assumed new religious meaning. Here, in New England's "green and pleasant land," they were brought by God to build a New Jerusalem. The American frontier was a re-enactment of the Biblical frontier. Their real mission, after all, was to conquer a wilderness, to subdue and Christianize it there,

${ }^{5}$. B. Perry, op. cit., p. 204. (Italics mine). See also Milier, The New England Mind. From Colony to Province lated sciences of theology, psychology, logic, and rhetoric - - they possessed coherent answers to all conceivable contingencies. But one thing they had not foreseen, was that experience in the New World might pose problems not on the schedule, which appeared to have no rationale whatsoever. (Italics mine).

${ }^{6}$ stow Persons, American Minds. A History of Ideas (New York: Henry Holt, 1958), p. 72 . 
by physically reconstructing Canaan in America.

"New England was born in a passion of spiritual pioneering," Lucy Lockwood Hazard tells us, "which almost obscured the aspects of the actual frontier." 7 In their need to assimilate a new experience into a religious framework, the Puritans acquired a symbolic awareness which launched America on its mission of recreating the Promised Land. Thus, the theology of community-building became a permanent institution. With an intense awareness of the religious drama they were participating in, "forest, rivers, and mountains (became) symbols, and objects of contemplation." 8 Nature was the new source of corroboration that their adventure was part of a divine mission. With an Hebraic sense of the holiness of matter, ${ }^{9}$ the Puritans pictured themselves as on a Biblical odyssey into the American wilderness. The following is an apt summary:

In the everyday life of New England images like 'The Holy Commonwealth' and the 'Wars of the Lord' converted human activity into a symbolic drama. New England was 'the place where the Lord will create a new Heaven, and a new Earth in, new Churches, and a new Commonwealth together.' The unfolding drama was at once human and divine;

7 The Frontier in American Literature (New York: Frederick Ungar, 1927), p. 162 .

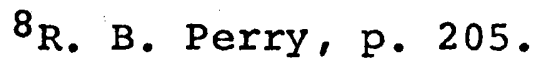

${ }^{9}$ Santayana, p. 12 . 
physical life was simultaneously spiritual. Every passage of life, enmeshed in the vast context of God's plan, possessed a delegated meaning. Under the aspect of the Holy Commonwealth, the crude huts and muddy streets were transmogrified into a focal symbol of God's emerging idea; 'We are as a City upon an hill, in the open view of all the earth, the eyes of the world are upon us.'10

What Perry Miller and others have called the decline of doctrine in the seventeenth century was really a series of theological adjustments to the new experience. The Puritan version of Calvinism proved itself exceptionally flexible and equal to the uncertainties of life on the frontier. The flagging religious fervor of the second and third generations and the jeremiad it evoked from their preachers were more than signals of decline. They hinted that something more important than mere compromise of doctrine to the situation was taking place. For these events heralded the beginning of a new era in which religion would accede to the demands of expansive experience. From this time on, America became a laboratory to demonstrate that religious experience thrives when it is called upon to cope with a dynamic and changing situation. In New England Puritanism we have the beginning of a truly experimental religion. As one writer says: "Recent studies have made abundantly clear - . that the Puritan system of thought was dynamic, active,

${ }^{10}$ Charles Feidelson, Symbolism and American Literature (Chicago: University of Chicago Press, 1953), pp. 79-80. 
experiential, and even experimental in a theological sense."1l Even truth itself, the revealed word of God, was a dynamic concept. The Puritans believed that the Bible contained the sum of truth and the entire prescription for human life. But their conception of Scripture, as we have seen, went far beyond the limits of the written word. It embraced the whole of the human historical experience. And they were a part of that Bible experience, in fact, a most important part.

How did they arrive at such an arresting view of the Bible" The answer is to be found in the puritan interpretation of Calvinism. New England theology was not a simple and complete reduplication of Genevan dogrna. The process of modifying this dogma had begun long before the first Puritan reached these shores. It began earlier in the seventeenth century when Reformation polemics had acquired a sophistication quite beyond that of Luther and Calvin. Calvinism needed to be rescued from the charge of dogmatism, and it needed to be rendered more humanistic. "In some fashion the transcendent God had to be chained, made less inscrutable, less mysterious, less unpredictable -- He had to be made, again, understandable in human terms." 12

11 R. R. Stearns, "Assessing the New England Mind," Church History, $\mathrm{X}$, (September, 1941), p. 248 .

12 Miller, "The Marrow of Puritan Divinity," Errand Into the Wilderness, p. 55. 
A way of achieving this was devised by a group of English Calvinists, William Perkins, John Preston, William Ames, and Richard Stibbes. ${ }^{13}$ They forged the doctrine of the covenant out of an interpretation of the Bible as the historical record of God's covenants with man. The initial impact with Adam was a Covenant of works, for God agreed to reward Adam upon the performance of certain prescribed duties. This failed, so God entered into another agreement with man in his fallen state, called the covenant of Grace. The terms were first drawn upon with Abraham. God guarantees the reward of salvation to man upon the fulfillment of the only act he is now capable of -- faith in the mediatorship of Christ in man's behalf before God in the Final Judgment. In Abraham's case it was an act of faith in the anticipated Redemption. In our case it is faith in the accomplished fact.

A most important aspect of this covenant is the obligation incurred by both signatories. Neither God nor man can violate its conditions.

It has pleased the great God to enter into a treaty and covenant of agreement with us his poor creatures, the articles of which agreement are here comprised. God, for his part, undertakes to convey ali that concerns our happiness, upon our receiving of them, by believing on him.

13 Miller suggests they form a school, along with their New England counterparts, John Cotton, Thomas Ehaprd, Thomas Hooker, and Peter Bulkley. 
Every one in particular that recites these articles from a spirit of faith makes good this condition. 14

The guarantees exacted from God in the covenant have a moderating influence on $\mathrm{His}$ arbitrary nature. If He would bind Himself to a compact, He would appear to be a more reasonable being than calvin had portrayed. And as a reasonable being He governed and regulated all things by the laws of nature that were being discovered by Seventeenth century science. Far from being inimical to science. these Calvinists saw the covenant as a way of reconciling religion to the rapid development of science. God's reasonableness was demonstrated further by the way He chose to disclose the terms of the compact. He allowed it to develop slowly through time, so as to use history as the vehicle by which man becomes educated to its terms. Hence, the doctrine of history is intrinsic to the covenant, and it enabled the Puritans to welcome every historical advance, including science and mathematics by means of such a rationale.

The effect of covenant theology was crucial to the formation of the Puritan character. Our conventional picture of him as a man of tremendous faith and endurance, and the wherewithal to conquer a stubborn wilderness is quite consonant with his theology. The typical Puritan was

${ }^{14}$ Richard Sibbes, cited by Miller, The New England Mind. The Seventeenth Century, p. 377. 
intolerant of those without a driving sense of progress and of empire building. "Faith, endurance, intolerance:

these aggravated by calvinistic theology, characterize the Puritan frontier."15 They characterize what Santayana called the gospel of work and the belief in progress.

By subduing a wilderness and building a new social order, the Puritans gave flesh and blood to the covenant of Grace. They opened the floodgates of experience with their sense of a God who revealed His plan in and through time. If the God of power was remote and utterly beyond human understanding, then that same Lord, as a God of Love, was discernible and stood in their midst. And while a God of Love was still not discernible to the intellect completeIy, man is capable of making an aesthetic response to Him in the New England forests. It was a Puritan who said:

The Scripture, that saith of God, that he is Life and Light, saith also, that he is Love, and Love is Complacence, and Complacence is Joy; and to say God is Infinite, Essential Love and Joy, is a better notion, than ... to say that God - - (is) but a Thought, or an Idea.16

If a God of love evoked such a response as this, then we must reconsider the traditional charge against the Puritans that they were deficient in a sense of beauty. Puritan theologians rhapsodized the beauty of nature as evidence of

\section{$15_{\text {Hazard, p. } 27 .}$}

16 Richard Baxter, "Epistle to the Reader," Poetical Fragments (London: 1681), pp. 4-5. Cited in Perry, p. 378. 
God's existence: They saw a Platonic world where beauty was the efficient order and harmony of all things fixed by God. John Preston defined beauty as "a conformity of all parts," and Thomas Hooker said it was the "sweet correspondence and orderly usefulness the Lord first implanted in the order of things." 17 Consider the eloquence of Preston:

Can we, when we behold the stately theater of heaven and earth, conclude other but that the finger, arm, and wisdom of God hath been here, although we see not him that is invisible, and although we know not the time when he began to. build? Every creature in heaven and earth is a loud preacher of this truth. Who set out those candles, those torches of heaven, on the table? - Who taught the birds to build their nests, and the bees to set up and order their commonwealth? ${ }^{8}$

The Puritans had no sophisticated theory of beauty. They simply saw God's image in the efficient order and harmony of nature, and they constantly drew analogies between the beautiful objects of ordinary experience and their perfect exemplar. God's beauty was especially seen in the artifacts of Puritan handicraft, for, in their struggle to survive, the axe and the rifle were vivid examples of good, efficient order. They had little appreciation for the fine arts. These did not fit into a frontier economy as did the practical arts. And yet they did not equate beauty with utility; beauty was still the

17 Miller and Johnson, Vol. I, p. 62.

$18_{\text {Miller, The New England Mind. The Seventeenth }}$ Century, p. 210. 
rightful order of all things. Thus, there was a dearth of aesthetic appreciation among them. Professor Miller is quite correct that "the Puritan aesthetics contributed to cosmic optimism." 19

We should be very surprised if such an optimism made no room for science. The overwhelming concensus of scholars is that the Puritans not only accepted the great scientific advances of the Enlightenment, but encouraged them and even made significant contributions. 20 scientific research was seen as a marvelous verification that nature reflects the wonder and beauty of God. In the midale of the seventeenth century Harvard taught Copernican astronomy from a standard textbook. By and large, European universities were forbidden to teach it until the end of the century, but Harvard disseminated the new system with enthusiasm long before, and the yearly almanac contained articles which popularized

${ }^{19}$ Miller, The New England Mind, p. 215. Cosmic optimism is his favorite term for describing the puritan weltanschauung. He calls it "the indispensable premise of all Puritan belief." p. 208 .

20In 1680, Thomas Brattle of Harvard made a series of comet observations to which Newton gave acknowledgment. "This study of the gravitational influence of the sun on the moon and comets was the actual foundation and the beginning of the writings of the immortal Principia." See Frederick E. Brasch, "The Newtonian Epoch in the American Colonies (16801783). "Proceedings of the American Antiquarian Society, XIIX (1939), 314-332. 
it. 21 The New England Puritans rapidly assimilated the work of Copernicus, Galileo, Gilbert, Boyle and Newton into their theology. Without a doubt, Puritans on both sides of the ocean were a part of the scientific community. 22 The tendency to contrast the humanism and enlightenment of the scientific movement with a conventional caricature of Puritanism as reactionary and obscurantist cannot be sustained by the evidence. "That Calvin and Puritanism had a stimulating influence upon science has been made evident by several recent studies." 23 Puritanism was an important factor in developing the type of empirically grounded thinking which would be conducive to scientific activity.

It is not enough to explain the Puritan's vigorous pursuit of science by attributing it solely to their penchant for logic, as some writers suggest. In fact, Covenant theology, because of its requisite tight logic, had trained the mind to rigorous thinking, and when books of Newtonian science arrived in the colony, their habit of systematic

21 Zechariah Brigden, "A Brief Explication and proof of the Philolaick Systeme," Almanack, Cambridge, 1659; reprinted in the New England Quarterly, VII (1934), pp. 9-12.

${ }^{22}$ See R. Hooykaas, "Science and Reformation," The Evolution of Science, Guy S. Metraux and Francis crouzet eds. (New York: Mentor, 1963), p. 256.

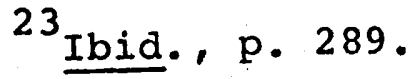


thought allowed them to digest the new physics. ${ }^{24}$ Thus, while the former thesis is quite true, it fails to take into account the Puritan aesthetic and their cosmic optimism. Their receptiveness to Copernicus and Newton was as much due to religious experience as to rigorous thinking. They saw scientific research as an approach to the beauty of God through the beauty of His creation; God made such matters known by His will. Science permitted them to see nature as the outward symbol of the inner life of God.

The employment of nature as symbol . . was for the Puritan mind much more important than the choice of which particular system of physics was used to explain nature. The universe was to be studied and expounded because it was the providence of God in operation; the essential disposition to see God's hand in events, a perception of the identity of natural order and divine decree, an ability to read the analogy between spiritual law and natural laws, and a faith in the fupdamental perfection of the plan of creation. ${ }^{25}$

The extent to which science and experience had made an inroad into the Puritan mind is vividly illustrated in cotton Mather. This high priest of Puritanism recognized the significance science held for religion, and wrote about the wonder and beauty of nature with the feeling of a

${ }^{24}$ Frederick C. Kilgour, "The Rise of Scientific Activity in Colonial New England," Yale Journal of Biology and Medicine, XXII (1949), 138. see also Brasch, p. 332 , He ence, giving rise to Puritan rationalism.

\section{Miller, The New England Mind. The Seventeenth} Century, p. 216 . 
poet-mystic. In his book The Christian Philosopher, he argues that the dazzling beauty of the world uncovered by science bespeaks a benevolent God, and that to study nature is to realize God's Goodness. ${ }^{26}$ of all the developments in science, astronomy and the new knowledge gained through the telescope excited him the most. ${ }^{27}$ Mather realized the telescope unveiled to man an infinite universe, and his rapture is unmitigated.

I hear a great voice from the starry heavens, ascribe ye greatness to our God. Great God, what a variety of worlds hast thou created! How astonishing are the dimensions of them! How stupendous are the displays of thy greatness, and of thy glory, in the creatures, with which thou hast replenished those worlds! Who can tell what angelic inhabitants may there see and sing the praises of the Lord! Who can tell for what uses, those marvellous globes may be designed! of these unknown worlds I know thus much, it is our great God that has made them all. 28

His exaltation confirms a religious-aesthetic response to the infinite world of modern science. Other texts confirm that God's glory is exhibited most clearly in such a world. 29

${ }^{26}$ Selections from Cotton Mather, Kenneth B. Murdock, ed. (New York: Hafner, 1960), pp. I-11.

27 The Christian Philosopher (Charlestown: Middlesex Bookstore, 1815), pp. 21-22.

28 Mather, The Christian Philosopher, p. 24.

${ }^{29}$ See Theodore Hornberger, "The Date, the Source, and the Significance of Cotton Mather's Interest in Science," American Literature VI (1935), 413-420. 
Mather was the first in a line of Puritan thinkers who saw the urgency of rethinking their conception of the universe in the light of science, and of rediscovering God within a world whose physical dimensions were no longer confinable to ordinary human concepts. Edwards followed in the eighteenth century with the best attempt at this task of reconciling religious belief with the demands of science.

The key to their conception of the universe had always been the idea of providence, and science was a new way, revealed by God's wisdom, of discovering it. In a universe of countless unknown worlds, they realized the infinite depth of his providence, and that God is not tied down to one plan. He does not answer to a classical.Greek world governed by reason, measure, limit, and proportion.

And yet this is a thoroughly moral world He has created. The Puritans had to see religious and moral truths written into it. This was the tension they lived with: they felt compelled to lead a moral life, but they could not say the same morality, where the full measure of divine grace was observable, was binding on the universe. They must strive for communication with the supreme force which governs the world, but they knew better than to expect that force, in the Platonic sense, to conform always to their conception of what is reasonable. They accommodated their lives to this tension, and out of it came a cosmic optimism and their peculiar sense of beauty. They 
achieved a fusion of religion and experience far better than the other Christians of their day. All the affairs of everyday life had religious significance. Faith in God was the decisive factor which carried them through their perils. It is here that we find a unique Puritan aesthetic.

There is more than one kind of beauty, and the Puritan, like many other men in all ages, discovered in what he saw as the beauty of holiness enough to satisfy all the cravings of his nature. His life seems sterile to us. Perhaps it was so in fact; perhaps we fail to appreciate hos passionate was his conviction and how challenging his ideal. While Puritanism was alive, with power to make history, its morality and its rules were developed from within as the fruit of individual faith. 30

We may draw the following conclusions from our discussion of the effects of science and experience on Puritanism. First, they had a religious vision of God's providence operating in the universe and in the life of man. More properly, it was a religious experience, for it penetrated all levels of life. Second, this vision, or experience, was founded on the covenant of Grace which implied a doctrine of history, and was enriched by seventeenth century science and by life in the New World. Third, the most important, it was the aesthetic experience of a moral universe, generated by the tension between what the world ought to be and what it is in fact.

30 Kenneth B. Murdock, "The Puritan Tradition in American Literature," The Reinterpretation of American Literature, ed. Norman Foerster (New York: Harcourt, Brace, 1928), p. 100 . 
CHAPTER IV

\section{OF BEAUTY AND SENSIBILITY IN EDWARDS ' DOCTRINE OF EXPERIENCE}

One of the distinguishing features of Edwards' thought is the way in which he organized it around a doctrine of experience. Quite early in his life he began to adapt his religious ideas to the requirements of Lockean empiricism, but he also moved beyond Locke toward his own unique formulation of experience. So it is imperative to study this doctrine in its origins and its development to demonstrate that his mystical theology is grounded in experiential categories. There are three elements, which, taken together, form the heart of his doctrine of experience. First, there is the idea of beauty, or excellence, which signifies Edwards' singular achievement as theologian and is basic to his philosophy, especially to what is commonly called his epistemological empiricism. Second, there is the element in this empiricism which he designates as a sense of the heart. It is a doctrine of knowledge in which affection is put on an equal footing with reason in the noetic act (process of cognition). Finally, there is the theological 
concept of grace, or love, which is the capstone of his whole doctrine of experience. A thorough explication of each of these components in themselves and in their interrelations will reveal the full meaning of experience for Edwards. 1

To begin with the first of these, the idea of beauty, it is important to note that an intense awareness of the aesthetic dimension in all things permeated his life. This sense of beauty suffused his experience and came to form the central insight of his religious and metaphysical thought. Edwards was never more original than in the way he demonstrated the connection between aesthetic and religious experience. This was not so much inferred from a theological or philosophical premise as it was sensually felt by him as though its were physically a part of his being. He fashioned a novel system of thought in which the greatest single influence was not any other system but an original aeshtetic view of things. It dominated his mind and guided the growth of his thought.

More than any one else of his time, Edwards perceived the subtle changes that life in the wilderness and the revolution in science and philosophy exerted over the New England Calvinist mind. He realized better than his adversaries the

$1_{\text {See }}$ for an exhaustive analysis of this area alone, Roland A. Delattre, Beauty and Sensibility in the Thought of
Jonathan Edwards (New Haven: Yale University Press, 1968). 
profound significance of the Great Awakening, a popular religious revival of the 1740's which was precipitated by the crisis within Puritanism. As a sociological phenomenon, it marked the point at which the wilderness replaced traditional doctrine as the primary source of theological meaning. ${ }^{2}$ After the Great Awakening, experience prevailed and assumed a major role in the development of philosophy and theology in America. ${ }^{3}$ When it merged with the Christian doctrine of providence, it gave rise to a philosophical and theological empiricism that sought the mind of God in the stream of human and natural history. 4 consequently, a cult of experience sprang forth from this theological empiricism and extended itself into the arts and literature where it

${ }^{2}$ See Miller, Errand Into the Wilderness, p. 153.

$3_{\text {Although there are great difficulties in the concept }}$ of an "American theology," there is a validity to ascribing to America an indigenous theological development. See Daniel B. Williams, "Tradition and Experience in American Theology," The Shaping of Religion in America, eds., James Ward Smith, A. Leland Jamison (Princeton, New Jersey: Princeton University Press, 1961).

${ }^{4}$ Williams, p. 473. "The most important root of the theological empiricism was the belief, derived from the Christian faith and present in the American consciousness from the Puritans and Edwards to the present, that a sufficiently faithful and realistic attention to the direction of historical events will disclose the hand and judgment of God. American theological empiricism in all its forms has an inward relation to the doctrine of Providence, whether this be expressed in Calvinist determinism, in ideas of progress, or in the criticism of progressive optimism." 
took the form of vernacular expression. 5

It was no accident of history that New England produced its outstanding genius, in whom its doctrine was summed up and transformed, at that precise moment when experience gained a position of dominance in shaping the nascent institutions of American life. The rapid turn of events in the first half of the eighteenth century, the influences of the Enlightenment permeating Massachusetts, resulted in two distinct developments in Puritanism. One was the growth and spread of evangelical religion which moved westward with the frontier, and the other was the rationalism and deism that dominated the east, leading toward nineteenth century Unitarianism. Edwards mediated these opposing tendencies by analyzing the Awakening, giving it a perspective, and constructing an empirical theology which would withstand assaults from both sides.

When we turn to his personal life, we find that from the beginning his uncommon sensibilities and acute responsiveness prepared him for the task of overhauling traditional empiricism and aligning it with the cause of religion. From Sereno Dwight we learn that "the refinement of manners and of character, which he witnesses in (his parents) and

${ }^{5}$ See John A. Kouwenhoven, Made in America. The Arts in Modern Civilization (New York: Doubleday, 1948) . Also, two essays by Philip Rahv, "Paleface and Redskin," and "The Cult of Experience in American Writing," Image and Idea (New York: New Directions, 1957). 
in their friends, prepared his own mind from his earliest years, to withdraw from everything low and grovelling, and to find a high enjoyment in all the varieties of intellectual and moral beauty." 6 By nature and inheritance, he was gifted with exceptional powers of observation and a love of beauty which made him an artist. His life was given to the pursuit of beauty in all things, and to the task of bringing religion together with an empirical view of the world in order to enrich the qulaity of all sensual experience. "One characteristic . . which he possessed in an unusual degree, was a fondness, minutely and critically to investigate the works of nature. This propensity was not only discovered in youth and manhood, but was fully developed in his childhood." 7 His "Personal Narrative," an autobiographical account of his religious conversion, constantly reflects this theme.

The books and sermons of Edwards indicate a man whose faculties were attuned "to the beauties of nature in the air and on the face of the earth." He was more than a keen observer of nature; he was an artist who intuited the infinite possibilities of nature because of its source in an infinite God.

The Life of President Edwards (1829), I, p. 19. ${ }^{7}$ Ibid., p. 22 
The beauty of trees, plants, and flowers with which God has bespangled the face of the Earth is Delightsome, and the beautiful frame of the body of Man, especially in its Perfection is Astonishing, the beauty of the moon and stars, is wonderful, the beauty of the highest heavens, is transcendent, the Excellency of angels and the saints in light, is very Glorious, but it is all Deformity and Darkness in Comparison of the higher glories and beauty of the creator of all. . .

This text recalls the lively exultation of Cusa and the exuberant joy of Bruno in their discovery of an abundantly rich universe. Nowhere does Edwards sing more joyfully about the opulence of nature than in The Beauty of the World.

How lovely is the green of the face of the earth in all manner of colours, in flowers, the colour of the skies, and lovely tinctures of morning and evening. - . Hence, the reason why almost all men, and those that seem to be very miserable, love life, because they cannot bear to lose sight of such a beautiful and lovely world. The ideas, that every moment whilst we live have a beauty that we take not a distinct notice of, brings a pleasure that, when we come to the trial, we had rather live in much pain in misery than 1ose. 9

other similar texts appear frequently in his writings. They show that in his descriptions of nature he never failed to introduce the aesthetic element.

That Edwards had the temperament of an artist cannot

${ }^{8}$ From an unpublished sermon quoted in Ola E. Winslow, Jonathan Edwards (New York: Macmillan, 1941), p. 139.

${ }^{9}$ Images or Shadows of Divine Things, ed. Perry Miller (New Haven: Yale University Press, 1948), pp. 136-137. 
be denied. Yet we tend to overlook the powerful influence his environment exerted over his temperament. He didmt operate in an intellectual vacuum, and we cannot minimize the circumstances of his life in a frontier society. His sensitive eye for beauty always alerted him to the magnificence and charm found everywhere in nature. He responded aesthetically to turbulent thunderstorms as well as to serene sunsets. He especially found exceptional delight in the magniture of the wilderness, and concluded that the mind has a natural propensity to beauty in great objects. Large rivers, large mountains, the great expanse of space experienced in the first western migration from Boston into western Massachusetts and Connecticut; these were the kinds of experience which enlarged Edwards' capacity to absorb a new kind of beauty. "So the beauty of the solar system (is) more than as great and as manifold an order and uniformity (than is to be found) in a tree." 10 At the time in history when Europe was discovering the aesthetic of the infinite, 11 Edwards was giving it new expression in the American wilderness. He was no classicist who confined beauty to the measurable, the limited, the rational. "He was no Latin,

${ }^{10}$ Quoted by A. C. McGiffert, Jonathan Edwards (New York: Harper, 1932), p. 191.

${ }^{11}$ See Marjorie Hope Nicolson, Mountain Gloom and Mountain Glory (New York: W. W. Norton, 1963). 
no Stoic - he was a Puritan, an American, and a barbarian." 12 So he rejoiced at a world replete with the infinite goodness of a God; a goodness which is accessible to man in immediate perception; a goodness and beauty too rich in all its concreteness to be assimilated by intellect alone. It was at a very early age that Edwards came to realize how inadequate the intellect is by itself as an instrument for confronting such a world. As a student at Yale, he discovered that the primacy of experience in his own life was far greater than he could ever imagine. In his later years he recalled that the turning point in the growth of his mind occurred upon reading Locke's Essay Concerning Human Understanding. He called himself "a great miser" gathering up "handfuls of silver and gold from some newly discovered treasure" as he pored through Locke's thesis that experience, and only experience can be the source of our mental life. Perry Miller calls Edwards the frontier aisciple of Locke with the erroneous implication that the Essay became the vade mecum of his entire philosophic life. He did not follow Locke in any fundamental sense; rather, Locke became a guide which aided him in his own exploration of experience. If he was a greedy miser counting the treasures of the Essay, he did not hoard these ${ }^{12}$ Miller, Jonathan Edwards, p. 183. 
treasures, but evaluated them for their relevance to his own situation. Locke's empiricism became a challenge to construct a theory which would do justice to his own wilderness experience, and not to Locke's.

After he had thoroughly read and absorbed the new empiricism, Edwards sketched out his precocious essay, "Notes on the Mind," which was a compendium of his entire philosophical career. A great deal of it was written while he was still a student, and it represents his formative work. It encompasses every major question to which he would devote a lifetime of study. Edwards differed from other thinkers of comparable stature because there was no substantial change throughout his life from the system of thought outlined here at the beginning. He never deviated in any significant way from the principles he set down as a college student, but spent his time amplifying and clarifying them. The Lockean motivation behind these "Notes" is quite evident, but the work reflects another important influence which cannot be atributed to Locke. One reads on every page the subtle influence of his own personality, nurtured by a religious-aesthetic experience of life on the western frontier of the New England Plantation. If we can discern the balance between both influences in this essay, then we shall have an authentic and greater appreciation of the foundation of his empiricism.

Throughout all his early works, which include the 
"Notes on Natural Science," and "Of Being" in acdition to "The Mind," Edwards consistently manifests an idealism. 13 on the question of the possible influence of Bishop Berkeley, the evidence indicates a high improbability that Edwards had access to his writings. There is a great tendency on the part of scholars to conclude that he arrived at the same conclusions as the Anglican bishop by an independent route. The reduction of Locke's primary qualities to secondary qualities was an easy step for him to take, since in all these works he manifests an overriding concern for the mysterious notion of consciousness. Every knowing philosopher, he tells us, agrees "that colours are not really in the things, no more than pain is in a needle; but strictly no where else but in the mind." By what right do we then say that body has an independent existence? None, according to Edwards. For the idea of body is "nothing but Colour, and Figure, which is the termination of this colour, together with some powers, such as the power of resisting,

13 For critical comment on his idealism, these earlier works are excellent sources to begin with: Egbert C. Smyth, "Jonathan Edwards' Idealism," American Journal of Theology, $\mathrm{V}$ (October, 1898), 950-64. Smyth works from early manuscripts, especially "Of Being." See also H. N. Gardiner, "The Early Idealism of Jonathan Edwards," Philosophical Review! IX (November, 1900), 573-596. Concludes that the inspiration came from Locke, Newton, and Cudworth, the Cambridge Platonist. The article also suggests that "Edwards' deepest spiritual affinity was not with Calvin, but with Dante." John H. MacCracken, "The Sources of Jonathan Edwards' Idealism," Philosophical Review, XI (January, 1902), 26-42. Believes that Edwards could not have been influenced by Berkeley. 
and motion, etc. - . And if that which we principally mean by the thing, itself, cannot be said to be in the thing itself, I think nothing can be." ${ }^{4}$ Nothing exists outside the mind, then, except atoms, which by their nature consist purely of solidity. "Any body . . were an atom, if it were a perfect solid." 15 so body and solidity are the same; and by solidity he means that which resists annihilation. But the idea of resistance is associated with the ideas of integrity and wholeness, and these have a relation to consciousness, specifically divine consciousness. ${ }^{16}$ Even atoms, therefore, cannot really claim an existence independent of mind.

Edwards' idealism rests on the principle that consciousness is intrinsic to being. Otherwise being becomes meaningless. There is no sense to a being which is not related to some form of consciousness. "We learn the necessity of the Eternal Existence of an All-comprehending mind" 17 the moment we discover that the concept of nothing is an empty and totally repugnant contradiction. It is a contradiction and it puts the mind into convulsion and confusion. There is a natural abhorrence to nothingness

14 "Notes on the Mind," Works (Dwight ed.), I, p. 668. 15 "of Being," Ibid., p. 711 .

16 For a full explanation of this point, see below, The Theology of Atoms, Space and Gravity" in Chapter VIII.

17 "The Mind," Works (Dwight ed.), I, p. 669. 
because the very matrix of being implies consciousness -is consciousness in the strict ontological sense.

How doth it grate upon the mind, to think that something should be from all eternity, and yet Nothing all the while be conscious of it. To illustrate this: Let us suppose that the World had a being from all eternity, and had many great changes, and wonderful revolutions, and all the while Nothing knew it, there was no knowledge in the Universe of any such thing. How is it possible to bring the mind to imagine this? Yea, it is really impossible it should be, that anything should exist, and Nothing has any existence but in consciousness: No, certainly, no where else, but either in created or uncreated consciousness.

When Edwards says that the universe can exist only in the divine mind, he makes of consciousness an irreducible cosmic element. The individual's mind participates in cosmic consciousness to the extent that he forms some kind of an awareness of totality and of the infinity of his own consciousness. Edwards was keenly aware of the absence of any boundaries to human consciousness. He knew that it encompasses not only its immediate environment, but something much deeper. He knew this because his experience of the boundless American landscape had given him a sense of the limitless capacity of the mind to absorb this experience. As a young student in a frontier college he was far ahead of most European thinkers in his intuition that the great expanse of outer space (which was a daily reality 18 "Of Being," Ibid., p. 707. 
to him) meant an equally large expanse of human consciousness. The youthful Edwards realized that the immensity of space extends simultaneously in two directions: into the outer cosmos and into the psychic space of man's inner consciousness; and he saw that these are two dimensions to the same fundamental reality which he linked with the divine.

No fact was more evident to Edwards than that the world reflects a universal consciousness and that everything stands in relation to an all-comprehending mind. He never denied an objective reality, but he asserted that the innermost nature of that reality was mental, and not material in any sense that would totally exclude the mental. An important consequence follows from his idealism. If the world exhibits such aesthetically pleasing qualities as unity, equality and proportion, then their source must be attributed to divine consciousness. This means that the ideas man possesses of beauty must also be attributed to this higher origin. Edwards' idealism appears to be only a means toward another end, the end be-ing a metaphysical account of the aesthetic structure of reality. 19 In this account, ideas are energies or sources

19 A similar conclusion is arrived at by Leon Howard; "Conclusion: The Mind of Jonathan Edwards," The Mind of Jonathan Edwards, a Reconstructed Text (Berkeley and Los Angeles: University of California Press, 1963), pp. 13334 . 
of power which transform an otherwise pale, flaccid and disparate world into a beautiful and dynamic cohesion. In other words, the intrinsic relation of consciousness to reality guarantees an aesthetic world; in Edwards' words, a world of universal mutual consent.

We have in the fact of universal consciousness the first principle of his doctrine of experience, because it accounts for the aesthetic character of the world and for man's ability to perceive it. But this fact must be seen within a religious context, for Edwards believed strongly that the highest form of aesthetic experience is religious in nature. When we perceive beauty in whatever shape or form, it is really God's excellence that we are perceiving according to our limited capacity. The first distinguishing feature of all religious experience is the aesthetic perception of divine beauty.

The point is best illustrated in his "Personal Narrative," an autobiographical description of his own conversion in which he depicts the aesthetic character of religious experience. At the time of this conversionhe experienced a "kind of delight in religion." The first instance of an "inward, sweet delight in God" occurred when he read these words from Timothy:

Now unto the King eternal, immortal, invisible, the only wise God, be honor and glory for ever and ever, Amen. As I read these words, there came into my soul, and was as it were diffused through 
it, a sense of the glory of the Divine Being; a new sense, quite different from anything I ever experienced before. . . I thought with myself, how excellent a Being that was, and how happy I should be, if I might enjoy that God, and be rapt up to him in heaven, and be as it were swallowed up in him forever! 20

His Calvinism was no barrier to this delight. On the contrary, the very idea of sovereignty now "appeared exceedingly pleasant, bright and sweet." The idea of God's sovereignty and majesty became curiously blended with a sense of his meekness. No longer could Edwards aesthetically appreciate one without the other. He tells of walking alone in his father's pasture and contemplating with a sweet sense, the "glorious majesty and grace of God. ..."

I seemed to see them both in a sweet conjunction; majesty and meekness joined together: it was a sweet, and gentle, and holy majesty; and also a majestic meekness; an awful sweetness; a high, and great holy gentleness.

He then records the permanence and the depth of his conversion. "After this my sense of divine things gradually increased, and became more and more lively, and had more of that inward sweetness." - Thereafter, the sense of God's beauty suffused his being, and religion became the one great source whereby experience took on a richness and intensity never before possible.

20 Works (Dwight ed.), I, p. 60.

${ }^{21}$ Ibid., p. 61. 
The appearance of everything was altered; there seemed to be, as it were, a calm, sweet, cast, or appearance of divine glory, in almost everything. God's excellency, his wisdom, his purity and love, seemed to appear in everything; in the sun, moon, and stars; in the clouds and blue sky; in the grass, flowers, trees; in the water and all nature; which used greatly to fix my mind. I often used to sit and view the moon for a long time; and in the day, spent much time in viewing the clouds and sky, to behold the sweet glory of God in these things: in the meantime, singing forth, with a low yoice my contemplations of the Creator and Redeemer.

It became forcefully clear to Edwards that the pursuit of beauty is not the proper undertaking of reason. "It is not a thing that belongs to reason," he said, "to see the beauty and loveliness of spiritual things." Defining reason as ratiocination, or the power of inferring by arguments, he never permitted an opportunity to pass without commenting on its inadequacy in the aesthetic and religious life of man.

The perceiving of spiritual beauty and excellency no more belongs to reason that it belongs to the sense of feeling to perceive colours, or to the power of seeing to perceive the sweetness of food. It is out of reason's province to perceive the beauty or loveliness of anything. . . Reason's work is to perceive truth and not excellency. . . . Reason may determine that a countenance is beautiful to others, it may determine that honey is sweet to others; but it will never give me a perception of its sweetness.23

The primacy of experience in all things thus became the ruling dictum of his philosophy. He asserted the general proposition "that experience is to be relied on," as

22 Ibid.

23"A Divine and Supernatural Light," Works (Dwight eda), VI, pp. 185-86. 
though it carried the persuasion of a self-evident truth. "That the experience of mankind is to be depended on; or, that those things which the world finds to be true by experience, are worthy to be judged true, is a general proposition, of which none doubt." 24 Reason itself dictates the primacy of experience, for how unreasonable it is to say that reason must first give credibility to the propositions of experience. The sources of experience are indisputable sources of truth. All the experience of mankind originates with the testimony of the senses, of the memory, of othex men, and of history and tradition.

The fullest expression of the aesthetic nature of religious experience is found in the Treatise Concerning Religious Affections. Edwards describes the objective source of the affections as a "transcendentally excellent and amiable" God. 'It is unreasonable to think otherwise, he states unequivocally, "than that (the) first foundation of a true love to God, is that whereby he is in himself lovely, or worthy to be loved, or the supreme loveliness of his nature." 25 To say that God merits our worship primarily because of his infinite beauty and not because of his sovereignty is quite exceptional for a calvinist.

24 "The Insufficiency of Reason as a Substitute for Revelation," Works (Dwight ed.), VII, p. 263.

25 Religious Affections, ed., John E. Smith (New Haven: Yale University Press, 1959), p. 242. 
God's nature : - is infinitely excellent;

yea 'tis infinite beauty, brightness, and

glory itself. 26

But then Edwards specifies the nature of infinite beauty

as a moral exceliency.

That kind of excellency of the nature of divine things, which is the first objective ground of 27 all holy affections, is their moral excellency.

Moral excellency, he tells us, is holiness, and in order to behold it, man must acquire a new sense. Holiness, or spiritual beauty, requires a special aesthetic sense which is also a moral sense. The implication here is that beauty and moral excellency are identified in God, and that therefore beauty and morality have an identity in the experience of regenerate man.

Edwards calls it a new spiritual taste, for it is more than an intellectual awareness. It is a totally new capacity for aesthetic and moral experience:

which is in its whole nature diverse from any of the other five senses, and that something is perceived by a true saint in the exercise of this new sense of mind, in spiritual and divine things, as entirely different from anything that is perceived in them by natural men, as the sweet taste of honey is diverse from the ideas men get of honey by looking on it or feeling of it; now this that I have been speaking viz. the beauty of holiness in that thing in spiritual and divine things, which is perceived by this spiritual sense, that is so diverse from all that natural men perceive in them: this kind of beauty is the quality that

$$
\begin{aligned}
& 26 \text { Ibid., p. } 243 . \\
& { }^{27} \text { Ibid., p. } 256 .
\end{aligned}
$$


is the immediate object of this spiritual sense: this is the sweetness that is the proper object of this spiritual taste. 28

As one writer says, "No idea in all of Edwards' works is more original." 29

What is conspicuously original is the way in which Edwards subsumed the spiritual taste for divine excellency under the broader category of moral experience. We learn from a later work that morality is an irreducible category of his metaphysics, that the end of all creation is the moral world.

The last end for which God has made moral agents, must be the last end for which God has made all things; it being evident, that the moral world is the end of the rest of the world; the inanimate and unintelligent world being made for the rational and moral world, as much as a house is prepared for the inhabitants. 30

Time and again, Edwards emphasized that the spiritual sense has as its object the beauty of God's moral perfections. "What that beauty or loveliness of divine things is, which is the proper and immediate object of a spiritual sense of mind.. . is the beauty of their moral perfections." 31 The aesthetic experience of a man ${ }^{28}$ Ibid. , pp. 259-60.

29 John E. Smith, "Editor's Introduction, "Religious Affections, p. 30 .

30"A Dissertation on the Nature of True Vi.rtue," Works (Worcester ed.) II, p. 412. See also, Religious Affections, p. 273: "The glorifying of God's moral perfections, is the special end of all the works of God's hands."

$31_{\text {Religious Affections, p. } 271 .}$ 
endowed with the spiritual sense of divine beauty is equivalent to a moral experience. In this, Edwards wishes to show. that the appreciation of beauty is not a passive affair of beholding an objective order; but it is an active moral response, a turning of the whole person towards God, and not merely an intellectual adequation to His objective existence.

The idea of excellency was undoubtedly the source from which a great deal of his most original thinking came. He first proposed a theory of aesthetics in "The Mind," and he suggested that beauty in its highest form be defined as the consent to being. Now the consent to being is the pivotal concept in Edwards' moral philosophy; and so as a precocious college senior he had already seen the intrinsic connection between beauty and morality, between aesthetic experience and moral experience. Edwards' genius is manifest in the explication of excellency written before he completed his course of study at Yale. He was aware even then of its great importance to his life and thought, for he indicated that it is "what we are more concerned with, than anything else whatsoever." 32

He beings his probe into the nature of beauty by repeating the classical formula: Excellency is harmony, 32 "The Mind," Works (Dwight ed.), I, p. 693. 
symmetry, or proportion. But of the three, proportion would seem to be the most fundamental. Proportion, a system of ratios, is further resolved into simple equality. "Excellency therefore seems to consist in Equality. Thus, if there be two perfect equal circles, or globes, together; there is something more of beauty than if they were of beauty of unequal, disproportionate magnitudes." 33

But this offers the lowest kind of aesthetic gratification; it is "Simple Beauty." When equalities proliferate into complex patterns, the resulting "Complex Beauty" offers a much more complete satisfaction to man's taste for excellency. In "Simple Beauty" one part of component of reality consents with but one other part. "But by proportion one part may sweetly consent to ten thousand different parts; all parts may consent with all the rest; and not only so, but the parts, taken simply, may consent with the whole taken together. ${ }^{34}$

Edwards introduces the notion of relation as central to the meaning of proportion. "All beauty consists in similarness or identity of relation." 35 The identity or similarity of relations between different sets of objects constitutes the innermost nature of beauty. As a matter of fact, "one alone, without any reference to any

${ }^{33}$ Ibid. , pp. 693-694.

${ }^{34}$ Ibid., p. 698 .

${ }^{35}$ Ibid., p. 695 . 
more, cannot be excellent; for in such case, there can be no manner of relation no way, and therefore no such thing as Consent."36 The absence of all relations contravenes the whole idea of excellency for Edwards, for this doctrine is rooted in a sense of an organic world in which the individuality of anything (and its beauty) is located in the sum of its relations. When he says that without a plurality there can be no excellency, he means the "various parts of the Universe" are related so as to produce a general consent or agreement.

The identity of relations occurs when parts of bodies are the same as parts of other bodies. When there are two bodies of different shapes in which there is no similarity between their parts, then the result is disproportion or deformity. But how does Edwards determine when there is no similarity between the parts? His answer marks the point at which he abandons the most narrow and restricted meaning of geometric symmetry as the criterion of beauty, and adopts a wider and more flexible norm which would meet the requirements of expansive experience. He concedes that there are millions of identities and similarities which make up a vast, limitless 36 Ibid., p. 697. 
network of relations, and that this calls for a new understanding of beauty. What we normally think of as "particular disproportions sometimes greatly add to general beauty."37 Particular disproportions may not be disproportionate at all if they are seen as part of a wider system. Edwards' aesthetic is reminiscent of the stoics and of st. Augustine here. He writes: "Excellency consists in the similarness of one being to another -- not merely Equality and Proportion, but any kind of Similarness." 38

It is significant that Edwards' theory of aesthetics in "The Mind" concludes by identifying beauty with the consent to Being, by which he means the most generic trait of all existence.

This is an universal definition of Excellency: - The Consent of Being to Being, or Being's Consent to Entity. The more the Consent is, and the more extensive, the greater is the Excellency. 39

Any further explication of beauty must therefore wait for a more complete, later analysis of the meaning of consent.

37

Ibid. , p. 695 .

38 Ibid., p. 696. (Italics mine.)

${ }^{39}$ Ibid. , p. 696. 
CHAPTER V

THE SENSE OF THE HEART

The formative essays on "The Mind" and "Natural Science" reveal how thorough was the influence of Locke and Newton on the developing mind of Edwards. These early works attest to the enthusiastic reception he gave to physical science and to empirical philosophy. If he was a person of unusual aesthetic and religious sensibilities, these did not inhibit his capacity to absorb the latest advances in scientific and philosophic thought. On the contrary, these sensibilities allowed him to accept Locke and Newton as the starting points of a new interpretation of religion and philosophy in which an original doctrine of experience was to become its rich and exciting foundation-stone.

He called the foundation-stone a "sense of the heart," and he first gave it expression in the early pages of "The Mind." The seat of man's cognitive life is situated in the affections, or the heart, he tells us.

The soul man... he said to be in the Heart, or the Affections, for its immediate operations 
are there also. Hence we learn the propriety of the Scriptures calling the soul, the Heart, when considered ${ }_{1}$ with respect to the Will and the Affections.

It follows that consciousness is a form of feeling. "It is a sort of feeling within itself. The mind feels when it thinks; so it feels when it discerns, feels when it loves, and feels when it hates." ${ }^{2}$

He was no disciple of Locke in any fundamental way. The originality of his version of empiricism likes in the un-Lockean way in which he conceived the idea as a unit of feeling, indeed the basic unit. The notion that the higher activity of intellectual cognition is really a species, however refined and abstract, of the elemental affections is quite extraordinary, and cannot be attributed entirely to Locke or to any other written source. It makes much more sense to see it as a native personal trait, and to see Locke's empiricism as the touchstone, or as a way of articulating and structuring the doctrine. Edwards understood cognition to be a complex and subtle expression of feeling and he sustained an intricate system of metaphysics on this doctrine.

If we are permitted to call Edwards an empiricist in the loose descriptive sense of the word, then his great

$$
\begin{aligned}
& \text { 1"The Mind," Works (Dwight ed.), I, p. } 679 . \\
& 2 \\
& \text { Ibid., p. } 680 .
\end{aligned}
$$


achievement was the construction of a metaphysical theology out of a perception of the visible world. Locke had opened up for him a "vision of the universe organized about the act of perception:" ${ }^{3}$ But Locke could not have characterized that vision as an affective response to a beautiful world. He could not have shown Edwards that the perceptive center of man is rooted in the heart; that one really experiences with the heart. This was learned from the wilderness of Northampton and stockbridge. It taught him the futility of trying to reduce it to a set of permanent abstractions. He saw that experience resulted from a constant collision of man with his environment, and that the environment did not passively conform to the wishes and demands of man. In the struggle to survive on the frontier, he saw that the environment responded to his demands with a fierce resistance. All the categories which generate experience were present: primitiveness, conflict, struggle, resistance. And Edwards responded with a deep mystical joy

The Essay had given him a blueprint for probing this mysterious world, but it lacked a doctrine which would be equal to the richness of his experience; in a word it

3 Miller, "Editor's Introduction," Images or Shadows of Divine Things, p. 19. 
lacked the sense of the heart. Locke helped him to see that the mind is really conjoined with things; that man is immersed in nature, and that mind and object, man and nature, form an inseparable unity. But Locke's "ideas" were discrete pellets of experience, and they failed to uncover an organic world which was for Edwards a daily reality. What was lacking in Locke was an appreciation of knowledge as an affective relation to that world.

A sense of the heart belies any mechanistic philosophy that would confine the operation of nature to the strictly defined laws of physics and mathematics. Edwards appreciated Newtonian physics for he saw in it a concatenated universe which existed in space and time. But he also saw that physics must be placed into a wider context in order that mechanism be absorbed into a more complete organic scheme. It was his intention, therefore, to show how the sense of the heart introduces one to the wider world of organic totality.

An organic view of the world was fundamental to Edwards, and he summed it up in his doctrine of the consent to being. ${ }^{4}$ It is certainly implicit in his conception of excellency as a web of relations. The sense of the heart enables a man to participate experientially and affectively in this organic web of relationships or 
mutual consents. Edwards calls love the center of experience, the highest kind of excellency; and he says that all other relationships of harmony in the universe are images of this exemplaristic consent between spiritual beings.

One of the highest excellencies is Love. As nothing else has a proper being but spirit, and as Bodies are but the shadow of being, therefore the consent of bodies one to another, and the harmony that is among them, is but the shadow of Excellency. The highest excellency must therefore be the consent of spirits one to another. And the sweet harmony between the various parts of the Universe, is only an image of mutual love.

Therefore, the harmonies and consents on lower levels of being reflect the love which is peculiar to God and men. Things are finite images of the infinite love communicated by God to the world; and so every creature is implicated in divinity in a fundamental way. With a sense of the heart, a man perceives the correspondence of love between creator and creature on all levels.

While the rudiments of Edwards' sense of the heart (or affective epistemology as it may be called) are outlines in "The Mind," the doctrine is fully developed in later writings. ${ }^{6}$ It rests upon his interpretation of

5 "The Mind," Works (Dwight ed.), I, p. 697.

6 "Miscellanies" \#782, published by Miller, "Jonathan Edwards on the Sense of the Heart," Harvard Theological Review, XLI (April, 1948), 123-145. This item is also published in Townsend, The Philosophy of Jonathan Edwards From His Private Notebooks, pp. 113-126. Other sources of material are: Religious Affections (Smith ed.), pp. 272-273; and an unpublished manuscript in the Yale collection, "Miscellanies" \#1183. 
Locke's conception of an idea. For both Locke and Edwards, the "simple idea" is the basic component of thought. The word stands as a generic term for any unit of perception, and Edwards concurs with the Essay on this point. Idea stands for "whatever is the object of the understanding," and is used "to express whatever is meant by phantasm, notion, species or whatever it is which the mind can be employed about in thinking." 7 simple ideas originate in immediate experience and are the irreducible units of knowledge. A number of them may be formed into complex ideas, or "mixed modes;" by organizing them into various combinations. The essential difference between them is in their respective origins. Simple ideas originate in perception and complex ideas originate only within the mind. The distinction is an important one, for only the simple idea is directly connected with a sensation; and Edwards realized the danger of confusing it with a mixed mode which does not correspond directly to any sensation. A further confusion arises in the relationship between thought and language. Simple ideas and mixed modes are capable of being expressed by words, Locke discovered in Book III of the Essay. Words can stand in place of ideas and function much in the same way as the ideas. A great

7 "Essay Concerning Human Understanding," The English Philosophers From Bacon to Mill, E. A. Burtt ed. (New York: Random House, 1939), p. 247. 
deal of our thinking is carried on by the use of "abstract" words rather than "concrete" ideas. The mental word replaces the sensation and serves as a method of mental shorthand in order to expedite the process of thought. "We thus, in the discourse of our minds, generally make use of signs instead of ideas." 8

There is very often no actual idea of those things when we are said to think of them ... the thought is not employed about things themselves immediately, or immediately exercised in the idea itself, but only some sign that the mind habitually substitutes in the room of the idea. 9

In standing in the place of an idea, a word can be the source of sensation; it can generate or excite an experience. But a great deal of caution must be exercised, Edwards warns us, because mixed modes are abstract ideas and do not pertain to any immediate sensation. So the word which stands in place of the mixed mode is not properly capable of generating a sensation.

When we, in the course of our thoughts... think of any sort of substance or distinct beings, as particularly of men, instead of going about with attention of mind actually to excite the idea of those things that belong to the nature of man, that are essential to it . . and so having actually such an abstract idea as $\mathrm{Mr}$. Locke speaks of, we have only an idea of something in our mind. ${ }^{10}$.

8"Miscellanies" \#782, The Philosophy of Jonathan Edwards From His Private Notebooks, p. 115.

${ }^{9}$ Ibid., p. 114.

${ }^{10}$ Ibid., p. 115. (Italics mine.) 
Those are what "Mr. Locke calls 'mixed modes, " and they are to be rigorously distinguished from the units of sensation called simple ideas.

At this juncture in his analysis Edwards departs from Locke and makes the identification of an idea with its sensation so complete so as to redefine the idea as a species of affection. "To have an actual idea of any pleasure or delight, there must be excited a degree of that delight; so to have an actual idea of any trouble or kind of pain, there must be excited a degree of that affection." 11 The essential meaning of the sense of the heart, of Edwards' empiricism, is summed up here.

In order to clarify further the meaning of this doctrine, he offers a distinction between two general ways of understanding or thinking: cogitation, which is the indirect grasping of reality through signs; and apprehension, the "direct ideal view" of reality. Moreover, there are two faculties whereby direct apprehension occurs. First, there is the understanding, "or what is figuratively called the head," and includes the modes of discerning, judging, or speculating. It is essentially characterized as a passive, detached way of understanding, void of any sense or taste of that which it is grasping.

11

Ibid. 
There is a second way of apprehending which Edwards denotes as the will, "or what is figuratively called the heart." The head and the heart, the understanding and the will, are not essentially opposed whereby one performs the thinking and the other performs the choosing. They are both modes of apprehension, but while the understanding is a speculative mode, the will is an experiential mode. It apprehends on a sensible level whereby things are pleasing or displeasing,

including all agreeableness and disagreeableness, all beauty and deformity, all pleasure and pain, and all those sensations, exercises, and passions of the mind that arise from either of those. An ideal apprehension or view of things of this latter sort is what is vulgarly called having a sense. 'Tis commonly said, when a person has an ideal view of anything of this 12 nature, that he has a sense of it in his mind.

The contrast between understanding and will is really a contrast between notional understanding (i.e. knowledge by signs), and direct sensible knowledge, which is by "some feeling of the heart." 13 In the case of notional understanding there is no "ideal apprehension"

\section{Ibid., p. 119.}

${ }^{13}$ In the Religious Affections, p. 272, Edwards distinguishes the speculative faculty from "the sense of the heart, wherein the mind don't only speculate and behold, but relishes and feels. . . The soul (is) a being that not only beholds, but has inclination, and is pleased or displeased. And yet there is the nature of instruction in it; as he that has perceived the sweet taste of honey, knows much more about it, than he who has only looked upon and felt of it." 
for this involves sensible knowledge. "An ideal apprehension - . is, in vulgar speech, called an having a sense of things." 14 But it is not perception in the populax sense, as restricted to the so-called five senses; it involves intellect and the whole register of human emotions. It means human experience of delight, beauty, comfort, pain, misery, hope, fear, loving, hating, etc., and not merely the perception of colors and sounds.

Edwards specifies within the sense of the heart two levels of sensible knowledge which are called natural and supernatural. There is a purely natural type of experience that men are capable of by which they have a sense of the "objects that are about them" through the laws operating in nature. There is also a natural sense of beauty "as when the ear hears a variety of sounds harmoniously proportioned." 15 But there is in addition a kind of supernatural sensibility which is clearly superior, and it depends on "some immediate influence of the spirit of God." It involves "a sense of spiritual and eternal things, or things that appertain to the business of religion and our eternal interest." 16 such a sense is beyond

14 The Philosophy of Jonathan E 1 From His Private Notebooks, p. 120 .

$15^{\text {Ibid. . p. } 121 .}$

16

Ibid., p. 122 . 
the range of man's natural capacity (the best that can be achieved on this level is a speculative knowledge). It requires the intervening influence of God to infuse a concrete sense or feeling of these things.

But this distribution of sensible knowledge into natural and supernatural is reinforced by the distribution of the objective order of nature into "natural good or evil" and "spiritual good or evil."

By spiritual good I mean all true moral good, all real moral beauty and excellency, and all those acts of the will or that sense of the heart that relates to it and the idea of which involves it, and all sense of it, all relish and desire of it and delight in it, happiness consisting in it, etc. By natural good and evil I mean all that good or evil which is agreeable or disagreeable to human nature as such, without regard to the moral disposition--as all natural beauty and deformity such as a visible, sensible proportion 17 or disproportion in figures, sounds, and colors.

Natural men (i.e. unregenerate men) have only an inchoate sense of spiritual good and evil. "They have very little of any ideal apprehension of any sort of divine and eternal things."18 Whatever sensible knowledge they do have is of natural good and evil, and this requires a divine assistance or what Edwards calls in another context the "common grace" of God. 19

But in order to have the full experience of spiritual

17 Ibid., p. 122. (Italics mine)

18 Ibid., p. 123.

${ }^{19}$ See "Treatise on Grace," Selections from the Unpublished Writings of Jonathan Edwards of America, ed. Alexander B. Grosart (Edinburgh: Printed for private crrculation, 1865) 
good which he designates as "all real moral beauty," a man must be infused with a supernatural principle. There is no other source of this experience than the excellency of God; it arises as the "sensible apprehension of the spiritual excellency of divine things." Therefore, the direct experience of God's beauty is the sole source of the conviction of its truth. Edwards is unequivocal in emphasizing this point.

An ideal and sensible apprehension of the spiritual excellency of divine things is (the) proper source of all spiritual conviction of the truth of divine things. . 20 There can be no saving conviction without it. 20

This conviction, however, is not entirely independent of experience in the natural order. The sense of divine excellency

also partly depends on a sensible knowledge of what is natural in religion--as this may be needful to prepare the mind for a sense of its spiritual excellency and, as such, a sense of its excellency may depend upon it. For as the spiritual excellency of the things of religion itself does depend on and presuppose those things that are natural in religion, they being as it were, the substratum of this spiritual excellency, so a sense or ideal apprehension of the one depends in some measure on the ideal apprehension of the other. 21

20 The Philosophy of Jonathan Edwards from his Private Notebooks, p. 125 .

$21_{\text {Ibid., In his sermon on "A Divine and Supernatural }}$ Light," Edwards says that the natural faculties are used by God. "They are the subject of this light: and in such a manner, that they are not merely passive, but active in it. God; in letting in this light into the soul, deals with man according to his nature." Works (Dwight ed.), VI, p. 179. 
The spiritual sense of God's moral excellency, therefore, has a foundation in the natural order and the natural sensibility of man. This is of decisive importance to the sense of the heart. Man can only experience the real moral beauty of God if the spirit stands within him and infuses his sensibility. But the spirit can stand within him only if the substratum of nature and natural experience first be present. The orders of grace and nature are thus joined in the sense of the heart. God does not impart his excellency to man apart from natural experience but works through and elevates man's natural capacity for grasping this excellency.

The sense of the heart represents the unique achievement of Edwards' epistemological doctrine, for it widens experience considerably beyond the atomistic sensations of Locke. In restoring experience to a position of primacy in the cognitive process, he saw that man is immersed in nature infinitely more than Locke could have ever imagined. With the sense of the heart, a man has access to the richness of experience far beyond any conception of Locke.

The distinction between understanding and will, speculative and sensible knowledge, serves a most important function in this doctrine. It is quite accurate to call it "the very core of his mature philosophy." 22 In our

22 Harvey G. Townsend, "The Will and the Understanding in the Philosophy of Jonathan Edwards," Church History, XVI (December, 1947), 210-20. 
modern idiom we would call it a distinction between judgment of fact and judgment of value, i.e., assertions about the objective order and assertions about subjective feelings.

It is the function of the understanding or the "head" to discern the presence of an outward objective order of fact, of a universal and transcendent reality. On the other hand, it is the function of inclination or the "heart" to judge of the subjective aspects of that reality. There is "that in the objects of our knowledge on the account of which they are worthy to be known, vis., their relation to our wills and affection and interest. "23 In other words, there is an inherent set of properties in objective reality which relates immediately to human life. We attach value to these properties by judging them to be good or evil, and man's mind is governed in all its thoughts by them.

The will, in all its determinations whatsoever is governed by its thoughts and apprehensions of things with regard to those properties of the objects of its thought wherein the degree 4 of the sense of the heart has a main influence.

In a pair of important sermons Edwards identifies the objective and subjective orders as the "Objective and

23 The Philosophy of Jonathan Edwards from his Private Notebooks, p. 121. (Italics mine.)

${ }^{24}$ Ibid. 
Inherent Goods."25 The object of all true knowledge, whether of the head or of the heart, is moral excellency, specifically the moral excellency of God. But God has made the human mind capable of a two-fold knowledge of his transcendent goodness. "The first (is) that which is merely notional; as when a person only speculatively judges that any thing is, which. . . is called good or excellent, viz. that which is most to general advantage." This is the Objective Good as it is beheld by the speculative faculty. The second kind of knowledge is "that which consists in the sense of the heart; as when the heart is sensible of pleasure and delight in the presence of the idea" of God's goodness. ${ }^{26}$ Thus the Inherent Good is a "kind of participation of" the excellency of God.

Our direct and immediate experience of God is a moral experience of his excellency, and we acquire it with the sense of the heart. It is wrong to think of some prior experience of God's being to which we subsequently attribute moral qualities. There can be no such distinction. Edwards argues clearly that no such priority can be put on existence over excellency.

${ }^{25}$ See "God Glorified in Man's Dependence," Works (Dwight ed.), VII, p. 156. (Preached in Boston in 1731); and its sequel, "A Divine and Supernatural Light," Works (Dwight ed.), VI, pp. 176-177. (Preached in New Haven in 1733).

${ }^{26} 6_{\text {Works, }}$ VI, pp. 176-77. 
Some have objected against a spiritual sight of divine things in their glorious, excellent, and divine form, as being the foundation of a conviction of the truth or real existence of 'em -because, say they, the existence of things is in the order of nature before forms or qualities of them, as excellent or odious. And so the knowledge of their existence must go before the sight of their form of quality. They must be known to be before they are seen to be excellent. I answer, it is true, things must be known to be before they are known to be excellent, if by this proposition this be understood: that things must be known really to exist before they can be known really to exist excellent ( $I y$ ) or really to exist with such and such a beauty. . . But if thereby be intended that things must be known to have a real existence before the person has a clear understanding, idea, or apprehension of the thing proposed or objected to his view, as it is in its qualities either odious or beautiful, then the assertion is not true. For his having a clear idea of something proposed to his understanding or view as very beautiful or very odious .. . does not suppose its reality; that is, it does not presuppose it, though its real existence may perhaps follow from it. But in our way of understanding things in general, of all kinds, we first have some understanding or view of the thing ${ }_{2} \mathrm{n}$ its qualities before we know. its existence.

The identification of the inherent and objective orders in experience has this important consequence: it means that a strict difference can no longer be maintained between the order of fact and the order of value. Edwards anticipated in many ways Kant's problem of a noumenal world of objective fact beyond the phenomenal world of appearance. For Kant, the categories of the understanding extend only to phenomena, and beyond this lies the noumenal

27 "Miscellanies" \#1090, The Philosophy of Jonathan Edwards from his Private Notebooks, pp. 251-52. (Italics mine.) 
order and all the questions of religion and morality which the understanding cannot reach. The result was the separation of facts and values, for the two reside in essentially different orders. Values have their existence in the noumenal world of freedom. Consequently they cannot be derived in any fashion from the phenomenal world of experience. Edwards had no such problem, however, for the sense of the heart is itself a type of spiritual understanding. Every fact experienced is a value experienced; the objective Good and the Inherent Good are conjoined. The Inherent Good is the transcendent goodness and moral excellency of God as it is possessed experientially by regenerate man. Herein lies the true meaning of the sense of the heart. It is a type of sensible knowledge which puts the two orders of facts and values together by allowing man to experience the world of fact as a communication of the supreme moral excellency of God. It enables the spiritually enlightened person to assimilate an alien world of impersonal and disparate facts into a cohesive moral and aesthetic experience.

But only the regenerate man, the person infused with Spiritual Light, is capable of such knowledge.. Time and again Edwards informs us of the fact that grace is a vital element in the sense of the heart. His doctrine of experience is made complete by it, and so we must now turn our full attention to its explication. 
CHAPTER VI

GRACE AND EXPERIENCE

In discussing the philosophical import of grace, we must remember that for Edwards theological categories had a far greater extension and applicability throughout experience than we in the twentieth century would imagine. Theological language was his specific medium for philosophizing and for articulating the doctrine of experience. His utterances had meaning beyond the limits of formal theology, and this was equally true of other Puritan divines of the seventeenth and eighteenth centuries. That age may be described as a time when a profound sense of experience sought to express itself through a modified Calvinist structure. ${ }^{1}$ Theological

${ }^{1}$ See John J. McDermott, "The American Angle of Vision --II" Cross Currents, XV (Winter, 1965), 437-56. "In the American seventeenth century, philosophy was all but nonexistent; yet reflection was intense and self-conscious, primarily as a response to a pressing and omnipresent collective experience of a situation that was novel at every turn. And although that period in American history offered no articulation of the notion of experience as such, there was a correspondingly rich awareness of the significance of this situation over against the tradition of reflection. It was a period that dealt with profound philosophical themes without an articulated philosophical language." 
language functioned as the symbolic medium through which experience became articulated and expanded. When it came time for the Puritans to fashion a theory of knowledge out of their rich sense of experience, they grafted their discoveries on to a set of religious symbols of which grace was the most important.

It can be said that the notion of grace rounds out and completes Edwards' doctrine of experience for a number of reasons. It is, first of all, the indispensable principle of all genuine human experience, or "ideal understanding" as he would call it. Grace is the catalytic agent within the heart which elevates the whole individual, body as well as soul, to a regenerated life and a new sense of the divine presence in reality. Moreover, it gives to the religious dimension of life a uniqueness and an independence whereby man is genuinely put into touch with the supernatural aspect of reality. In our exposition of the meaning of experience thus far, it might be inferred mistakenly that for Edwards the sense of the heart is no more than the awareness of moral excellency, and that religion is reducible to an aesthetic-moral experience of a natural kind. But he did not seek to reduce religion to morality or to obscure in any way the uniquely religious aspect of human life. He sought to reverse this tendency and to elevate the source of all moral and aesthetic experience beyond the boundaries of nature. Thus, the first sign 
by which the authenticity of such an experience may be established is that it arises "from those influences . . which are spiritual, supernatural, and divine." ${ }^{2}$ It was Edwards' explicit intention to preserve in human experience what might be called the distinctively religious element by which man becomes aware of his relationship to a wider order of reality. He achieved this by defining grace as a principle of experience or a "new simple idea" ${ }^{3}$ in the sense that Locke had used the term idea--as the basic unit of experience.

Grace is a multi-faceted doctrine for Edwards. It can mean the presence of God within man as the intrinsic source of his experience of moral excellency; and in another sense it can mean the objective middle term, or medium, through which the natural and the supernatural achieve continuity. To be more specific about this second point, grace enables the spiritually enlightened person to make an identification between judgments of fact and judgments of value because it allows him to see

\section{${ }^{2}$ Religious Affections, p. 197.}

${ }^{3}$ Ibid., p. 205. It is quite evident to Edwards that grace is entirely above nature in its source and operation: "Gracious affections are from those influences that are supernatural." It follows that there is a corresponding change in a man's nature: "There is a new inward perception or sensation. . . If God produces something new in a mind, that it a perceiving, thinking, conscious thing; then doubtless something entirely new is felt, or perceived, or thought. . . There is what some metaphysicians call a new simple idea." (Italics mine.) 
that the Inherent Good participates in the Objective Good. only the gracious person is capable of this, for in the final analysis Edwards marks grace as Divine Love and the individual's participation in it; and love is the act of joining together what appears to be essentially dissimilar in our experience--the order of facts and the order of values. What is more immediately to the point for Edwards is that by making grace an essential principle of experience he demonstrates the inadequacy of sensational psychology and the mechanical view implicit in it to explain the world and our experience of it. The purpose of science is to make strict statements of objective fact, but the full meaning of these statements can be comprehended only when they are absorbed into the wider order of value judgments. But the ability to assimilate scientific fact in this way depends upon the agency of grace.

One of Edwards' deepest insights is into the nature of grace as a transforming principle of experience in the absence of which the truly human character of experience is unattainable. He discovered that to call experience human in the fullest sense means that it is an integral awareness in which both the understanding and the will closely cooperate in eliciting the value orientation from every judgment of fact.

Grace, therefore, is the indwelling of the Holy Spirit as the vital principle of a newly created nature. 
It enables one to experience or to taste the excellency of God's moral nature as it manifests itself throughout the various levels of creation--physical, moral, and spiritual. Such a sense of divine moral excellency is most properly called love, so that "true saving grace is no other than that very love of God." 4 There are three elements in this description which can be distinguished for further analysis. First, there is the idea of a new principle of nature within man. Second, grace is a taste. for, or a sense of moral excellency. Third, it is specifically designated as love.

In calling grace an "indwelling principle" within a man's heart and "not an accidental union" with it, Edwards wishes to stress three points. The first is that it originates from a source entirely outside of man and beyond nature. Thus,

The exercises and operations of this spirit are after the manner of a natural principle in many respects, but yet there is that in it that shews it. . to be something supernatural not only in such a sense as to be a principle besides all the principles of human nature as such, but also so as to be above all nature. 5

In a corollary to this text he adds this comment: "Grace is a supernatural thing" in the sense that it is "from the

${ }^{4}$ Selections from the Unpublished Writings of Jonathan Edwards of America, p. 53 .

5"Miscellanies" No. 818. Yale University Library collection. (Quoted by permission.) 
supernatural and immediate operation of the spirit." Further evidence of this can be found in the important sermon on "A Divine and Supernatural Light" in which God is stated to be the source of all knowledge and understanding whatsoever. He is the author of the "secular" knowledge men have of human arts and sciences, but only in an intermediate and secondary way, for men are of themselves capable of imparting such knowledge. But of spiritual knowledge, or grace, "God is the author -. and none else: He reveals it, and flesh and blood reveals it not. He imparts this knowledge immediately, not making use of any intermediate natural causes." 6

The second point of grace as an indwelling principle is that it creates a new nature. The infusion of grace is the complete conversion of a soul and hence a new creation of God. He does not merely perfect that which previously existed, but he creates an entirely new mode of experience. Edwards compares it to a resurrection. Wicked men are said to be dead and brought to life through the influx of grace. But there is no middle ground between life and death. Citing scripture in behalf of this argument, he notes that God "is represented as being ... . so united to the faculties of the soul that he becomes there a

6orks (Dwight ed.), VI, p. 172 . 
principle or spring of new nature and life. " 7 In other words, God (especially in the person of Christ) abides in the soul and illumines it from within, not without. Grace is intrinsic to the nature of the saint, so that the divine light emanates from the soul as sunlight emanates from the sun. The light of grace is not merely a reflected light but an original emanation of a "lightsome" body.

Third, grace is no transitory principle but a permanent source of action within the soul. Thus, "the Spirit of God is given to the true saints to dwell in them, as his proper lasting abode." 8 The scriptures represent spiritual conversion as a transformation of nature, by speaking of being born again, and putting off the old man, etc. The hallmark of such a conversion is its permanence. If the virtuoas action of a person is sporadic and inconsistent, then there is no certain sign of the presence of grace. The truly converted person manifests a constancy of nature. "God gives his Spirit to be united to the faculties of the soul, and to dwell there after the manner of a principle of nature; so that the soul, in being imbued with grace, is imbued with a new nature: but nature is an abiding thing." 9

${ }^{7}$ Religious Affections, p. 200. (Italics mine.) ${ }^{8}$ Ibid.

${ }^{9}$ Ibid., p. 342. (Italics mine.) 
The second element inEdwards' definition of grace is that it is a new sense or taste of God's moral beauty. "He that is spiritually enlightened truly apprehends and sees it, or has a sense of it. He does not merely rationally believe that God is glorious, but he has a sense of the gloriousness of God in his heart."10 Grace is nothing less than the principle of a new sense of experience whereby the soul is capable of embracing the divine beauty as it is embodied in nature. The divine light gives rise to an aesthetic experience the intensity of which far exceeds any natural sense of beauty.

The first effect that is produced in the soul, whereby it is carried above what it has or can have by nature, is to relish or taste the sweetness of the Divine relation. . . The first effect of the power of God in the heart in REGENERATION, is to give the heart a Divine taste or sense; to cause it to have a relish of the loveliness and sweetness of the supreme excellency of the Divine nature.

The effect of grace is to elevate a person's experience of himself and of his world to an entirely new level of joy and happiness :

This knowledge is... sweet and joyful. Men have a great deal of pleasure in human knowledge, in studies of natural things; but this is nothing to that joy which arises from this divine light shining into the soul. This light gives a view of those things that are immensely the most

${ }^{10}$ Works (Dwight ed.), VI, p. 176.

${ }^{1}$ Selections from the Unpublished Writings of Jonathan Edwards of America, p. 53 . 
exquisitely beautiful, and capable of delighting the eye of the understanding. This spiritual light is the dawning of the light of glory in the heart. There is nothing so powerful as this to support persons in affliction, and to give the mind peace and brightness in this stormy and dark world. 12

However, this divine spiritual taste "which is in its whole nature diverse from any former kinds of sensation ${ }^{13}$ is not without an intellectual content. No concept is more central to Edwards! doctrine of grace than what he calls "spiritual understanding." To speak of a taste or sense is to imply also that the soul is capable of an intellectual apprehension, a new kind of knowledge. "Holy affections are not heat without light; but evermore arise from some information of the understanding, some spiritual instruction that the mind receives, some light or actual knowledge. " 14

Edwards is careful to strike a delicate balance between inclination and cognition in his explanation of grace, the same balance that we find in his explanation of the sense of the heart. Indeed, he identifies the spiritual understanding with the sense of the heart, so that intellect and will are seen to be in the closest possible working cooperation to produce a genuine human

$12_{\text {Works }}$ (Dwight ed.), VI, p. 187

13 Religious Affections, p. 259.

${ }^{14}$ Ibid. , p. 266. 
experience of God's excellency.

Spiritual understanding consists primarily in a sense of the heart; for it is not speculation merely that is concerned in this kind of understanding: nor can there be a clear distinction made between the two faculties of understanding and will, as acting distinctly and separately, in this matter. When the mind is sensible of the sweet beauty and amiableness of a thing, that implies a sensibleness of sweetness and delight in the presence of the idea of it: and this sensibleness of the amiableness or delightfulness of beauty, carries in the very nature of it, the sense of the heart; or an effect and impression the soul is the subject of, as a substance possessed of taste, inclination and will.

Grace causes the spiritually enlightened person to experience in an entirely new way through the coordinated activity of intellect and will. "It as it were opens a new world to its view," 16 - a world in which the glory of God and of his works are manifest to man.

In the above text Edwards raises a crucial question concerning the spiritual understanding, the question of the relationship between the understanding and the will. He asserts that the opposition between these "faculties" cannot be permanent, but only functional, for they are two aspects of what he calls inclination -- the basic orientation or direction of the soul. The difference between understanding and will is the difference in the expression

$$
\begin{aligned}
& { }^{15} \text { Ibid., p. } 272 . \\
& 16_{\text {Ibid., p. } 273 .}
\end{aligned}
$$


of the same basic inclination. Thus, when the inclination receives expression through the understanding it is called the "heart," and when it receives its expression in direct action it is called "will."

Another question must be introduced at this point-the question of the affections. They are identified by Edwards as "the more vigorous and sensible exercises of the inclination and will of the soul." ${ }^{17}$ what precise meaning does he intend for the affections here? On first hand it would appear that they are identical with the will to the exclusion of the understanding. But this would be an overly simplified interpretation. The affections are the more visible and sensible exercises or inclination, to be sure; but specifically they are the expressions of inclination through the mind as well as through the overt action of the will. Affections are not bare feelings or blind passions, but orientations within the soul which are guided by the light of understanding.

It must be confessed, however, that Edwards was inclinea to see the identification of the will and the affections as most fundamental.

The will, and the affections of the soul, are not two faculties; the affections are not essentially distinct from the will, nor do they differ from the mere actings of the will and inclination

17 Ibid., p. 96 . 
of the soul, but only in the liveliness and sensibleness of exercise.18

The foundation is prepared here for his doctrine on the freedom of the will, the most influential aspect of Edwards' philosophy in relation to later American theory and our latter day impressions of intellectual American Calvinism. However, that is not to indicate it is therefore of greater value as a tool in understanding of Edwards' thought than is "affections." A person wills only what his heart inclines to; the will is identified with the strongest inclination. "The will is always determined by the strongest motive, or by that view of the mind which has the greatest degree of previous tendency to excite volition."19 But the most vigorous inclinations are what he calls the affections. In abolishing any permanent difference between mind and will, and seeing their connection with inclination, Edwards strikes out in a direction which leads him far away from Locke who insisted on maintaining a rigorous distinction between "will and desire," saying that a man may will something but not desire it. Edwards rejects this argument by noting that the objects of will and desire, in this case are two in number. His

\section{${ }^{18}$ Ibid. , p. 97.}

19 Freedom of the Will, ed. Paul Ramsey (New Haven: Yale university Press, 1957), p. 148. Here can be found a full discussion of this particular aspect of Edwards' thought, and its relationship to the theories of John Locke. 
conclusion is that the will is desire, or inclination.

This serves as the main thesis of his doctrine on the freedom of the will.

In every volition there is a preference, or a prevailing inclination of the soul, whereby the soul, at that instant, is out of a state of perfect indifference, with respect to the direct object of the volition. So that in every act, or going forth of the will, there is some preponderation of the mind or inclination, one way rather than another; and the soul had rather have or do one thing rather than another; or than not to have or do that thing; and that there, where there is absolutely no prefering or choosing, but a perfect continuing equilibrium, there is no volition. 20

The preponderation or inclination of the soul to act in one way rather than another originates within the soul itself according to its mode of experience. In the case of the regenerate man, the inclination is due to the indwelling spirit of God, and such a man chooses and acts out. of an innate sense of good. When a man's soul is suffused with divine grace, then is he capable of choosing and acting in accordance with the highest source of holiness within him, and his affections truly originate from God and are oriented toward Him.

In making a final comment on Edwards' doctrine of the affections and their relation to the will and the understanding, we would agree with the statement of 
Professor Smith that "it is difficult to avoid confusion" over their differences and mutual connections. 21 While he perhaps wished to keep them distinguished, he was equally concerned to show the fundamental unity and integrity of the soul. In the end Edwards never gave us a satisfactory account of the distinctions and the unity they came to form in the soul.

summing up our discussion of the spiritual understanding, the truly gracious man experiences a universe which is the radical imaging of God's goodness. The fundamental characteristic of an aesthetic experience transfigured by grace is its moral nature. There is no aesthetic experience of fact which is not a moral experience of value. To illustrate this, Edwards argues that we can only understand the fact of Christ's mediatorship if we appreciate the moral beauty of such a position. "Tis only by the discovery of the beauty of the moral perfection of Christ, that the believer is let into the knowledge of the excellency of his person (which, in turn, allows us a knowledge of) his sufficiency as a mediator." 22

We have in this notion of the identification of the aesthetic and moral experience, and of the fusion of facts and values, the heart of Edwards' meaning of experience

$$
\begin{aligned}
& \text { 2l"Editor's Introduction," Religious Affections, p. } 14 \text {. } \\
& { }^{22} \text { Religious Affections, p. } 273 .
\end{aligned}
$$


and his most universal insight into the mystery of human knowledge. The indwelling energy of grace is the unifying agent of experience. The two universes of the "is" and the "ought" had been sundered by the analytic process of reason throughout the centuries. They are now merged into a single, unified experience of a single reality, a moral reality whose source is in God.

He that sees the beauty of holiness, or true moral good, sees the greatest and most important thing in the world, which is the fullness of all things, without which all the world is empty, no better than nothing, yea, worse than nothing. Unless this is seen, that is worth seeing: for there is no other true excellency or beauty. Unless this be understood, nothing is understood, that is worthy of the exercise of the noble faculty of understanding.

The fusion of facts and values is possible only "in the lively exercise of grace," whereby a man "easily distinguishes good and evil, and knows at once, what is suitable amiable behavior towards God, and towards man." It remains outside the province of discursive reason to discern the morally good. A man "judges what is right, as it were spontaneously, and of himself, without a particular deduction, by any other arguments than the beauty that is seen, and goodness that is tasted." 24

23 Ibid., p. 274

24 Ibid., p. 282 . 
What Edwards calls grace, then, is the medium within which man intuitively grasps value. But this is also the medium through which the fusion is effected between the two orders of human life, whether they be called the objective and Inherent Goods, or simply facts and values. What is achieved by grace is the reconciliation of man's religious life and his life in nature, i.e., the supernatural and the natural. The reconciliation is achieved experientially in a new simple idea.

The third element in Edwards' conception of grace is love. Nowhere does the universality of his thought sing with more brilliance than in his handling of the phenomenon of love. His "sense of the heart" or "spiritual understanding" is a way of viewing the cognitive nature of knowledge. In proposing the thesis that man's cognitive response to his world is an aesthetic response involving both head and heart, Edwards' claim to being an American Pascal has more substance than some writers would be willing to allow. 25 The spiritual understanding is capable of a higher and more subtle logic than that of discursive reason.

${ }^{25}$ In a discussion of the affinities between Edwards and Pascal remarkable for its lack of insight, Rufus suter argues that Pascal's scientific interests were "smothered by what some of us today would call a pathological obsession with the morbid side of religion," and that similarly "the harrowing theology of Edwards.. . swallowed up both his natural philosophy and science." See "An American Pascal: Jonathan Edwards," Scientific Monthly, 68 (May, 1949), 338-42. 
Love permeates the cognitive and rational life; it is "the fountain of all affection." What constitutes the essence of love is a new sense or relish of the divine beauty shining forth from God and through the created world. The rational life remains incomplete to the extent that it is lacking in this taste for excellency. Edwards' theology rests on the idea that love for God, and not fear of him, constitutes the heart of rationality. He celebrates, over and over, the fact that love is the core of supernatural life. He distinguishes God's love (or his excellency--the ontological state of love) from his natural perfections such as greatness and majesty, and tells us that a sense of these perfections amounts to naught in us without a sense of his love.

If persons have a great sense of the natural perfections of God, and are greatly affected with them, or have any other sight or sense of the beauty of his moral perfections, it is no certain sign of his grace: as particularly, men's having a sense of the awful greatness and terrible majesty of God; for this is only God's natural perfection, and what men may see, and yet be entirely blind to the beauty of his moral perfection, and have nothing of that spiritual taste which relishes this divine sweetness.

If a man has a sense of fear of God's power without having a sense of love of his beauty, it is no sign of grace. What are the implications of this? It means that every. ${ }^{26}$ Religious Affections, p. 263. 
relation between God and man, is imperfect in the absence of the basic relation--love. Love performs an indispensable cognitive function, for it promotes a type of certainty--a moral certainty of grace, which is guaranteed by its overflow into action. For the affection of love has its fruition in Christian practice; it takes hold "of the very inmost springs of life and activity. Herein chiefly appears the power of true godliness, viz. in its being effectual in practice." 27

Love's source is in the infinite Godhead, so Edwards endows it with a transcendence. The creature's love is by way of participation in transcendent love. Edwards says that the Divine principle within us "which we have observed does radically and essentially consist in Divine Love, which is God." 28 Through participation in divine love man is capable of establishing a reciprocal relationship with God.

Continuity, therefore, is an important category for Edwards. Since all love participates in the plenitude of divine love, he establishes a continuing identity of expression throughout the various levels of experience. A single relation of love stretches from its origins in carnal love of one's self to the most sublime reach of mystical fusion

27 Ibid. , p. 393.

28 Selections from the Unpublished Writings of Jonathan Edwaras of America, p. 53 . 
with God. For. Edwards, love is "the same principle flowing forth towards different objects." It is a single relation reaching out simultaneously to God and creature. "A Christian love to God, and Christian love to men, are not properly two distinct principles in the heart. These varieties are radically the same." 29

An important consequence of the participated nature of love is Edwards' re-interpretation of self-love of God. The Christian precept to love one's neighbor as one's self is the profusion of self-love, the extension of the self into its social dimension. But love of neighbor is possible only through participation in the abundance of God's love for mankind. Edwards fashions a doctrine of self-love which makes it a derivative of divine love. Antecedent to any genuine love of self is disinterested love of God; self-love is not the cause of love in God, but a result of it. "A man must first love God . • before he will esteem God's good his own, and before he will desire the glorifying and enjoying of God, as his (own) happiness." 30 He has to see God as good in Himself before he can see God as good for him; the former is the cause of the latter.

${ }^{29}$ Selections from the Unpublished Writings of Jonathan Edwards of America, p. 35 .

${ }^{30}$ Religious Affections, p. 241. 
Professor Smith, in discussing this point, comments on the inaccuracy of saying that "self-love is excluded from the highest relationship between God and man." 31 Edwards defines self-love as the "capacity of enjoyment or taking delight in anything." So that man's love of God and of himself "are not opposite things entirely distinct, but one enters into the nature of the other." 32 In another context Edwards distinguished between "simple self-love" and "compounded self-love" which helps to clarify his position. The latter type arises from two sources. First, self-love originates in the consciousness of a person, a "willing and perceiving being," who desires his own personal pleasure or delight. Second, it also arises from a principle which unites "this person with another that causes the good of another to be its good, and makes that to become delight which otherwise cannot." 33 It is compounded self-love that Edwards thinks of in the Nature of True Virtue when he talks of self-love as benevolence, or taking happiness in the happiness of others.

How comes our happiness to consist in the happiness of such as we love, but by our hearts being first united to them in affection, so that we as it were look on them as ourselves, and so on their happiness as our

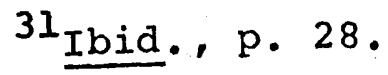

32 The Philosophy of Jonathan Edwards from his Private Notebooks, p. 202 .

${ }^{33}$ Ibid. , pp. 203-204 
own? Men who have benevolence to others have pleasure when they see other's happiness, because seeing their happiness gratifies some inclination that was in their hearts before. 34

So it is quite impossible for a man to love God more than himself or to love himself more than God. Self-love of the compound type is a participated love in its divine original; it is the effect and not the cause of love in God. The most important aspect of Edwards' doctrine of love is its ontological status. It is clear from what has been said that love as a principle of knowledge is antecedent to any intellectual apprehension, and has a metaphysical structure of its own which he calls the consent to Being. This is the most original concept in Edwards' philosophy. In essence the consent to Being.is a metaphysical principle whereby all things participate in the fullness of Divine Love, and make response to that love. The response is an act of love which adds a new moral value to the general scheme of reality. So values are objective entities, sensible phenomena with essences which are grasped by the perceptive center of man in his heart.

34 Works (Dwight ed.), III, p. 119. 


\section{CHAPTER VII}

\section{CONSENT TO BEING:}

\section{A METAPHYSICS OF VALUE}

Thus far we have had a view of the aesthetic nature of Edwards' doctrine of experience. We have seen how it took a noval direction away from the narrow formulations of Locke and Berkeley, and resulted in a significant broadening of the meaning of experience. Man's capacity for experience is located in his affections which are vitalized by the infusion of grace in the form of new simple ideas. This infusion is effected through the instrumentality of a symbolic medium (i.e., language) so that grace is extended from the supernatural to the order of nature through the fficient causality of words and ideas which are the basic units of experience. Words and ideas have the efficient power, as special articulations of experience, to generate new kinds of experience. And so Edwards is prepared to say that God communicates his grace, or love, through the ordinary channels of human experience as they are rendered meaningful in human language. 
Let me mention briefly three points about the metaphysics of consent which will occupy our attention in this section. The first thing to be said about the consent to being is that it gives Edwards an opening wedge into the Neo-Platonic tradition and its understanding of the category of substance. That is to say, with the notion of consent he fashions a new category which circumvents the pitfalls of a substance metaphysics. So many classical theologies have been bedeviled by the attempt to reconcile Hellenic notions of substance with the Christian mystery of immanence and transcendence. The importance of the consent to being with respect to this dilemma is found in the emphasis given to relations vis-a-vis the traditional understanding of substance.

Second, and perhaps more important, the consent to being broadens Edwards' aesthetic empiricism and grounds man's affective life in a transcendent object. The truly significant fact of the doctrine resides in the concept of value-that value is an objective reality from which man derives the sustenance of his spiritual and moral life. Third, the consent to being is at the heart of a new theological notion of "Communication" by which Edwards understands the affective life of man as a response to the "evocative communication of God. By denoting the categories of relation, value, and communication as the 
constitutive elements of consent, we shall come to a full appreciation of Edwards' metaphysics.

\section{THE PRIMACY OF RELATION}

It is essential at the outset to appreciate the consent to being as a cosmology depicting an organic world. And we must note carefully the function of relation in this cosmology. One of the overriding concerns of Edwards' polemics was the impact of seventeenth century physics on religious-philosophical mentality. ${ }^{1}$ A mechanistic (or what is often termed an organic interpretation in line with the instrumentalist views of Locke and Hoobes) view was beginning to prevail in cosmology, ${ }^{2}$ and its effects were being felt within the structure of Calvinism. When Edwards confronted the heresies of Arminianism, he was really combating the insidious influence of a mechanistic attitude in religious and philosophical matters.

In order to combat mechanism successfully, he saw that it was not enough simply to dislodge it from its position of primacy. For it had entrenched itself firmly in a

$1_{A}$ full discussion of the inlfuence of Newton on Edwards, and of the theological effect of gravity and atoms will follow in the next chapter.

IIn this century the notion of the mechanical explana: tion of all the processes of nature finally hardened into a dogma of science." A. N. Whitehead, Science and the Modern World (New York: Mentor, 1959), p. 59 . 
universal scientific mentality. Edwards' polemical mind was much more subtle than to launch a frontal attack on mechanical explanation. He did not overpower mechanism, but sought to place it into a wider context within which its truths would be absorbed into the truths of aesthetic experience. This he achieved admirably in the consent to being.

The doctrine is a cosmology in the wider sense of an aesthetic experience. It is an attempt to portray the world as an organic scheme in which the notion of substance as the underlying entity is given wider meaning. In a mechanical world substance has simple location, to borrow the term from Whitehead. 3 It is where it is, in space and time; without reference to any other region of space or duration of time. Substance as the ultimate constituent of reality (in the Aristotelian sense), has a selfcontained existence. If we pursue this notion a bit we discover that the meaning of a simply located entity, its raison d'etre or its intelligibility, does not extend beyond the fact of its simple location, but is totally contained therein. Its whole meaning is to be found

3 Science and the Modern World, pp. 50-54, 57. Whitehead sums up the inadequacy of mechanical philosophy to handle the categories of organic life: "the seventeenth century scheme of scientific ideas involves a fundamental duality, with material on the one hand, and on the other hand mind. In between there lie the concepts of life, organism, function, instantaneous reality, interaction, order of nature, which collectively form the Achilles heel of the whole system." 
within the fact that it is a discrete substance. Descartes noted that clarity and distinctness are the hallmarks of our comprehension of it.

But in the organic view, the meaning of substance is to be found in its relations beyond itself as a simply located thing. If we may use the terms "representation" and "autonomy" to describe the two ways in which substance can possibly exist, then we must say its primary mode of existing is representative. A substance represents the total scheme into which it fits. Its intrinsic meaning resides in the relations it bears to that scheme. Any autonomous existence that can be attributed to it is a derivative of $i t s$ representative nature. It gains its indpeendence as a discrete entity from the way it represents. Its autonomy is a function of its representation. There is one relation, however, which is fundamental and determinative of all other relations. It is the relation a thing bears to consciousness. This relation above all others determines the fundamental meaning of a thing and no entity is lacking in it, according to Edwards. No principle in his philosophy is as basic as the enunciation that every entity has a relation to the infinite and all-comprehending mind of God.

That, which truly is the substance of all Bodies, is the infinitely exact, and precise, and perfectly stable Idea, in God's mind, together with his stable will, that the same shall gradually be communicated to us, and to other minds, according to certain fixed and established Methods and 
Laws; or in somewhat different language, the infinitely exact and precise Divine Idea, together with an answerable, perfectly exact, precise, and stable Will, with respect to correspondént communications tq Created Minds, and the effects on their minds.

The consent to being rests on this primary relation matter has to thought. It is an organic view of material nature wherein the meaning of material entities is derived from their relation to higher consciousness. Therefore, this relation is not extrinsic or tangential to the material world; it is an intrinsic dimension of every entity. The world becomes an expression of consciousness, the articulation of a spiritual mind. It destroys the view of nature as the loose juxtaposition of entities, and replaces it with the view of an organic-aesthetic arrangement of things within the purview of divine consciousness. Things are not outside God, but inside; and their radical "thingness" is lost in their intrinsic relationship to his mind. The doctrine of consent rests on the idealism of Edwards, in the primacy of consciousness as the universal relation underlying all being. If we inquire as to the specific nature of the relation, we see that it focuses on excellence. The universal relation of matter to mind, and of being to consciousness, is aesthetic in nature. Excellence is the mark of God's beauty in the world, and

${ }^{4}$ Works (Dwight ed.), I, p. 674. 
it consists in the highest degree of "similarness" among all things. "This is an universal definition of Excellency: -- The Consent of Being to Being, or Being's Consent to Entity. The more the Consent is, and the more extensive, the greater is the Excellency." 5 The more universal the consciousness, the greater is the presence of God's beauty.

Thus greatness becomes the criterion for God!s beauty, for it is defined as the capacity for excellence. "The greater a Being is, and the more it has of Entity, the more will consent to Being in general please it." It follows quite evidently that only an infinite capacity for excellence can be the aesthetic criterion. And indeed this is so, for "not only may Greatness be considered as a capacity of Excellency; but a Being, by reason of his greatness considered alone, is the more excellent, because he partakes more of being." It follows as a corollary that "it is impossible that God should be any otherwise, than excellent; for he is the Infinite, Universal and Allcomprehending Existence." 6 God is the infinite criterion of beauty because he has an infinite capacity for it; and every created entity represents, to the extent of its own capacity, the infinite beauty of God. Every creature, in other words, has an intrinsic relation to the

$$
\begin{aligned}
& 5_{\text {Ibid., p. } 696 .} \\
& 6_{\text {Ibid. , p. } 698 .}
\end{aligned}
$$


"Al1-comprehending" beauty of its creator.

Excellence is primarily the consent of minds. "There is no other proper consent but that of Minds." ${ }^{7}$ And so beauty can be predicated only of beings with a spiritual and moral nature. Yet there is an inferior kind of beauty found in inanimate things which is an image of spiritual, moral beauty. It "consists in a mutual consent and agreement of different things in form, manner, quantity, and visible end or design." But most especially does the consent consist in the agreement of the purpose or design of all material things with each other. For in this kind of agreement, beauty is achieved in the uniformity of purpose and design throughout the variety of things..

The beauty which consists in the visible fitness of a thing to its use and unity of design, is not a distinct sort of beauty from this (beauty of uniformity amidst variety). For it is to be observed, that one thing which contributes to the beauty of the agreement and proportion of various things, is their relation to one another; into view and consideration 8 and whereby one suggests the other to the mind.

What Edwards attempts to demonstrate is the unity of the utility of material things (in the way they harmonize) with the glory of God's higher beauty. The former images the latter, because by the uniformity of their utility, "diverse things become as it were one... And it

$7_{\text {Ibid., p. } 699 .}$

${ }^{8}$ Works (Worcester ed.) II, pp. 413-14. (Italics mine.) 
pleases God to observe analogy in his works, as is manifest in fact in innumerable instances; and especially to establish inferior things in an ananlogy to superior." 9 Edwards suggests that in an organic world in which everything images the "Al1-comprehending" mind of God, the utility of material things and the glory of God's beauty form a single continuous whole. So that in such a world as this, meanings which attach to material things are at once physical and spiritual, utilitarian and aesthetic. Physical events immediately suggest to the mind their relationship with a non-physical reality of an aesthetic and moral nature. They are the immediate occasion for a person inclined toward moral virtue to experience the continuity between utility and glory. 10 Edwards himself was naturally disposed to tracing out the hidden moral significance behind the external forms of nature. He was inclined to think of nature symbolically, that its design and purpose is connected with and representative of (partially, from its own perspective) a universal moral plan.

\section{${ }^{9}$ Ibid., p. 415 .}

10 "God has so constituted nature, that the presenting of this inferior beauty . . as the harmony of sounds, and the beauties of nature, have a tendency to assist those whose hearts are under the influence of a truly virtuous temper, to dispose them to the exercises of divine love, and enliven in them a sense of spiritual beauty." Ibid. 
II. CONSENT AND THE RESPONSE TO VALUE

We have yet to consider the consent to being as the cornerstone of a metaphysical system in which value is bestowed with the status of an objective and transcendent reality. Behind the consent is the idea that God is the universal source of moral consciousness, and that this universal moral consciousness is mirrored throughout creation. Every entity, both animate and inanimate, intelligent and non-intelligent, reflects this universality, each to the extent of its capacity. Value, therefore, is an ultimate ontological category as much as being and truth. Edwards' reasoning follows this line. The essence of consciousness is situated in conation, which is the inclination and movement of mind toward the possession of that which lies beyond it, and is good in itself. Universal consciousness represents the total, actual possession of the object of its inclination, and so every object of universal moral consciousness possesses actual moral value.

The distinctive difference in all this for Edwards is that man experiences these values. Immersed as he is in a world of concrete values, man's access to them is not through reason, but primarily within experience. In the profound depths of experience we reach immediate contact with the reflected image of moral consciousness. We do not enter into this image by intellectuality, but we seize upon 
it in experience. These values which constitute the nature of true consent are integral components of every experience. They do not need to be mediated by reason operating alone and apart from direct perception. Indeed it becomes impossible to behold the objectivity of values with the speculative faculty if one truly apprehends with a sense of the heart.

When we look at the notion of excellency more closely, it becomes evident that Edwards sees it as a universal system which interlocks its various components into an ordered whole. A beautiful thing is. false and deformed when "considered by itself separately," i.e. when it falls short, in its comprehension, of relating to universal being. That which is beautiful "only with respect to itself and a few other things, and not as a part of that which contains all things--the Universe--false beauty and a confined beauty. That which is beautiful, with respect to the university of things, has a generally extended excellence and a true beauty."ll

A.lso evident is the contrality of Mind. So that bodies, the objects of our external sense, "are but the shadows of beings." The idea of excellency as a system of universal consent implies that beneath it all is a rational intelligence. Beauty, therefore, consists first 11 Works (Dwight ed.), I, p. 697. 
and foremost in the consent of intelligent beings to the universal system of intelligence.

If every intelligent Being is some way related to Being in general, and is a part of the universal system of existence; and so stands in connexion with the whole; what can its general and true beauty, be, but its union and consent with the geat whole. 12

It follows that Edwards would designate the beauty of intelligent beings as virtue. Virtue is something beautiful, not the beauty of flowers or rainbows, ${ }^{13}$ but the beauty belonging "to Beings that have perception and will. - a beauty that has its original seat in the mind. " 14

The highest beauty consists in the highest act an intelligent being is capable of -- love. Consent to being is the mutual love of all "spiritual beings," and the mutual consent of all lower creatures is an image of this love. ${ }^{15}$ Virtue most essentially consists in love,

12 Works (Worcester ed.), II, p. 397.

${ }^{13}$ Except in a secondary, participated sense.

14 Works (Worcester ed.), II, p. 395.

15 "When one thing sweetly harmonizes with another, as the Notes in musick, the notes are so conformed, and have such proportion one to another, that they seem to have respect one to another, as if they loved one another. So the beauty of figures and motions is, when one part has such consonant proportion with the rest, as represents a general agreeing and consenting together; which is very much the image of Love, in all the parts of a society, united by a sweet consent and charity of heart." Works (Dwight ed.), Vol. I, p. 697 . 
but a participated love derived from God's own nature. This is why Edwards insists that virtue consists in nothing short of a particular being's love to being in general. The true consent of any being is the measure of its participation in being in general, i.e. universal love.

No one act of the mind or exercise of love is of the nature of true virtue, but what has being in general, or the great system of universal existence, for its direct and immediate object - . No affection towards particular persons, or Beings, are of the nature of true virtue, but such as arise from a generally benevolent temper, or from that habit or frame of mind, wherein fonsists a disposition to love Being in general.

There can be no question for Edwards but that all love is firmly grounded in divine love as its "direct and immediate object." Love among created beings can only be virtuous when it is derived from love to God. ${ }^{17}$ But love to God cannot be different from a sharing in his love for the world. Creatures share in God's love by consenting to the design and purpose for which he makes all things. But the design and purpose of all things coincides with the design and purpose of moral creatures, "it being evident, that the moral world is the end of the rest of the world."18 So Edwards gives a metaphysical priority to

${ }^{16}$ Works (Worcester ed.), II, p. 398.

17"It is sufficient to render love to any created Being virtuous, if it arise from the temper of mind wherein consists a disposition to love God supremely." Ibid..' p. 411 .

$$
{ }^{18} \text { Ibid., p. } 412 \text {. }
$$


the moral world over the physical, thereby adding a new dimension to every reality--the dimension of value. Everything has value insofar as it is the object of universal moral consciousness--is, in other words, the object of God's love. But the full measure of participation in this new value-dimension is reserved for man, who, with a sense of the heart, is capable of experiencing it. The full meaning of consent is to be found, then, in the sense of the heart and man's affective relation to the world. The aesthetic nature of this relation points up his ability to experience values as concrete, sensible phenomena, and to make response to them. It is plain enough that the consent to being is a response to value: the conscious, intentional affirmation of objective value which takes the form of moral, affective response. It is also clear that it consists in a transcendent relation to the universal moral consciousness of God. It pertains to the nature of true virtue, Edwards tells us, to have being in general as the primary object of its benevolence. "Or perhaps to speak more accurately, it is that consent, propensity and union of heart to Being in general, that is immediately exercised in a general good will. 19 virtue cannot be authentic if benevolence be limited in any way "to a particular circle of Beings."

\section{Works (Worcester ed.), I, p. 397.}


For then the value response does not genuinely transcend, because the limitation must come from the subjective side. It must be imposed arbitrarily by the subject. And so there is no conformity at all when virtue is restricted by the "private affections" as Edwards calls them.

III. CONSENT AND THE THEOLOGY OF COMMUNICATION

Thus far we have established that consent, of virtue, is the relation an entity bears to universal moral consciousness, and is in itself the participation in and response to the objective value that constitutes the nature of moral consciousness. We have also seen that man's place in this scheme of values is eminent, for he participates fully by conscious, direct experience.

His consent, in other words, is first in rank among creatures, the consent of lower things participates only through man's consent. Only he has the ability to grasp in an intuition the meaning of that relation we call consent or virtue. By his ability to grasp this relation as such, 20 man is endowed with a moral consciousness above all other creatures. More accurately, he is capable of intuiting the universal moral consciousness of God and thereby capable of sharing in its nature.

${ }^{20}$ Perry Miller writes that true virtue "is an elevation of consciousness above the web of relations to the idea of relationship itself." Jonathan Edwards, p. 287. 
A most important aspect of this doctrine is to be found in the notion of communication, or conversation. Edwards defines conversation as "intelligent beings expressing their minds one to another, in words or other signs," 21 and he tells us that we especially find conversation among intelligent beings when they are concerned with moral affairs. The existence of objective moral value makes language necessary as a symbolic medium because discourse is of the essence of the moral order. "All moral agents are conversable agents," i.e. they are capable of consent, or response to value, and this in itself is what Edwards means by conversation.

Especially do we find conversation proper and requisite between intelligent creatures concerning moral affairs, which are most important: affairs wherein especially moral agents are concerned, as joined with society, and having union and communion with one another. . . By all that we see and experience, the moral world, and the conversable world, are the same thing.

Consent to being, the response to objective value and its source in God, is really a form of discourse. Just as the dialectic was an instrument for the discovery of truth for Socrates, discourse is the medium for the emergence of values for Edwards. Moral values arise out of discourse, for it is the very nature of conversation to generate

$21^{\prime \prime}$ on the Medium of Moral Government--particularly Conversation," Works (Dwight ed.), VII, p. 277.

22 Ibid. , p. 281. 
values. But by conversation Edwards means experiential commerce between a person and his world and God.

This commerce, or moral conversation between God and man in the consent to being has its seat in the communicative nature of God. Edwards' understanding of creation is expressed in terms of this nature in The End For Which God Created The World. God does not create the world as an effect, in the sense of an after-thought or an addendum to his own being. Creation is not a fact extrinsic to his nature. The mode of his creation is communication, and he communicates a manifestation of himself. The nature of God is infinite goodness, and this infinite goodness is utterly communicative. The world, therefore, is no detached fact, but the communicated value of God's own goodness. If the plenitude of goodness, the fullness of every perfection

is capable of communication or emanation ad extra; so it seems a thing amiable and valuable in itself that it should be communicated or flow forth, that this infinite fountain of good should send forth abundant streams, that this infinite fountain of light should, diffusing its excellent fullness, pour forth light all around.

It follows that

if the fullness of good that is in the fountain, is in itself excellent and worthy to exist, then the emanation, or that which is as it were an increase, repetition or multiplication of it, is excellent and worthy to exist.

23 Works (Worcester ed.), VI, pp. 32-33. (Italics mine.) 
What is communicated, then, possesses value inasmuch as it is the outpouring of the plenitude of value. It seems fitting that man should participate in the communication of God's excellency in a special way through his intellect and will. It appears "to be a thing in itself valuable, that there should be such things as the knowledge of God's glory in other beings, and an high esteem of it, love to it" because these things are "the emanation of God's own knowledge, holiness and joy."

It is a thing valuable and desirable in itself, that God's glory should be seen and known . . . valued and esteemed, loved and delighted in.

But of the two ways of participation, mind and heart, Edwards chooses the latter as superior to the former. "If the idea of God's perfection in the understanding be valuable, then the love of the heart seems to be more especially valuable, as moral beauty especially consists in the disposition and affection of the heart. ${ }^{24}$

We can reasonably conclude that God's communication of objective value and man's participation in it has an experiential base in the affections. Experience is the specific medium through which God and man conduct their commerce. God communicates a concrete world of value, and man responds to it with his concrete affections. Understanding plays an important but secondary role in this

$$
24 \text { Ibid., p. } 32 .
$$


response. But we must point out that a medium is by definition symbolic, whether it be called experience, language, or discourse. Whatever it be, its sole function is to refer an agent beyond itself, to transport an individual into a matrix of relations and patterns which find their ultimate unity in a transcendent God.

Also, a symbolic medium is evocative, and herein lies a most significant aspect of the consent to being. A world which is the emanation of God's supreme value evokes a response from man in some way commensurable with itself. Consent to being implies a world speaking to man, an evocative world which draws man out of himself and into a meaningful conversation with it. To stand in the presence of God's manifest glory is to stand in the midst of objects capable of stirring up within man meaningful correspondences. These correspondences are of a moral and aesthetic character. Man gains full access to such a world by attuning all his faculties of head and heart. Every external fact has a subjective dimension in man, for the fact itself emerges from the fruitful dialogue he engaged in with an evocative world. Through his affectivity man is capable of adding this new dimension to physical facts. Things are emanations of God. The outer world is Subjective Fact, a Subjective Experience into which man enters through his own subjectivity. There are no discrete subjects and discrete objects, but there is 
one system of mutual consent of all things among themselves and to God.

But many of these remarks anticipate questions to be raised in the next section. My conclusion here is that to Edwards man transcends himself in the moral experience of an objective value through the symbolic medium of a created world, to its source in God. 


\section{CHAPTER VIII}

\section{EDWARDS' METAPHYSICAL THEOLOGY : \\ THE PRESENCE OF GOD DISCERNED}

We would be grossly mistaken to suppose our interpretation of the consent to being to be complete at this point. It is certainly valie as far as it goes: The consent is essentially a system of objective values which issues forth from the affective affinity of all things in God. But to leave it at this would be to miss the major point of Edwards' philosophical endeavor. He never intended philosophy to have any purpose apart from theology, and the whole direction of his intellectual inquiry was toward the study of divinity. He saw his life's work as neither establishing an ethics nor a system of metaphysics so much as confronting the mystery of God's presence. He was dedicated to the validation of religious experience and the many ways in which we perceive the divine nature. In failing to appreciate this, while his theory is of great secular value, we would have failed as much as to have missed the religious motivation in the work of a 
Kirkegaard or a Teilhard de Chardin. ${ }^{1}$

If we would come to appreciate Edwards' metaphysics at all, we must look to his theology and probe it for his originality on the subject of God's nature and of the manner of his presence to man. ${ }^{2}$ The full significance of all the aspects of his philosophy--especially the doctrine of experience and the importance of its aesthetic dimension, and also the objectification of aesthetic experience in the consent to being--resides here in the core of his theology. Christian thought has traditionally focused attention on the compatability of a transcendent God who takes his abode in the cosmos of man's experience while still maintaining his full transcendence. It is apparent throughout the work of Edwards that the roots of Christianity are in the mystery

$l_{B y}$ the time a reader has advanced to this point in his analysis of the discussion under way, he should be fully aware of the fact that while Jonathan Edwards did incorporate the doctrine of experience into his own philosophical conception of perception, he did this as a devout Calvinist minister in Puritan New England of the late Seventeenth and early Eighteenth centuries. Therefore, we must expect him to integrate his empiricism into a rigorous religiously focused paradigm in keeping with both his cultural and religious orientation; Edwards could not have done otherwise. Thus, as we proceed we must remain cognizant of this point of reference, regarding particularly the ensuing discussion of Edwards' Metaphysical Theology, lest the significance of our analysis should prove elusive.

2 The central question of Puritan Protestantism, John E. Smith tells us, is precisely this: "How shall the presence of the divine Spirit be discerned?" And in the Great Awakening this question reaches a cultural climax. "Editor's Introduction," Religious Affections, p. 1. 
of a transcendent-immanent Deity, and that all theological problems and major historical crises of Christianity are variations of this one theme. The Incarnation by its nature is a doctrine which promotes historical and cultural tensions in experience as well as in thought. Christianity as a lived experience has a fundamental ambivalence built into it, an ambivalence which is born out of the struggle to convert the mystery of the Incarnation into concrete reality. It is not too extravagant to say that we see this inner tension personified in the life and thought of Edwards, and that he was dedicated. to coming to grips with the Incarnated God in the fullness of his concrete presence.

Perhaps no one in the colonies understood better the revolution that science and philosophy had worked in the eighteenth century mind, and the implications it held for traditional doctrine. And perhaps there was none better equipped to inrdocue these new ideas into a theologically oriented setting. The traditional problem of Presence was understood by Edwards in these specific terms: How does God fit into the new world-scheme of Newton and Locke? ${ }^{3}$ What aspect of the world of Newton's psychology would refer to the God of Christian revelation? In answering these questions, he was interested in preserving

3 ${ }^{3}$ See Perry Miller's discussion of this point in Jonathan Edwards, Chapters on "The Inherent Good," "The Objective Good," and "Naturalism." 
the classical Calvinist doctrine of God as the ground of being. But more than this, he wanted to show that this God is the ground of the Newtonian-Lockean Universe.

Why should Edwards be singled out as having greater success at the reconciliation of science and religion than his contemporaries? Why should he have seen, as a young student, that Newton and Locke taken together constitute a radical shift away from the traditional concepts of God? Many factors of biography, history, and the nature of his own intellect, too numerous and complex to mention here, account for his uniqueness in the America of the early eighteenth century. But if we demand an answer, I think it must be found in the degree of seriousness with which he accept experience as the primary source of our knowledge of both God and the physical universe. More than the others of his generation, he saw the urgency of resolving the religious crisis completely within experience, or of facing the alternative possibility of not resolving it at all. This, then, will be the chief purpose of our present discussion: to show the degree of success he had in applying the principles of experience to the problems of theology with the specific intention of penetrating the mystery of God's presence. First, it is necessary to see something of his understanding of the new science, of the manner in which he converted the mechanical physics of Newton into an organic metaphysics, thereby paving the way for a conception of God as the ground of organic nature. Then we will 
be able to show that within this metaphysical context

Edwards develops a doctrine of nature as sacrament, whereby all creatures in esse are symbols of God, the objective presence of the transcendent Deity.

\section{THE THEOLOGY OF ATOMS, SPACE AND GRAVITY}

Edwards' scientific interests and the relationship

between science and theology in his thought have been the subject of many studies. 4 It seems an established fact that science affected his idea of God, and that his theological categories were formed and continued to be shaped by his interest as a college student in Newton. The original Dummer collection of books at Yale included the opticks and the Principia to which he had access. His "Notes on Natural Science" was probably written at

4 For the best literature on Edwards' knowledge of science, see the following: James Tufts, "Edwards and Newton," Philosophical Review, XLIX (Nov. 1940); Rufus Suter, "An American Pascal; Jonathan Edwards," Scientific Monthly, 68 (May, 1949), 338-42; Harvey G. Townsend, "Jonathan Edwards' Later Observations of Nature," New England Quarterly, XIII (Sept. 1940), 510-18; Clarence H. Faust, "Jonathan Edwards as a Scientist," American Literature, I (1930), 393-404; Theodore Hornberger, "The Effect of the New Science Upon the Thought of Jonathan Edwards," American Literature, IX (1937), 196-207; Henry C. McCook, "Jonathan Edwards as a Naturalist," Presbyterian and Reformed Review, I (July, 1890), 393-402. Harvey G. Townsend writes that a fundamental belief of Edwards is "that the physical world is the direct expression of God's being and nature, and therefore that physical science is the source of man's knowledge of God." The Philosophy of Jonathan Edwards from his Private Notebooks, p. viii. 
this time, 5 as a result of his contact with the British physicist. Some writers argue that he was side-tracked from a promising career in science by his conversion experience, and that the pursuit of theological matters diverted his attention from the natural world. But the evidence is to the contrary. Clarence Faust, for example, says that his theology was a direct development of his scientific activity. And Carl Van Doren writes that his "profession from science and philosophy to theology was in no sense a desertion; the three subjects possessed him side by side." ${ }^{6}$ A. C. McGiffert suggests that his understanding of God derives from physics as well as theology: "As to the existence of God, he had long since reached a positive conclusion, driven thereto by the three-fold suggestions of physics--God is space; of philosophy--God is mind; and of religious experience--God is the source of our intuitions." 7 We find supporting evidence for this thesis in Douglas Elwood. 8 And the entire work of Perry Miller is premised on the continuity of science and theology. 9

5

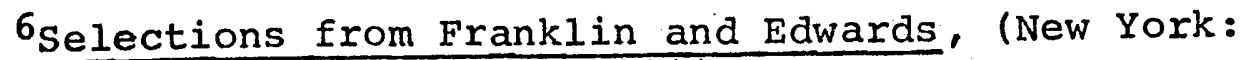
c. Scribner's Sons, 1920), p. xiii.

${ }^{7}$ Jonathan Edwards, p. 175.

8he Philosophical Theology of Jonathan Edwards, pp. 9-10. ${ }^{9}$ Jonathan Edwards, passim. The quote is taken from p." 2. 
Edwards would not compartmentalize his thinking. He is the last great American, perhaps the last European, for whom there could be no warfare between religion and science. . . He was incapable of accepting Christianity and physics on separate premises.

How, then, did he render a theological interpretation of the then contemporary interpretation of Newtonian physics? The answer begins not with Edwards but with Newton himself, for Newton, the eighteenth century man and deist, had devoted considerable effort to establishing an amicable relationship between his mathematical physics and a wider theological view of the world. In fact, it was one of his primary concerns to introduce God into his mechanical scheme not as a superfluous embellishment, but as an integral factor in the whole system. "Religion was something quite basic to him and in no sense a mere appendage to his science or an accidental addition to his metaphysics." 10

For Newton the world of matter is ultimately composed of indestructible atoms which combine to form bodies capable of being seen and of being measured mathematically. ${ }^{11}$

\section{${ }^{10}$ Burtt, p. 284.}

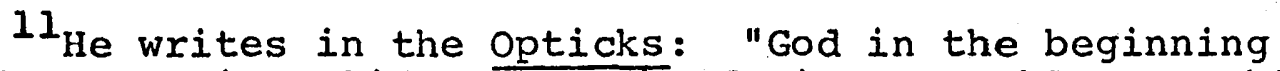
formed matter in solid, massy, hard, impenetrable, movable particles, of such sizes and figures, and with such other properties, in such proportion to space, as most conduced to the end for which he formed them; and that these primitive particles, being solids, are incomparably harder than any porous bodies compounded of them; even so very hard, as never to wear or break in pieces: no ordinary power being able to divide what God himself made on in the first creation." Quoted in Burtt, pp. 232-33. . 
They move about within the frame of absolute space and time. The existence of absolute space being subject to empirical verification. And so the absolute motions of bodies can be determined by a reference to it. Their relative motions can be calculated by a reference to other bodies which are themselves in motion. Bodies move in absolute space and with reference to measurement in time. To the scientist for whom an experimental proof is always desirable, the postulation of absolute space is necessary in terms of such calculations as these regarding the proof of atomic movement. However, as Newton observes in Opticks, in relation to his discourse on the phenomenon of space and time, an absolute cause of creation must be traced back to an all powerful source substance termed God. Two factors have relevance here--the omnipresence of $\operatorname{God}^{12}$ and the infinite scene of his knowledge:

Does it not appear from phenomena that there is a Being incorporeal, living, intelligent, omnipresent, who in infinite space, as it were in his sensory, sees the things themselves intimately, and thoroughly perceives them, and comprehends them who $13 y$ by their immediate presence to himself.

12 " (God) endures for ever, and is everywhere present; and by existing always and everywhere, he constitutes duration and space. ... He is omnipresent, not virtually only, but also substantially, for virtue cannot subsist without substance." Principles. Quoted in Burtt, p. 258.

13 Opticks. Quoted in Burtt, p. 260. 
If absolute space is God's sensorium, then all physical motion remains ultimately resolved by a reference to that which passes beyond the realm of empirical verification and into the realm of theology. It is here that Newton finds the ultimate explanation of motion and gravity. The mind of God, while not the absolute center of reference for all things in space and time, is, however, in the deistic sense, the ultimate and original source of all motion as its first creative cause. "All real or absolute motion in the last analysis is the resultant of an expenditure of divine energy. "14

Thus, by the end of the eighteenth century, when Edwards was reading Newton, absolute space had lost its theological significance. It was transformed from the organ of God's perception into an impersonal, fixed framework, geometric in nature, originally set in motion by divine creation, which functioned solely as the measure of mass in motion. ${ }^{15}$ The world of necessity was no longer viewed within a divinely transcendent context, but now stood as an independent machine of immense complexity. The concept of a world-machine prevailed where once Newton has sought desperately to place mechanical physics into a wider

\section{Burtt, p. 261.}

15 Burtt writes: Absolute space was "divested of both logical and theological excuse, but yet unquestionably assumed as an infinite theatre in which, and an unchangeable entity against which, the world-machine continued its clocklike movements." Ibid., p. 262. 
theological setting. With such a view, God has been reduced to the minimal role of an absentee landlord, and deism issued forth as a popular religious consequence. It can be said of Edwards that he represents a notable exception to the deistic tendency of the eighteenth century. ${ }^{16}$ His interpretation of Newton, quite contrary to the prevailing mood in scientific and philosophic circles, was entirely consonant with his religious convictions of a God who in some mysterious way is organically continuous with the world at the same time that he is the independent foundation of it. In other words, he accomplished with remarkable facility what other theological minds of his time attempted, but only with a great deal of agony. He assimilated the Newtonian conception of atoms, absolute space, and gravity, to a theological system which was an enrichment of the traditional themes of Calvin and Augustine. But more than this, he effected a complete transmutation of these themes into something quite new and startlingly different in the order of theological explanation.

We are struck immediately by the noticeable shift in theological metaphor--a shift from mechanical conception

${ }^{16}$ In a nineteenth century work on the theology of Edwards, Alexander V. G. Allen writes: "At a time when the prevailing Deism represented God as if a passive agent, governing the world by general laws and second causes, as well as far removed from the scene of human activity, Edwards presented Deity as immanent and efficient will." Jonathan Edwards (New York: Houghton, Mifflin, and Co., 1889), p. 58 . 
to organic conception. By stripping the fudamental principles of Newtonian physics of their mechanical connotation, 17 atoms, space, and gravity acquired new significance as basic metaphors of an organic cosmology. This allowed Edwards to say things about the nature of God which had not been said by any other theologian with as staunch a sense of orthodoxy as his. In proclaiming that the transcendent sovereign God is also the immanent principle of an organically structured world, Edwards was not aware of himself as heretical or in any way exceptional to orthodox Calvinism. To him it was a matter of enlisting the concepts of physical matter--or atoms, space, and gravity--into the service of traditional theology.

Let us now look at the way he proposes to do this. It can be shown, I believe, that he adapts the rudiments of Newtonian science to a theological purpose in these successive but related steps. First, he broadens the definition of an atom so as to mean any integral unit of being. An atom is an inviolate whole, an entity with an integrity of its own. As an integral whole, it manifests one of the basic properties of an organism: it exists in protection of its wholeness. Second, space is an atom,

17 "Hence we learn, that there is no such things as Mechanism; if that word is intended to denote that, whereby bodies act, each upon the other, purely and properly by themselves." "Notes on Natural Science," Works (Dwight ed.), I, p. 714. 
a unit of life with self-possessed integrity. But it is also infinite, and so Edwards identified space with the ultimate unit which men call God. Third, since the unity of space (and everything within $i t$ ) is accounted for by. gravity, God providing all worldly perfection, then gravity must be theologically identical with grace. Grace, as we had seen in a previous chapter, is the medium through which God and his world (or the ultimate unit of space and everything within it) achieve their unity and harmony. The term grace denotes for Edwards the vast network of relations between God (as the ultimate unit of space) and his various manifestations:

First, the atom.

All bodies whatsoever, except Atoms themselves, must, of absolute necessity, be composed of Atoms, or of bodies that are indiscernible (sic), that cannot be made less, or whose parts cannot, py any finite power, be separated from one another. 18

The common conception of the atom has always been of a tiny particle incapable of any further reduction. But Edwards rejects this as too simple and distorted a picture. An atom, he tells us, is really a plenum, and has "every part of space (in miniature scaled form) included within its surface." It resists every finite effort to be divided, because it is a unity, a whole, and jealously protects its integrity. So the physical hallmark of an atom is its

${ }^{18}$ Ibid. , pp. 708-709. 
resistance to the intrusion of anything that would destroy its unity and hence its being, just as the universe becomes absolute space.

The conception of the atom as a plenum is not a priori assertion, but the application of Lockean empiricism to a basic philosophical issue; what is a body? Experience teaches us to call those parts of space bodies in which the motion of another body is terminated and resisted. Bodies resist violation of their parts of space to the extent that they are perfectly solid. This is manifested in experience, according to Edwards. "It is intuitively certain, that, if Solidity be removed from Body, nothing is left but empty space." 19 So if a body connotes solidity, then $a$ body with absolute solidity is indiscernible; it is a plenum or an atom. In scientific jargon, he defines the atom as "a body whose parts are no ways separated by pores, but has all its parts conjoined by an absolute continuity of matter." 20

So an atom has nothing to do with size. Its nature is marked by the ability to resist annihilation, and the ability to persevere and maintain its autonomy. This ability is attributed to its solidity. "An atom... does not at all consist in littleness, as generally used

$$
\begin{aligned}
& { }^{19} \text { Ibid., p. } 674 . \\
& { }^{20} \text { Ibid. , p. } 724 .
\end{aligned}
$$


to be thought; for by our philosophy an Atom may be as big as the Universe; because any body, of whatsoever bigness, were an atom, if it were a perfect solid."21 when we strip away the references to physical matter in Edwards' discussion of the atom (they are incidental to his overall purpose which is metaphysical and theological), we are left with this definition: an atom is an entity having integrity by virtue of its "solidity," i.e., by virtue of the absolute continuity and homogeneity of the substance of which it is composed.

Accordingly, as Edwards discerns space, absolute space fulfills the requirements of an atom. In the essay "Of Being," in which he outlines the principles of his idealism, Edwards contrasts the repugnant concept of nothing to the notion of "necessary, eternal, infinite, and omnipresent" space. Space is the only concept that can properly oppose the contradiction of nothingness, for the only way to conceive nothingness is to conceive the total absence of space. But this is manifestly impossible. Infinite and omnipresent space cannot have the physical solidity of a material atom, for solidity implies resistance, and there is nothing for space to resist. But it does have a solidity in the abovementioned sense of continuity and homogeniety.

$$
21 \text { Ibid., p. } 711 .
$$


If a man would imagine space any where to be divided, so as there should be nothing between the divided parts, there remains space between, notwithstanding, and so the man contradicts

himself. 22

Infinite and omnipresent space, therefore, possesses the same inaiscernibility as an atom. He continues, depicting space as a plenum, an infinite plenum, by identifying it with God:

It is self-evident I believe to every man, that Space is necessary, eternal, infinite and omnipresent. But I had as good speak plain: I have already said as much as, that space is God. And it is indeed clear to me, that all the space there is, not proper to body, all the space there is without the bounds of creation, all the space 23 there was before the creation, is God himself.

The strong and unequivocal identification of space with God is less an adaptation of Newton and more of an expression of something deeply felt within himself. We may ask: what is the source of his idea of space? It seems to be such a strong point in his theological system that we can legitimately doubt if it took shape solely from a reading of the opticks. The idea of space as the universal matrix within which things get related in their mutual consent, must be attributed as much if not more to his experience of the limitless expanse of the American 22 Ibid. , p. 706 23 Ibid. 
wilderness. ${ }^{24}$ The fusion of Newton's absolute space with the geographic space of frontier New England forms the basis of Edwards' notion of God in "The Mind," and

"Notes on Natural Science." This notion is carried into his later theological work where he develops the full meaning of man's experiential approach to God--through the experience of space.

We turn now to the third element of Newtonian science --the revolutionary concept of gravity--to see what theological implication it holds for Edwards. First, on the level of strict scientific analysis he agrees with Newton that "the existence and motion of every Atom, has influence, more or less, on the motion of all other bodies in the Universe, great or small, as is most demonstrable from the Laws of Gravity and Motion." 25 But in a wider view this means there is a universal attraction "in the whole system of things" including "the whole system and series of ideas in all created minds."26. Universal

${ }^{24}$ For a most enlightening treatment of the role of space in the formation of the religious mind of early America, see Sidney E. Mead, The Lively Experiment, The Shaping of Christianity in America (New York: Harper and Row, 1963); Chapter I: "The American People: Their Space, Time and Religion." Mead speaks of the abundance of "organic, pragmatic space--the space of action." "He who would understand America must understand that through all the formative years, space has overshadowed time--has taken precedence over time in the formation of all the ideals most cherished by the American mind and spirit." p. 12 .

$$
\begin{aligned}
& 25_{\text {Works }} \text { (Dwight ed.), p. } 672 \text {. } \\
& 26_{\text {Ibid. , p. } 671 .}
\end{aligned}
$$


attraction extends to mental atoms, or ideas, as well as to physical atoms, and is accountable by the underlying presence of the "Supreme mind" to all things.

He tells us further that an atom is really gravity, because it is the culmination of an immense concentration of gravitational force (since it exercises an amount of attraction, however large or small, over every other particle in the universe). "Solidity is gravity; so that, in some sense, the Essence of bodies is Gravity . . the very bare being of body, without supposing harmonious being, necessarily infers Gravity." 27 If gravity, the power of an atom over every other atom, constitutes the essence of bodies both real and ideal, then it must be the exertion of divine power according to Edwards' reasoning:

Creation of the corporeal Universe is nothing other, than the first causing resistance in such parts of space as God saw fit, with a power of being communicated successively, from one part of space to another, according to such stated conditions, as his Infinite wisdom directed, and then the first beginning of this communication, so that ever after it might be continued 28 without deviating from those stated conditions.

Hence, resistance or solidity strictly speaking is no inherent property of the atom, but the communicated essence of God's creative power:

The substance of bodies. . becomes either nothing, or nothing but the Deity, acting in that particular manner, in those parts of space

27 Ibid. , p. 723.

${ }^{28}$ Ibid. , pp. $713-14$. 
where he thinks fit: so that.. there is no proper substance but God himself. 29

Because it is universally allowed, that Gravity depends immediately on the Divine influence, and because it may be proved that solidity and Gravity are in a good sense the same, and resolvable into each other, and because Solidity has been proved to be the very being of a body; therefore, we may infallibly conclude, that the very being, and the manner of being, and the whole, of bodies depends immediately on the Divine Being. -- if Gravity should be withdrawn, the whole universe would in a moment vanish into nothing; so that not only the well being of the world depends on it, but the very being. 30

We have here in the idiom of eighteenth century science a further corroboration of the consent to being-the insight that the universe is constituted by a network of internal relations, or mutual consents that go to make I up an organic continuum which is the very matrix of God's creative power. The matrix manifests itself either materially as gravity, or spiritually as grace. Regardless of its mode, it is the same manifested energy of divine creativity--the dynamic presence of a God who is organically linked to his world. The generic term grace is used by Edwards to refer to this presence. In a previous discussion, ${ }^{31}$ we had seen that grace is an ontological medium of human experience, the via of man's

${ }^{29}$ Ibid., p. 713.

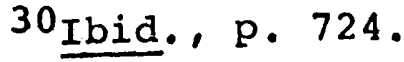

${ }^{31}$ Chapter VI. 
experience of God and of himself and his world.

What, then, can we say of Edwards' appreciation of Newton? We can say, first of all, that it was the empirical method that attracted him to the ideas of atoms, space and gravity--that these were to Edwards articulations on the level of physics of a profound theological truth. An atom is a unit with a metaphysical integrity or wholeness, and the ultimate atom is infinite and omnipresent space, or God. The term gravity in the physical order, or grace in the theological order, adequately describes the relationship between God as the ultimate atom and the infinite variety of his manifestations or presences. We can almost say that for Edwards each and every particular atom in its own simplicity "prehends" the infinite and omnipresent God, for "there is not one leaf of a tree, nor a spire of grass" but what represents a cognition of God's presence "all over the universe." 32 In each and every atom God comes to a realization of his own integrity. It is that realization which we may call the atom's prehension; and Newton first gave it scientific intelligibility by calling it gravity. It was, to repeat, the empiricism behind Newton's physics which turned Edwards toward the firm resolve that the deepest theological insights are to be achieved through the empirical method--or the way of experience. And so by

32 Works (Dwight ed.), I, p. 707. 
calling grace a "new simple idea," he introduced the element of experience into the heart of theological doctrine. He meant two things by this term: first, that grace is the mode of man's actual experience of God's presence in the atom; second, that every atom itself is a kind of simple idea inasmuch as it prehends God, or represents God's coming to an awareness of his own infinite integrity through the finite integrity of the atom. But in both cases, grace is the same identical reality--it is the actual medium through which man and nature (in this case the atom) pass into the full experiential presence of God. Edwards never insisted on any point more strongly than the fact that grace is entirely beyond man's nature, and is a gift of God. We shall see the full significance of this in our discussion of transcendence.

\section{A SHIFT IN THEOLOGICAL METAPHOR}

The adaptation of Newton to theology was really a subtle adaptation of scientific language to theological language. What this means, of course, is a subtle shift in metaphor. The metaphors which enabled Newton to describe the physical order from a mathematical viewpoint were adapted to theological use by Edwards. For he never doubted that the meaning of such concepts as those of atoms and gravity extended far beyond the realm of sheer mechanics; and he never doubted about "the folly of seeking 
for a mechanical cause of Gravity" ${ }^{33}$ without taking into account the reality of a wider organic world in which it is situated. The language which describes the mechanical world is the basis for a descriptive language of the organic world. From the very beginning of his intellectual life he was dominated by a single insight--that everything in the universe, physical or otherwise, bears a special relation to universal consciousness. Now Newtonian physics allowed a clear understanding of how that relation exists in the physical order, and how it could be made the foundation of a metaphysical understanding of the over-all relationship between God and the world.

Edwards construed this relationship by the metaphor of life rather than of being simply considered. Traditional theology was satisfied with an omnipotent God who stands outside the order of his creation as a separate substance. It appeared to be bothered not at all by the difficulties, the tangle of inconsistencies, of a being with absolute power who reigns from a remote and detached position. Such a God was inconceivable to Edwards, for it violated the principle that consciousness reigns supreme in the world. Therefore, God had to be recast into the role of "immanent and efficient will" (to borrow the expression from A. V. G. Allen) ${ }^{34}$ whose relation to his creation resembles that of a 
living organism to its various modes of dynamic expression.

Such an interpretation permitted Edwards to establish the compatibility between the total "otherness" of God and his immediate presence in the world of man's experience, for they are two essential dimensions of the one infinite organism. The transcendent God is the matrix of all possible and actual experience, and the immanent God is the very substance of the same experience. Or to put the same idea on a different footing: to call God a living being is to entertain the possibility of seeing him as the totally other (but not totally removed), and the totally present (but not enclosed within or circumscribed by the world). A living God, st. Bonaventure said long before Edwards, is "within all, though not included in them; beyond all, but not excluded from them; above all, but not transported beyond them; below all, and yet not cast down beneath them." 35

It is important to note that when the shift in metaphor frambeing to life occurs in theology, a concomitant shift from substance to symbol must occur in metaphysics. While this is not an uncommon insight, among modern writers scheler has given it a most cogent expression. When the world is viewed as a whole, he tells us, as a

35 The Mind's Road to God, trans. George Boas (New York: Liberal Arts Press, 1953), p. 38. 
"collective organism, permeated by a unitary life;"

it requires an organic mode of approach to things. Given such a viewpoint, the ideal and real (teleological or causal) connections between things, as studied in science and philosophy are supplemented by a new sort of relationship, coexistensive with what is real in life and its mode
of expression, a specifically symbolic relation.

only when we look at our world as a collective organism does it occur to us that "all natural phenomena appear both as the undivided total life of a single world-organism and the universal fluid matrix in which it is expressed." We come to realize that the perceptible attributes of all natural phenomena "are only the outward aspect and frontier of the inner life" of the world. 37

The relationship described by scheler is symbolic in the sense that an organism and its modes of expression are related internally and not externally, these being its common parts and unitary life. Things are modes of life and not isolated particles of inert matter. For that matter things are not things at all-for this implies mere juxtaposition to their source, and spatial separation from it. We replace the notion of "thingness" with symbol, and conclude that everything is inside its source, not spatially so much as relationally. Douglas Elwood is perhaps

${ }^{36}$ Max Scheler, The Nature of Sympathy, trans. P. Heath, ed. W. Stark (New Haven: Yale University Press, 1954), p. 81.

${ }^{37}$ Ibid., p. 82 ff. Scheler cites a statement by Rodin that "a Ehing is simply the shape and outline of the 'flame' which gives it birth." 
alone among all the commentators on Edwards' theology to emphasize the point that God is neither a first cause, remote from the world, nor a substance coextensive with it, but the life-principle which suffuses all that is:

(Edwards') employment of what Tillich calls 'symbolic use' of substance and causality enabled him to overcome both naturalistic pantheism and rationalistic theism. . . The being of God interpenetrates the universe, recreating it in each new moment, yet without cancelling the relative and dependent individuality of the creature. In terms of experience, individuality consists in the degree and manner of our participation in God, without whom we would not be at all. 38

We have only to note here that the theological shift from a mechanical to an organic view was prepared for and even implicit in the sense of the heart and the consent to being. The reading of Newton was the occasion of the shift, but certainly not the sole cause. The dominance of experience, especially aesthetic experience, must have been the decisive inlfuence. To construe God as the life-principle of an organic world could not have been the conclusion to a logical syllogism whose premises were derived exclusively from Newtonian science. God's mysterious presence in the world can never be penetrated by reason alone, apart from intuition. William James never passed an opportunity to illustrate the paucity of logic in dealing with religious or philosophical matters, and with a world

56 . The Philosophical Theology of Jonathan Edwards, p. 
in which life is a primary datum. In The varieties of

Religious Experience he says:

The old logic of identity never gives us more than a post-mortem dissection of disjecta membra - . the fullness of life can be construed to thought only by recognizing that every object which our thought may propose to itself involves the notion of some other object/3 which seems at first to negate the first one.

It remains for us to see how Edwards transcended these limitations of logic with regard to the presence of God.

\section{THE LOGIC OF CREATION}

James' point is well taken that the fullness of life does not lend itself to anything but a post-mortem dissection when one chooses to employ logic. And Edwards' doctrine of creation is clearly a theological case in point, for he illustrates the impossibility of any logic to putting God at a distance from the world and to impose a limitation on his creative will. The first point lof separation) will be dealt with later. For the present, let us dwell upon the second: God cannot be controlled or

${ }^{39}$ The Varieties of Religious Experience (New York: Collier, 1961), p. 351. In a similar vein, he announces his abandonment of logic as the measure of experience: "I have finally found myself compelled to give up the logic, fairly, squarely, and irrevocably. It has an imperishable use in human life, but that use is not to make us theoretically acquainted with the essential nature of reality. . . Reality, life, experience, concreteness, immediacy, use what word you will, exceeds our logic, overflows and surrounds it." Pluralistic Universe (New York: Longmans Green 1940), pp. $21 \overline{2-13 .}$ 
directed by any constraining logic of creation which is prior to and above his nature. Whatever logic there is emerges out of the act itself and is created along with everything else. It can only be discerned with a sense of the heart, i.e., on the level of experience.

There are two aspects of this matter: (1) creation is the utter communication of God's goodness; and (2) the logic of creationis bound up with the simple fact of his disposition to communicate--and nothing more. What can be inferred from these statements is that God uses what might be called an "experimental" logic, and our access to it is through an analogous experimentalism, or through openness to experience.

As to the first proposition, Edwards makes the idea of communication central to his understanding of creation. This is manifest throughout his writings, in the "Miscellanies" as well as "God's Chief End in Creation.". The texts are quite clear that "the great and universal end of God's creating the world was to communicate Himself. God is a communicating being." 40 The theme is repeated again in "God's Chief End in Creation."

Thus it appears reasonable to suppose that it was God's last end, that there might be a glorious and abundant emanation of his infinite fullness of good ad extra, or without himself; and that

40 The Philosophy of Jonathan Edwards from his Private Notebooks, p. 130 . 
the disposition to communicate himself, or diffuse his own Fullness was what moved him to create the world. 41

Communication constitutes the inner life of God but it puts no restrictions on his nature to say that he takes delight in his communication with creatures. It is a fallacy to impose a dichotomy between God and the object of his communication, and then to say that the need to communicate with it limits him. It is fallacious because there cannot be the severe separation between his communicative nature and the object of communication. Indeed, God's communication is an act of self-discovery, and the creature is the medium through which divine self-communication is enacted. "God can't be said to be the more happy for the creature, because He is infinitely happy in Himself. He is not dependent on the creature for anything, nor has He received any addition from the creature." But because the creatures are intrinsically related to God as the medium of his self-communication, "God has the more delight for the loveliness and happiness of the creature, fiz., as God would be less happy if He were less good, or if it were possible for Him to be hindered in exercizing His own goodness or to be hindered from glorifying Himself." 42

$41_{\text {Works }}$ (Dwight ed.), III, p. 20.

42 The Philosophy of Jonathan Edwards from his Private Notebooks, pp. 138-9. 
In his own infinite fullness he has no need of creatures, yet takes genuine delight in them because they constitute an aspect of that fullness.

Now to the second proposition, which follows from the fact that creation is the continuous diffusion of God's nature. It is expressed in this manner: the logical structure of creation is to be found in the diffusive process and not prior to it. The rationale of creation resides in, and originates with, God's disposition to diffuse and communicate himself and not in any preexisting hierarchy of Platonic Ideas. Edwards states his position on this matter of Ideas unequivocally. It is wrong to assume that God has an inclination "to communicate himself to an object," for this seems to presuppose "the existence of the object, at least in idea." And it would be inconsistent with his nature to be bound by an idea prior to his communication.

The diffusive disposition that excited God to give creatures existence, was ... a communicated disposition in general, or a disposition in the fullness of the divinity to flow out and diffuse itself. Thus the disposition there is in the root and stock of a tree to diffuse sap and life, is doubtless the reason of their communication to its buds, leaves and fruits, after these exist. But a disposition to communicate of its life and sap to its fruits, is not so properly the cause of its producing those fruits, as its disposition to diffuse its sap and life in general. Therefore, to speak. strictly and according to truth, we may suppose, that a disposition in God, as an original property of his nature, to an emanation of his own infinite fullness, was what excited him to create the 
world; and so, that the emanation itself was 3 aimed at him as a last end of the creation.

We might say that, if anything, God is governed by a kind of "experimental logic," in the sense that the whole rationale of creation manifests itself only as he creates, or "experiments" with his diffusive nature. The emanations of God are actually a self-revelation. So intimate is the bond between his inner nature and his expressive nature, that the former is revealed to God himself through the latter. He can only know what his inner life is when it becomes diffused in space and time. For example, in order to appreciate the fullness of his infinite glory, he must "experiment" with it through emanation and thus discover its finite expression in the creature:

This propensity in God to diffuse himself, may be considered as a propensity to himself diffused; or to his own glory existing in its emanation. A respect to himself, or an infinite propensity to, and delight in his own glory, is that which causes him to incline to its being abundantly diffused, and to delight in the emanation of it. . . So God looks on the communication of himself, and the emanation of the infinite glory and good that are in himself to belong to the fullness and completeness of himself; as though he were not in his most complete and glorious state without it.

43 Works (Dwight ed.), III, p. 21.

44 Works (Worcester ed.), VI, p. 37. (My italics.) In the "Miscellanies" he writes: "For God to glorify Himself in His works or to communicate Himself in His works, which is all one." The Philosophy of Jonathan Edwards from his Private Notebooks, p. 129 . 
An important aspect of the divine fullness which is communicated is knowledge. The creature's knowledge of himself is a participation in divine self-knowledge; it is an instance of God's self-revelation. "This knowledge (or the creature) is most properly a communication of God's infinite knowledge which primarily consists in the knowledge of himself. . . This knowledge in the creature... is the image of God's own knowledge of himself. It is a participation of the same. ${ }^{45}$ And so it is with happiness and delight: in the creature they are exemplifications of God's happiness and delight in himself. "God's delight in (the happiness of the creature) is only a delight in His own brightness, communicated and reflected, and in his own action of communicating, which is still to be resolved into a delight in Himself." 46 The intention of Edwards in these texts is to assert that God's glory, his knowledge of himself, and his happiness in himself are mediated through his emanations. Therefore, the rationale of his creation must reside entirely within his emanative nature; which is to say that the rationale itself is an emergent reality.

${ }^{45}$ Ibid. , p. 39.

46 The Philosophy of Jonathan Edwards from His Private Notebooks, p. 147 . 
IV. NATURE AS SACRAMENT

A major consequence of immense practicality follows from this analysis of God's unrestrained disposition to diffuse himself--a consequence which is crucial to Edwards' doctrine of Presence. If God is revealed to himself through the experimental process of emanation, then man can discern his communicated presence only with a similar experimental approach--with a complete openness to experience. God speaks with "a kind of voice or language. . . to instruct intelligent beings in things pertaining to Himself," 47 and man must respond by cultivating an open attitude to nature as the infinite lexicon of God's language. First of all, multiplicity is in God; it constitutes an aspect of his nature.

There is a variety in light. One and the same white light, though it seems to be an exceeding simple thing, yet contains a very great variety of kinds of rays, all of so many different excellent and lovely appearance. So the same simple spirit of God seems to contain a great variety, and therefore $H e$ is in Revelation seven spirits. There is one body, one spirit, and yet a vast variety of gifts. 48

Therefore, if man would share in the variety of his gifts, he must open his experience out to their accessibility in nature. He must, in other words, be accustomed to seeing

47 Image 57 , Images or Shadows of Divine Things, p. 61. ${ }^{48}$ Image 58 , Ibid. , p. 63. 
nature as a sacrament, as a medium through which he can experience the infinitely various ways that God gives expression to the rich variety of his nature.

The notion of a sacramental nature cannot be tossed off lightly, for Edwards allows it full play in his thought, especially in the cryptic volume of Images or Shadows of Divine Things. Ever since their publication by Perry Miller the question has persisted: What is precisely the meaning of the words "image" and "shadow"? Are they intended to be mere tropes used for petty moralizing, or do they convey a deeper meaning? Does Edwards declare that the images in nature express some profound truth about themselves, telling us that they are sacramental conveyances which enable a man to attain to God's presence? This is the more likely interpretation, and the one we shall pursue here. Professor Miller's claim that Edwards supplanted the Bible with nature as the superior source of revelation remains unsatisfactory for its unbalanced view; that he ever intended to subordinate scripture to a direct perception of God's presence in nature seems rather far-fetched and certainly inconsistent with the bulk of his thought and work, and yet such an interpretation has been put on the Images and on Miller's commendable 
essay. $^{49}$ However, this is an extreme to the opposite direction from dismissing the Images as an exercise in rhetoric. All the evidence indicates that Edwards considered scripture and nature as distinct but complementary aspects of the same divine communication, and the two must be held in equal esteem. Both are fully within the purview of human experience, and cooperatively assist man in his quest for the presence of God.

The theme of the "Images". is summed up in the view that throughout nature there are adumbrations of God. All events and objects of our ordinary experience bear a significant relation to God; in their very natures they constitute the finite embodiment of their infinite original. They are not merely the occasions of the discovery of some fact about God, nor are they analogous illustrations of a profound spiritual truth. But they are the actual presence of that fact and truth. Thus:

Christ often makes use of representations of spiritual things in the constitution of the (world) for argument, as thus: the tree is known by its fruit. These things are not

${ }^{49}$ For a discussion of this point, see the review of Miller's essay by $\mathrm{H}$. Shelton Smith in American Literature, XXII (May, 1950), 192-94. "Miller concludes that Edwards carried his theory to the place where he really subordinated scripture to a direct perception of God through natural images. One may, according to Edwards, listen to God's spoken word in the Bible, but, better still, one may 'see Him in Images.' This, says Miller, 'is Edwards' peculiar and inspired conception. " 
merely mentioned as illustrations of his meaning, but as illustrations 5 gnd evidences of the truth of what he says.

The scriptural science of typology, which is the study of prophetic events in the old Testament, called types, and their fulfillment in the events of the New Testament, called antitypes, is now extended into nature by Edwards, so that natural events are "typical" of the spiritual, "antitypical" world.

The system of created being may be divided into two parts, the typical world, and the antitypical world. The inferior and carnal, $i . e .$, the more external and transitory part of the universe, that part of it which is inchoative, imperfect, and subservient, is typical of the superior, more spiritual, perfect, and durable part of it which is the end, and as it were, the substance and consummation of the other. Thus the material and natural world is typical of the moral, spirifual, and intelligent world, or the city of God.

What is distinctive about the Images, then, is that it attempts to see the world from within, for to call natural objects and events "wonderful resemblances and shadows" of spiritual realities is no denigration of their status as second-hand imitations of spiritual realities. They are called imitations because "they are wholly being from the fountain," 52 i.e., they bear, in the Platonic sense,

${ }^{50}$ Images or Shadows, p. 49.

$51_{\text {Works }}$ (Dwight ed.), IX, pp. 110-11.

52 The Philosophy of Jonathan Edwards from his Private Notebooks, p. 146 . 
an intrinsic relation to the communicative nature of God as his theophanies, equally with Man reflecting God's divine spirit of creation on earth. But to say this is to say that the sensible world of objects and events really bears God from within. It stands as his total presence, and we must learn of his transcendence as an aspect of that presence. What Edwards is suggesting in the Images is an understanding of nature as the wider (indeed, infinite) reality within which man finds himself actually standing as in the presence of God.

The idea that within nature events and objects stand for themselves as theophanies, is by no means original with Edwards. It is a new variation of a traditional theme which found its highest expression within the medieval Franciscan movement. St. Francis of Assisi effected a revolution in Christianity when he extended the non-cosmic personal love of Christ, as scheler calls it, so as to encompass all of nature. Before this, Christianity was more or less encumbered by a notion inherited from the Greeks and the Romans that man stands in opposition to nature, that he must struggle to disengage himself from it in the name of an invisible God who stands as its Lord and Creator. Man must extxicate himself from dependence on nature, it was thought, in order to fulfill his vocation as the imago dei. He, like God, must stand to nature as a lord to his dominion. 
But the feeling that man must dominate nature is missing fromst. Francis. In addressing the sun, the moon, fire and water as his brothers and sisters, he puts these things on an equal footing with man ashaving an immediate and intrinsic relation to God. They are all "varying forms of the same ultimate energy; shifting symbols of the same absolute unity," as he says in his "Chant of the Sun."53 Hence, the whole natural world expresses something about itself, something that cannot be mediated by discursive reason, but must be interpreted on the deeper levels of experience. Scheler captures this insight into st. Francis when he says,

What is really new and unusual in st. Francis's emotional relationship to nature, is that natural objects and processes take on an expressive significance of their own, without any parabolic reference to man or to human relationships generally. - A natural object, for St. Francis, is a. symbol, a mark, a sign-post, a significant pointer to the spirit and person of Godinot because it is interpreted, recognized or inferred to be such by man, : . : but simply in and because 5 f its being objectively there, just as it is.

We are not surprised to find that st. Bonaventure, the leading exponent of Franciscan thought, manifests the same ability to grasp the god-like life of nature from within. He also accepts nature at face value as the embodiment of divinity. This is evident in his famous Mind's Road

53 Translated by Henry Adams, Mont-Saint-Michel and Chartres (London: Constable and Co., Ltd., 1936), p. 341.

${ }^{54}$ The Nature of Sympathy, p. 89. 
to God, in which he uses metaphors such as speculum (mirror) and vestigium to express the relationship between God and nature. Nature is seen as a mirror which holds the image of God, or as a work of art which expresses the personality of the artist. In either case, all creatures constitute a necessary medium through which one must pass in order to arrive at what God is in himself. But Bonaventure hastens to point out that in addition to being a medium, nature is also the actual embodiment of that for which it serves as a medium. "With respect to the mirror of sensible things," he tells us, "it happens that God is contemplated not only through them, as by His traces, but also in them, in so far as He is in them by essence, potency, and presence." 55 Again, when considering man as image, he says: "Not only passing through ourselves but also within ourselves is it given to us to contemplate the First Principle." 56 In recapitulating the theme of God's interpenetration of all creation, Bonaventure writes the puzzling pronouncement that divinity is an "intelligible sphere whose center is everywhere and whose circumference (is) nowhere, as one of the noblest and most exalted flights of human understanding." 57

55 The Mind's Road to God, p. 14.

56

Ibid., p. 28.

57 Ibid., p. 38 . 
The same kind of symbolic world that appealed to Francis and Bonaventure appeals also to Edwards. The substantial reality of all things resides not in their independent, truncated essences, but in their relation to the transcendent nature of God. Edwards makes this abundantly clear in the consent to being. To call events and objects of nature symbols is to assert that what they are in themselves passes infinitely beyond the limitations of space and time, or any restrictions human reason is capable of imposing on them. Every event and every object is the finite embodiment of the infinite God. In his admirable study of the nature of religion, Mircea Eliade notes that symbolism plays a decisive role in the religious life of man, for "it is through symbols that the world becomes transparent, is able to show the trancendent." 58

But the symbol does more than show the transcendent; it is the actual presence of it. This is what Edwards clearly saw, and what he wanted to make manifest. The message of the Images or Shadows is that God is present in the image in all its limitation, in all its finitude, and not in spite of it. This is why the images are illustrations of truths about themselves, and not about some higher reality for which they are the mere occasion to draw an analogy. This is the difference between a type and a trope.

58 The Sacred and the Profane (New York: Harper and Row, $196 \pi$, p. 130 . 
The former, the type, is a real symbol of itself as the presence of God; the trope is a figure of speech used for the convenience of human expression. The system of types presented by Edwards suggests that the infinite God would not come into his fullness without the infinitude of finite creatures. Thus,

The emanation or communication of the divine fullness . . has relation indeed both to God and the creature: but it has relation to God as its fountain, as the thing communicated is something of his internal fullness. The water in the stream is something of the fountain; and the beams of the sun are something of the sun. And again they have relation to God as their object: for the knowledge communicated is the knowledge of God; and the love communicated, is the love of God; and the happiness communicated, is the joy in God. In the creature's knowing, esteeming, loving, rejoicing in, and praising God, the glory of God is both exhibited and acknowledged: his fullness is received and returned. Here, is both an emanation and remanation. The refulgence shines upon and into the creature, and is reflecting back to the luminary. The beams of glory come from God; are something of God, and are refunded back again to their original. So that the whole is of God, and in God, and to God; and he is the beginning, and the middle, and the end. 59

Every creature represents the presence of God's fullness because it is a sui generis, an utterly unique and individual manifestation of that fullness. Since there is nothing else in the universe like this creature, it is an aspect of God's infinity. Without it, without its sheer singularity, God would be less than he actually is.

${ }^{59}$ Works (Dwight ed.), III, p. 84 . 
The idea of calling Edwards a metaphysical symbolist is by no means a novelty. It had occurred to an early student of his thought that his "deepest spiritual affinity was not with Calvin, but with Dante."60 And among a later generation of writers, A. C. McGiffert was well aware that Edwards "thought of nature symbolically."61 But what seems to be lacking in their suggestion is an awareness of how thorough-going a symbolist he was. A common interpretation of his doctrine has prevailed which would make it at best a mystical flirtation with the beauty of nature. In the same text, McGiffert writes: "The loveliness of nature and its majesty suggested to his enraptured eye the lovely and majestic glory of God." 62 But it did more than suggest: it was the beauty and majesty of God. To a symbolist, nature is an overpowering force and not a gentle persuasion. So Edwards saw nature as the highest expression of beauty.

We can conceive of nothing more beautiful . . than the beauties of nature here, especially the beauty of the more animated parts of this world. We never could have conceived of these if we had not seen them; and now, we can think of nothing beyond them; and therefore the highest beauties of art consist in imitation of them. ${ }^{63}$

${ }^{60}$ H. N. Gardiner, "The Early Idealism of Jonathan Edwards," Philosophical Review, IX (Nov., 1900), p. 596.

${ }^{61}$ Jonathan Edwards, p. 30.

62 Ibid.

63 "Miscellanies," No. 296, quoted by Miller, Images or Shadows of Divine Things, p. 35 . 
For the person with a symbolic view of the world, nothing less than a direct perception of God's presence will do; man's relationship with him can be nothing short of immediate experiential contact.

The manifestations God makes of Himself in His works are the principle manifestations of $\mathrm{His}$ perfections, and the declaration and teachings of His word are to lead to these. By God's declaring and teaching that He is infinitely powerful and wise, the creature believes that He is powerful and wise as He teaches, but in seeing His mighty and wise works, the effects of His power and wisdom, the creature not only hears and believes, but sees His power and wisdom, and so of His other perfections.64

Man has to orient himself experientially to a symbolic world--a world in which the ineffable is always present. In all his contacts with this kind of a world, there is an aspect of it which always escapes the conceptualizing power of his mind. And herein does Edwards find the true meaning of transcendence. The source of experience is always beyond all actual and possible experience. Yet this source is nevertheless an integral dimension of every experience. It is the objective presence of what Edwards calls grace: the medium through which man becomes capable of experiencing God's presence in nature. As a medium, grace has an objectivity to it, an ontological status which he describes as the Objective Good. But whether we call it the Inherent or Objective Good, what matters here is that grace comes as a gift from the sovereign and free God; it is a "fruit of 64 "Miscellanies," No. 777 , Ibid., p. 36. 
the spirit" totally beyond the boundaries of nature. So the doctrine of grace is Edwards' last word on the mystery of transcendence. The transcendent God who is the infinite ground of all reality, all experience, is fully present in all his transcendence as the Inherent and Objective Good, i.e., as the individual's participation in grace and its full presence. What the truly enlightened man, the gracious man, calls the ineffableness of his experience, that which surrounds and bathes it, Edwards calls the gracious presence of God. 
CHAPTER IX

CONCLUSION

Among the major themes in the development of a native philosophical tradition in America, experience has had a position of preeminence. Ore can say that the tension between experience and thought, the "way things are" and "the way they are traditionally conceived to be," has been the source of much creative energy in our history. To the extent that traditional categories of thought openly clashed with the demands of experience, then to that extent America has proven that this unstable situation can, at its best, produce an experimental frame of mind which is fertile and creative. It is not surprising to discover that the golden age of American philosophy asserted the supremacy of experience over the universal principles of thought which governed the European mind for 
centuries. 1

This primacy of experience did not originate in the philosophies of James and Dewey nor with the transcendentalists, but its origins can be traced back to the Puritans of the seventeenth and eighteenth centuries. The contribution of these early settlers of New England to the tradition of experience has been brought into sharp focus by a whole generation of students of American thought and culture beginning with the work of Perry Miller. As the Puritan mind reached maturity in the genius of Jonathan Edwards, it is possible to consider him a pioneer and early exponent of this tradition. The present work has sought to cast light on the rich sense of experience which underlies his philosophy, and to see that his systematic thought is organized around and constructed out of a primary fidelity to the act of perception.

${ }^{1}$ John J. McDermott has admirably marshaled the support of evidence and scholarly authority for the claim that "the persistent tension between ideas and experience should be the focal point" of American thought. He states: "The tensions between beliefs held and experiences generated by incessantly novel circumstances, often of a physical kind, is a central theme in the thought of John Winthrop, Jonathan Edwards, Horace Bushnel1, Emerson, Whitman, and of course James and Dewey. . . For the most part, that tradition of American thought which we now regard as seminal and even patriarchal, clearly sides with experience over reflection as the primary resource in formulating beliefs." "The American Angle of Vision--I," Cross Currents, XV (winter, 1965), p. 440 . 
There are two general conclusions to be drawn from our study of Edwards. The first is that he had developed an original and novel doctrine of experience. And the second is that it is possible to show that his system of philosophy is organized around this doctrine. Or, to put it in another way, it is a plausible thesis that Edwards' philosophy is the systematic explication of his doctrine of experience. We have seen that Edwards' aesthetic sensibility and his complete attention to the concerns of religion spawned a mystical temperament and consequently the need for this systematic exposition. The essential components of his doctrine of experience were the idea of excellency, the sense of the heart, and the concept of grace. We then saw that these components were extended into the realm of value philosophy and resulted in the Consent to Being, a doctrine in which values are held to be objective realities capable of being immediately grasped in direct perception. We also saw the extension of experience into the theological realm where it lent itself to a fresh interpretation of the traditional question of God's presence. For Edwards the Puritan this was the ultimate value of the doctrine of experience.

The work of further refinement of the extension of experience into these areas has yet to be done. And yet the present work hopes to have established the conclusion that one cannot appreciate the genius of Edwards without seeing 
that an elaborate doctrine of experience and religious orientation is central to that genius. Such a study as this one is intended to lend a clearer focus to the contributions of Puritan New England and specifically Jonathan Edwards, to the Mainstream of American Thought. 


\section{BIBLIOGRAPHY}

\section{WORKS OF EDWARDS.}

COLLECTED WORKS.

Works. Edited by S. Austin. 8 vols. Worcester: Isaiah Thomas, 1808.

Works. Edited by Sereno E. Dwight, 10 vols. New York: S. Converse, 1829 .

Works. Edited by Perry Miller. 2 vols. Vo1. I. The Freedom of the Wi11. ed. Pau? Ramsey. New Haven: Yale University Press, 1957. Vol. II. Religious Affections. ed. John E. Smith. New Haven: Yale University Press, 1959.

Selections. Edited by Clarence H. Faust and Thomas H. Johnston.

INDIVIDUAL WORKS.

Images or Shadows of Divine Things. Edited by Perry Miller. New Haven: Yale University Press, 1948.

The Mind of Jonathan Edwards, A Reconstructed Text. Edited by Leon Howard. Berkeley and Los Angeles: The University of California Press, 1963.

Observations Concerning the Scripture 0economy of the Trinity. Edited by Egbert C. Smyth. New York: Charles Scribner's Sons, 1880.

The Philosophy of Jonathan Edwards from His Private Notebooks. Edited by Harvey Townsend. Eugene, Oregon: The University of Oregon Press, 1955. 
Selections from the Unpublished Writings of Jonathan Edwards of America. Edited by Alexander B. Grosart. Printed for private circulation: 1865.

An Unpublished Essay of Edwards on the Trinity. Edited by George P. Fischer. New York: Charles Scribner's Sons, 1903.

\section{BIOGRAPHY AND CRITICISM}

Aldridge, Alfred 0. Jonathan Edwards. New York: Washington Square Press, 1964.

Allen, Alexander V. G. Jonathan Edwards. Boston and New York: Houghton, Miffl in and Company, 1889 .

Carpenter, Frederic I. "The Radicalism of Jonathan Edwards," New England Quarterly, IV (October, 1931), 629-44.

Chase, Mary Ellen, Review of Jonathan Edwards, by Perry Miller, New York Times Book Review (December 11, 1949), 4.

Cherry, Conrad. The Theology of Jonathan Edwards. A Reappraisal. New York: Doubleday, 1966.

Delattre, Roland Andrew. Beauty and Sensibility in the Thought of Jonathan Edwards: An Essay in Aesthetics and Theological Ethics. New Haven and London: Yale University Press, 1968.

Duff, William B. Jonathan Edwards, Then and Now. A Satirical Study in Predestination. Pittsburgh: The Guttendorf Press, 1959.

Dwight, Sereno E. The Life of President Edwards. Volume I of Works. Edited by Dwight. New York: S. Converse, 1829.

Elwood, Douglas J. The Philosophical Theology of Jonathan Edwards. New York: Columbia University Press, 1960.

Faust, Clarence H. "Jonathan Edwards as a Scientist," American Literature, I (1930), 393-404.

Feidelson, Charles. Symbolism and American Literature. Chicago: The University of Chicago Press, 1953.

Fischer, George P. "The Philosophy of Jonathan Edwards," North American Review, CXXVIII (March, 1879), 284-303.

Gardiner, H. N. "The Early Idealism of Jonathan Edwards," Philosophical Review, IX (November, 1900), 573-96. 
Gardiner, H. N. Jonathan Edwards, A Retrospect. Boston and New York: Houghton, Miffl in and Company, 1901.

Griffin, Edward M. Jonathan Edwards. Minneapolis: University of Minnesota Press, 1971 .

Haroutunian, Joseph G. "Jonathan Edwards: A Study in Godliness," Journal of Religion, XI (July, 1931), 400-19.

"Jonathan Edwards: Theologian of the Great Commandment," Theology Today, I (October, 1944), 361-77.

- Review of Jonathan Edwards, by Perry Miller, Theology Today, VII (January, 1951), 554-56.

Holbrook, Clyde A. "Jonathan Edwards and His Detractors," Theology Today, $X$ (October, 1953), 384-96.

Hopkins, Samuel. The Life and Character of the Late Reverend Mr. Jonathan Edwards, President of the College of New Jersey: Together with a Number of his Sermons on Various Important Subjects. Boston: 1765.

Hornberger, Theodore. "The Effect of the New Science Upon the Thought of Jonathan Edwards," American Literature, IX (November, 1937), 196-207.

Johnson, Thomas H. Review of Jonathan Edwards, by Perry Miller, Saturday Review (January 7, 1950), 17.

Lewis, R.W.B. "The Drama of Jonathan Edwards," Hudson Review III (1950), 135-40.

MacCracken, John H. "The Sources of Jonathan Edwards' Idealism," Philosophical Review, XI (January 1902), 26-42.

McCook, Henry C. "Jonathan Edwards as a Naturalist," Presbyterian and Reformed Review, I (Ju7y, 1890), 393-402.

McGiffert, Arthur C. Jonathan Edwards. New York: Harper and Brothers, 1932.

Miller, Perry. Errand Into the Wilderness. Cambridge, Mass.: The Belknap Press of Harvard University, 1956.

- Jonathan Edwards. New York: Meridian Books, 1953.

"Jonathan Edwards on a Sense of the Heart," Harvard Theological Review, XLI (Apri1, 1948), 123-45. 
Morris, William S. "The Reappraisal of Edwards," New England Quarter1y, XXX (December, 1957), 515-25.

Murphy, Arthur E. "Jonathan Edwards on Free Will and Moral Agency," Philosophical Review, LXVIII (May, 1959), 181-202.

Nichols, J. H. Review of Jonathan Edwards by Perry Miller, Church History, XX (December, 1957), 75-82.

Niebuhr, Reinhold. Review of Jonathan Edwards, by Perry Miller, Nation, CLXIX (December 31, 1949), 648.

Opie, John. Jonathan Edwards and The Enlightenment. Lexington: D. C. Heath and Company, 1969.

Rhoades, Donald H. "Jonathan Edwards: America's First Philosopher," Personal ist, XXXIII (Summer, 1952), 135-47.

Schafer, Charles H. "Jonathan Edwards and the Principle of SelfLove," Papers of the Michigan Academy of Science, XXXV (1951), $341-48$.

Smyth, Egbert C. "Jonathan Edwards' Idealism," American Journal of Theology, I (October, 1897), 950-64.

Suster, Rufus. "An American Pascal: Jonathan Edwards," Scientific Month1y, LXVIII (May, 1949), 338-42.

"The Conception of Morality in the Philosophy of Jonathan Edwards," Journal of Religion, XIV (JuTy, 1934), 265-72.

"A Note on Platonism in the Philosophy of Jonathan Edwards," Harvard Theological Review, LII (October, 1959), 28384.

. "The Strange Universe of Jonathan Edwards," Harvard Theological Review, LIV (April, 1961), 125-8.

Tomas, Vincent. "The Modernity of Jonathan Edwards," New England Quarterly, XXV (March, 1952), 60-84.

Townsend, Harvey G. "Jonathan Edwards' Later Observations of Nature," New England Quarterly, XI I I (September, 1940), 510-18.

"The Will and the Understanding in the Philosophy of Jonathan Edwards," Church History, XVI (December, 1940), 210-20.

Tufts, James H. "Edwards and Newton," Philosophical Review, KLIX (November, 1940), 609-22. 
Watts, Emily J, Jonathan Edwards and the Cambridge Platonists. Urbana, I11 inois: University of Illinois, 1963. (Unpublished Doctoral Thesis.)

Whittemore, Robert $C$. "Jonathan Edwards and the Theology of the Sixth Way," Church History, XXXV (March, 1966), 60-75.

Winslow, 01a E. Jonathan Edwards, 1703-1758: A Biography. New York: MacMil1an, 1941.

Woodbridge, Frederick J. E. "Jonathan Edwards," Philosophical Review, XIII (JuTy, 1904), 393-408.

\section{BACKGROUND}

Adams, Henry. Mont-Saint-Michel and Chartres. London: Constable and Co., Ltd., 1936.

Adams, James Truslow. The Founding of New England. Boston: Atlantic Monthly Press, $19 \overline{21 .}$

Ahlstrom, Sidney E. "Theology in America: A Historical Survey," Religion in American Life. ed. James Ward Smith and A. Leland Jamison. Princeton University Press, 1961.

Beitzinger, A. J. A History of American Political Thought. New York and Toronto: Dodd, Mead and Company, 1972.

Blau, Joseph L Men and Movements in American Philosophy. Englewood Cliffs; New Jersey: Prentice-Ha71, 1952.

Bonaventure. The Mind's Road to God. Translated by George Boas. New York: Liberal Arts Press, 1953.

Boorstin, Daniel. The Americans. The Colonial Experience. New York: Randan Huse, 1958.

Brasch, Frederick E. "The Newtonian Epoch in the American Colonies (1680-1783)," Proceedings of the American Antiquarian Society, XLIX (1939), 314-32.

Brauer, Jerald C. "Francis Rous, Puritan Mystic, 1579-1659: An Introduction to the Mystical Element in Puritanism," Unpublished doctoral thesis, University of Chicago, 1948.

- "Puritan Mysticism and the Development of Liberalism," Church History, XIX (September, 1950), 151-70. 
Brooks, Van Wyck.' America's Coming of Age. New York: Doubleday, 1958.

Burane11i, Vincent. "Colonial Philosophy," William and Mary Quarterly (third series), XVI (JuTy, 1959), 343-362.

Burtt, E. A. The Metaphysical Foundation of Modern Science. New York: Humanities Press, 1931.

Butterfield, Herbert. The Origins of Modern Science, 1300-1800. New York: Macmi 11 an, 1959.

Cassirer, Ernst. An Essay on Man. New Haven: Yale University Press, 1944.

- The Individual and the Cosmos in Renaissance

Philosophy, trans. Mario Domandi. New York: Harper, 1963.

Cohen, M. R. American Thought. New York: Collier Books, 1962.

Curti, Merle. The Growth of American Thought. New York: Harper and Row, 1964 .

Dawson, Christopher. Medieval Essays. New York: Doubleday, 1959.

Dolbeare, Kenneth M. Directions in American Political Thought. New York: Joln Wiley and Sons, Inc., 1969.

Fay, Jay Wharton. American Psychology Before William James. New Brunswick, New Jersey: Rutgers University Press, 1939.

Fisch, Max A. Classic American Philosophers. New York: AppletonCentury-Crofts, 1951.

Gabrie1, Ralph Henry. The Course of American Democratic Thought, Second Edition. New York: The Ronald Press Company, 1956.

Gilson, Etienne. The Mystical Theologi of St. Bernard. New York: Sheed and Ward, 1940.

Gohdes, Clarence. "Aspects of Idealism in Early New England." The Philosophical Review, XXXIX (November, 1930, 537-55.

Grob, Gerald N. and Robert N. Beck. American Ideas - Volume One: Foundations (1629-1865). London: The Free Press of GTencoe, 1963.

Haller, William. The Rise of Puritanism. New York: Columbia University Press, 1938. 
Haroutunian, Joseph. Piety Versus Moralism; the Passing of New England Theology. New York: Henry Holt, 1932.

Harrison, Wilfrid. Sources in British Political Thought: 1593-1900. New York: The Free Press, 1965.

Hartshorne, Charles and Reese, William. Philosophes Speak of God. Chicago: University of ChicagoPress, 1953.

Hazard, Lucy Lockwood. The Frontier in American Literature. New York: Frederick Ungar, 1927.

Hooykaas, R. "Science and Reformation," The Revolution of Science, ed. Guy S. Metraux and Francis Crouzet. New York: Mentor, 1963.

Hornberger, Theodore. "The Date, the Source, and the Significance of Cotton Mather's Interest in Science," American Literature, VI $(1935), 413-20$.

Hudson, Wirthrop C. "Mystical Religion in the Puritan Commonwealth," Journal of Religion, XXVII (January, 1948), 51-56.

Inge, William. Christian Mysticism. New York: Meridian, 1956.

James, William. The Varieties of Religious Experience. New York: Collier, $19 \overline{61 .}$

Jones, Adam Leroy. Early American Philosophers. New York: Columbia University Press, 1898.

Jones, Rufus M. Mysticism and Democracy in the English Commonwealth. Cambridge, Mass.: Harvard University Press, 1932.

Kilgour, Frederick C. "The Rise of Scientific Activity in Colonial New England," Yale Journal of Biology and Medicine, XXII (1949) 123-38.

Kouwenhoven, John A. Made in America. The Arts in Modern Civilization. New York: Doubleday, 1948.

Koyre, Alexandre. From the Closed World to the Infinite Universe. New York: Harper, 1957.

Lockridge, Kenneth A. A New Engl and Town: The First Hundred Years (Dedham, Massachusetts, 1636-1736) New York: W. W. Norton and Company, 1970.

Lovejy, Arthur 0. The Great Chain of Being. A Study of the History of an Idea. Cambridge, Mass.: Harvard University Press, 1936. 
Mather, Cotton. The Christian Philosopher. Charlestown: Middlesex Bookstore, 1815 .

McDermott, Jom J. "The American Angle of Vision--II," Cross Currents, XV (Winter, 1965), 437-56.

Mead, Sidney E. The Lively Experiment, The Shaping of Christianity in America. New York: Harper and Row, 1963.

Miller, Perry. The New England Mind. The Seventeenth Century. New York: Macmilian, 1939.

- The New England Mind: From Colony to Province. Cambridge, Mass.: Harvard University Press, 1953.

- Orthodoxy in Massachusetts. Cambridge, Mass.:

Harvard University Press, 1933.

Miller, Perry and Johnson, Thomas (eds.). The Puritans. A Source. Book of Their Writings. New York: Harper and Row, $\overline{1963 .}$

Murdock, Kenneth B. "The Puritan Tradition in American Literature," The Reinterpretation of American Literature, ed. Normal Foerster. New York: Harcourt, Brace, 1928.

Newl in, Claude M. Philosophy and Religion in Colonial America. New York: Philosophical Library, 1962.

Nicolson, Marjorie Hope. Mountain Gloom and Mountain Glory. New York: W.W. Norton, 1959.

- The Breaking of the Circle. New York: Columbia University Press, 1960 .

Parkes, Henry Bamford. The American Experience. New York: Alfred Knopf, 1947.

Parrington, Vernon L. The Colonial Mind, 1620-1800. New York: Harcourt, Brace, $192 \overline{7 .}$

Perry, Ralph Barton. Puritanism and Democracy. New York: Vanguard, 1944.

Persons, Stow. American Minds, A History of Ideas. New York: Henry Holt, 1958 .

Rahv, Philip. Image and Idea. New York: New Directions, 1957.

Randa11, John Herman, Jr. The Career of Philosophy from the Middle
Ages to the Eni.ightenment. New York: Columbia University Press, 1962. 
Raphael, D.D. Problems of Political Philosophy. New York: Praeger Publishers, 1970.

Riemer, Neal. The Democratic Experiment: American Political Theory-Vol. I. Princeton: D. Van Nostrand Company, Inc., 1969.

Riley, I. Woodbridge. American Philosophy: The Early Schools. New York: Russe11 and Russe11, 1958.

Roback, Abraham A. History of American Psychology. New York: Library Publishers, 1952.

Rolt, C. E. Dionysius the Areopagite on the Divine Names and the Mystical Theology. New York and London: Macmillan, 1920.

Santayana, George. Character and Opinion in the United States. New York: Doubleday, 1958.

Scheler, Max. The Nature of Sympathy, trans. Peter Health, ed. W. Stark. New Haven: Yale University Press, 1954.

Schneider, Herbert W. A History of American Philosophy. New York: Columbia University Press, 1963. - The Puritan Mind. New York: Henry Holt, 1930.

Sharpe, A. B. Mysticism: Its True Nature and Value. London: Sands and Company, 1910.

Simpson, Alan. Puritanism in 01d and New England. Chicago: University of Chicago Press, 1955.

Stewart, Randa11. American Literature and Christian Doctrine. Baton Rouge, Louisiana: Louisiana State University Press, 1958.

Strout, Cushing. Intellectual History in America. New York: Harper and Row, PubTishers, 1968.

Smith, H. Shelton, Handy, Robert T., and Loetscher, Lefferts A. American Christianity: An Historical Interpretation with Representative Documents. New York: Charles Scribner's Sons, 1960.

Stearns, R. R. "Assessing the New England Mind", Church History, $X$ (September, 1941), 246-62.

Taylor, Henry Osborn. The Medieval Mind, A History of the Development of Thought and Emotion in the Middle Ages, 2 vols. Cambridge, Mass.: Harvard University Press, 1949. 
- The Classical Heritage of the Middle Ages. New York:

Harper and Row, 1963.

Vanneste, Jan. "Is the Mysticism of Pseudo-Dionysius Genuine?", International Philosophical Quarterly, III (May, 1963), 286-306.

Vignaux, Pau1. Philosophy in the Middle Ages, an Introduction. trans. E. C. HalT. New York: Meridian, 1959.

Volkomer, Walter E. The Liberal Tradition in American Thought. New York: Capricorn Books, Inc., 1970.

Whitehead, A. N. Adventures of Ideas. New York: Macmi11an, 1933. - Science and the Modern World. New York: Macmilian, 1925.

Wilder, Amos. "The Puritan Heritage in American Culture", Theology Today, V (Apri1, 1948), 22-34.

Zuckerman, Michael. Peaceable Kingdoms: New England Towns in the Eighteenth Century. New York: Vintage Books, 1970. 